\title{
The Structure and Properties of Polyethylene Films Used in Heavy Lift Balloons
}

Report for the Period Jariuary-May, 1984 NASA Order S01834D

December 1984

Issued March 1985

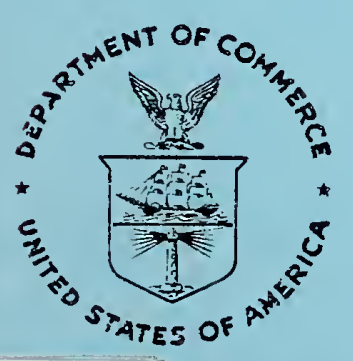

$-Q C$ 100 .456

84-2989

1985

C. 2
EPARTMENT OF COMMERCE

AL BUREAU OF STANDARDS 

NBSIR 84-2989 (NASA)

The Structure and Properties of

Polyethylene Films Used in Heavy

Lift Balloons

F. Khoury

J.M. Crissman

B.M. Fanconi

H.L. Wagner

L.H. Bolz

C.A. Harding

Report for the Period

January-May, 1984

NASA Order S01834D

December 1984

Issued March 1985

U.S. DEPARTMENT OF COMMERCE, Malcolm Baldrige, Secretary NATIONAL BUREAU OF STANDARDS, Ernest Ambler, Director 



\section{Abstract}

The following features of five polyethylene films used by NASA in the construction of heavy lift balloons have been examined: molecular weight, molecular weight distribution, branching, melting behavior, density, surface texture, birefringence, orientation of crystalline regions, uniaxial deformation in the machine and transverse directions, and the effect of sample geometry and strain rate on deformation behavior. The goal of this exploratory study was to determine whether there are significant differences in any of the above mentioned features, or combination of features between the films. The acquisition of such information is a first step towards determining whether there are any specific correlations between film characteristics and the incidence of catastrophic failure of balloons during ascent through the troposphere. This exploratory study has resulted in the identification of similarities and differences between various features of the films. Close similarities have been found in methyl group content, crystallinity, and peak melting temperature. The preferred orientations in the crystalline regions appear to be qualitatively similar or related. Differences among the films have been revealed in two features, namely between their molecular weights, and in the balance of the strain to break behavior in the machine direction relative to that in the transverse direction. 
Table of Contents

A. Introduction 1

B. Molecular Weight and Molecular Weight Distribution 2

(i) Dilute Solution Viscosity 2

(ii) Size Exclusion Chromatography (SEC) 2

C. Fourier Transform Infrared (FT-IR) Analysis of Methyl Group Content 4

D. Differences between Infrared Spectra of Films 5

E. Density Measurements 6

F. Differential Scanning Calorimetry (DSC) 6

G. Fine Structure and Orientation 8

(i) Fine Structure 8

(ii) Orientation 9

(a) Birefringence 9

(b) Wide Angle X-Ray Diffraction and
Infrared Spectroscopy

H. Mechanical Properties $\quad 15$

(i) Creep Behavior 15

(ii) Elongation to Break, Tensile Strength, Yield

(iii) Effect of Strain Rate 18

(iv) Comparison of Tensile Properties of Different

(v) Haziness 19

(vi) Wide Strip Geometry 20

(vii) Bubble Inflation 21

(viii) An Example of the Influence of Molecular Weight and Molecular Weight Distribution on

I. Summary 23

J. Concluding Remarks 25

$\begin{array}{ll}\text { K. References } & 27\end{array}$

L. List of Tables 29

M. List of Figures 30 


\section{A. Introduction}

The study described in this report was sponsored by the Balloon Projects Branch of the National Aeronautics and Space Administration (NASA). It was carried out in the period January-April 1984 as part of an ongoing investigation by NASA to determine the causes of the catastrophic failure of 'heavy-lift' balloons.

Helium filled heavy-lift balloons, in which the helium is contained by low density polyethylene film, are used by NASA to raise instrument payloads of up to $-5000 \mathrm{Kg}$ (gross inflation) to elevations of over $30 \mathrm{Km}$ for various research projects. The thickness of the polyethylene film is usually in the range $13 \mu \mathrm{m}-25 \mu \mathrm{m}$. The capacity of the balloons at float altitude can be as large as $1 \cdot 16 \times 10^{6} \mathrm{cu}$. meters. Since 1980 NASA has experienced an increased incidence of catastrophic balloon failures during ascent at elevations between $12 \mathrm{Km}-18 \mathrm{Km}$ where the ambient temperature is $\sim-70^{\circ} \mathrm{C}$. The causes of the increased failures of this type from 1980 to the present as compared to the performance of balloons prior to 1980 have been elusive. Limitations inherent in the design characteristics of the balloons, inadvertent flaws which may occur in the process of balloon assembly (construction), and differences between the mechanical properties of the polyethylene film used in the balloons prior to and since 1980, are among the possible causes NASA is investigating. The present exploratory study is concerned with the latter of these possibilities.

The mechanical properties of polyethylene films are governed by both the molecular characteristics (molecular wt., molecular wt. distribution, chain branching) of the polymer, and the film microstructure (e.g. crystallinity, orientation of the crystalline regions etc.). The microstructure is governed in part by the molecular parameters, and in large measure by the processing conditions used in film production. The details of the tubular film extrusion process(es) used in the production of the films for the heavy-lift balloons are proprietary. Films must meet various acceptance criteria set by NASA. An important empirical criterion is that in uniaxial extension tests the extension to break in the machine and in the transverse directions should not be less than $250 \%$ at $-70^{\circ} \mathrm{C}$.

The purpose of the short-term exploratory study described below was to examine various features of the molecular characteristics, microstructure, and mechanical properties of polyethylene films representative of those produced and used in heavy-lift balloons prior to 1980 and from 1980 onwards. The primary goal was to determine whether there are significant differences in any of the above mentioned features, or combination of features, between the films. Such knowledge is clearly a necessary first step towards determining whether there are correlations between film characteristics not covered by present acceptance criteria, and balloon performance. 
The five low density polyethylene films studied were selected by NASA and are identified as Category I to IV and B1. Only the Category III was representative of film produced prior to 1980.

B. Molecular Weight and Molecular Weight Distribution.

Two types of measurements which are related to the molecular weight and molecular weight distribution of the polyethylene in the films have been carried out, namely (i) the determination of the viscosity of dilute polymer solutions, and (ii) size exclusion chromatographic measurements.

\section{(i) Dilute Solution Viscosity.}

These measurements consisted in determining the flow times in a capillary viscometer at several concentrations of the polymer in $1,2,4-t r i c h l o r o b e n z e n e ~ a t ~ 130^{\circ} \mathrm{C}$, and extrapolating to zero concentration to obtain a "limiting viscosity number" or intrinsic viscosity [ $n$ ]. The results for polymer taken from one sheet of film from each of the five categories submitted by NSBF, as well as the pellets used to produce Category $\mathrm{B} 1 \mathrm{film}$, are given in Table 1.

The precision in $[n]$ is $\pm .01-.02$ indicating a small difference between Categories I and IV on the one hand and Categories II and III on the other. A much larger difference is observed between these four categories and the polymer of Category $\mathrm{B} 1$ both as film and pellets. These limiting viscosity numbers cannot be directly translated into a viscosity average molecular weight by means of the Mark-Houwink relation $[\eta]=K M^{\alpha}$ ( $M=$ mol.wt., $K$ and $\alpha$ are constants) because the polymer in the films is branched polyethylene for which such a relation is inapplicable.

Two types of branching are usually present, long chain and short chain. A branched polymer molecule of a given molecular weight will have a smaller hydrodynamic volume than a linear chain of the same molecular weight, and hence a lower viscosity. Hydrodynamic

volume also determines elution volume in size exclusion chromatography. Long chain branches are more effective in reducing hydrodynamic volume than short chain branches. Hence, the extent and nature of the branching determines the magnitude of the effect on viscosity and elution volume.

\section{(ii) Size Exclusion Chromatography (SEC):}

In these experiments the polymer is separated into its constituents by molecular size. For linear (unbranched) polymers this is equivalent to obtaining the molecular length or weight distribution. In the case of branched polymers such as the polyethylene in the films under study, size is determined by branching as well as molecular length, thus making interpretation of the chromatograms more complex. 
The chromatograms were obtained with the Waters* Model 150C Liquid/Gel Permeation Chromatograph containing five microstyrogel columns with nominal pore size $10^{2}, 10^{3}, 10^{4}, 10^{5}$ and $10^{6} \&$, covering completely the commercially available range of pore sizes. Runs were carried out at $135^{\circ} \mathrm{C}$ with purified 1,2,4 -trichlorobenzene as the eluant. Each solution contained about $0.25 \%(\mathrm{w} / \mathrm{v}$ ) of polymer to which $0.2 \%$ ( $/ \mathrm{v}$ ) Santonex* antioxidant was added and was filtered through a $5 \mu \mathrm{m}$ Teflon* filter. Calibration was carried out with Linear Polyethylene SRM 1475 as well as with eleven narrow molecular weight distribution polystyrene standards using the universal calibration technique to give a calibration range of 850 to $4.6 \times 10^{6}$ for linear polyethylene.

The chromatograms of the branched polyethylene in the five categories of film indicated that the molecular size distributions are very broad and extend beyond the accessible range of the columns. Since the polyethylene is branched the molecular weights very likely extend to greater than about 5 million, depending on the amount and type (long and/or short) of branching.

Calculations of molecular weight were carried out for polymer only within the calibration range, and assuming the polyethylene is linear. These "apparent" molecular weights are given in Table 2. As already indicated the correct molecular weights are likely to be higher because of the effect of branching and because extremely high molecular weight material was excluded from fractionation by the columns; some of this extremely high molecular weight material might include microgels, known to occur in branched polyethylenes.

A method of calculating molecular weights of branched whole polymers, requiring several assumptions, has been given in the literature [1]. It is assumed that the extent of branching is independent of the molecular weight of the species making up the distribution, an assumption which would not be expected to be generally true and which has been shown to be incorrect for low density polyethylene [2]. In addition the relationships used to derive the dependence of the number of branch points on the radius of gyration [3] apply to a specific type of branching which does not necessarily occur in low density polyethylene. For this reason, and because the molecular weight range in the films extends beyond the limits of commercial columns, no attempt was made to use this method to calculate "corrected" molecular weights or the extent of branching.

Two separate size exclusion chromatography runs were carried out, each at different times, requiring two calibrations of the columns.

In the first series of experiments (denoted A in Table 2) films of Category I through IV were compared. In the second series ( $B$ in Table 2) designed to evaluate Category $B 1$ film and the pellets from which it was produced, measurements on samples of Category I and III were repeated as a cross-check with the first series. The apparent molecular weight values for both runs for the Category I and III films fall within the expected error of the measurements. The chromatograms of all five Categories of film are similar to one another, showing evidence of a

*Certain commercial materials and equipment are identified in this

paper in order to specify adequately the experimental procedure. In no

case does such identification imply recommendation or endorsement by

the National Bureau of Standards, nor does it imply necessarily the best

available for the purpose. 
bimodal distribution with a hint of a third peak. These features are likely the result of a blending of polymers. Upon comparing the normalized chromatograms, which have been superimposed in Figures $1-6$, it is evident that the Category III sample has a greater amount of high molecular weight species than all the other samples. The sample of Category II also contains a greater amount of nigher molecular weight material than I, IV, and B1, but less than category III. These differences are reflected in the molecular weight averages given in Table 2 , and are consistent with the limiting viscosity numbers of Table 1 , which are higher for Categories III and II than those of Categories I, IV, and B1.

The Category B1 film and the raw polymer from which it was produced have very similar bimodal distributions as shown in Figure 4. No great significance can be attached to the small differences at the peak. However the size exclusion chromatography results, substantiating the viscosity data of Table 1, demonstrate a substantial difference between Category $B 1$ and the polymer from Categories I and III. Superposition of the normalized chromatograms in Figures 5 and 6 shows that Category B1 contains less of the high molecular weight polymer than any of the others. It is possible that this would also result in a smaller microgel content in film B1. On examination of the low molecular weight ends of the chromatograms, not shown in the figures, no differences among the films were observed below a molecular weight of 1,000.

\section{Fourier Transform Infrared (FT-IR) Analysis of Methyl Group Content.}

Infrared spectroscopy provides an indirect measure of the degree of branching in polyethylene chains through analysis of infrared bands attributable to methyl $\left(-\mathrm{CH}_{3}\right)$ and methylene $\left(-\mathrm{CH}_{2}{ }^{-}\right)$groups. The presence of methyl groups which occur at the ends of chains and at the ends of the side branches attached to carbon atoms along the chains is distinguished in IR spectra by an absorption band at $1378 \mathrm{~cm}^{-1}$. This band which corresponds to the methyl deformation mode is assignable to methyl group vibrations irrespective of the chemical bonding of the carbon atom to which the methyl group is attached. The method of analysis which was used to compare the methyl group content of the films relative to one another is based on determining the ratio of the intensity of the resolved $1378^{-1}$ absorption band divided by the total integrated intensity in the frequency range $1400 \mathrm{~cm}^{-1}$ to $1328 \mathrm{~cm}^{-1}$, which, in addition to the $1378 \mathrm{~cm}^{-1}$ methyl band, includes bands that arise from wagging modes of methylene groups in the non-crystalline regions of the polymers (see later).

Single thicknesses of the films were too thin to yield spectra which could be analyzed meaningfully for methyl group concentrations. Samples composed of several layers of film were also not suitable owing to spectral effects arising from multiple reflection from the thin films. To overcome these limitations samples were prepared by melting three layers of each type of $\mathrm{film}$ in a press which was heated to $110^{\circ} \mathrm{C}$ and then cooled to room temperature. This preparation procedure destroys any 
orlentation present in the original films, it is known however from previous work that the methyl group vibrations are not sensitive to orientation effects.

Spectra of the five categories of $\mathrm{film}$ in the frequency range $1400 \mathrm{~cm}^{-1}$ to $1328 \mathrm{~cm}^{-1}$ are shown in Fig.7. As indicated above the band at 1378 $\mathrm{cm}^{-1}$ is assigned to the methyl group and the remaining bands in the $\mathrm{fig}^{-}$ ure arise from the methylene wagging mode in the non-crystalline regions of the film. The complex band shapes exhibited by the spectra were decomposed into individual components using the method of Rueda, BaltaCalleja and Hidalgo [4], and the value of the intensity of the resolved $1378 \mathrm{~cm}^{-1}$ band divided by the total integrated intensity from $1400 \mathrm{~cm}^{-1}$ to $1328 \mathrm{~cm}^{-1}$ was determined for each film. The resulting ratios for the five categories of film are listed in Table 3 from which it can be seen that they are approximately the same for all five films. In short there is no appreciable difference in methyl group content between the films. Using the following empirical relationship developed by Rueda et al [4]

$$
E=(0.085) K_{1378}-0.09
$$

(where $E$ is the number of methyl groups per 100 carbon atoms in the polyethylene, $K_{1378}$ is the resolved intensity of the $1378 \mathrm{~cm}^{-1}$ methyl band per unit thickness of the film in cms) and assuming that the molten and pressed films were all approximately $2.4 \mathrm{mils}\left(6.1 \times 10^{-3} \mathrm{~cm}\right)$ thick, it is estimated from the data in the third column in Table 3 that the methyl group content in the films is $\sim 2.1$ methyl groups $/ 100 \mathrm{C}$ atoms.

(D) Differences between Infrared Spectra of the Films.

Although the FT-IR room temperature spectra of the samples of the five film categories taken after melting, pressing, and cooling (see previous section) were essentially similar to one another in the frequency range 1328-1400 $\mathrm{cm}^{-1}$, differences between the spectra of these samples were observed at other frequencies in the mid-frequency range $400 \mathrm{~cm}^{-1}-1800$ $\mathrm{cm}^{-1}$. Thus, the $\mathrm{Bl}$ film exhibited two prominent absorption peaks at 471 $\mathrm{cm}^{-1}$ and $1085 \mathrm{~cm}^{-1}$ which were not observed in any of the Category I-IV films. The difference spectrum obtained by subtracting the spectrum of the Category I sample from that of Category B1 is shown in Fig.8. In addition to the two prominent bands mentioned above weak absorption bands are found at 613,671 , and $792 \mathrm{~cm}^{-1}$. No other significant differences between these two films were observed in the frequency range $400-4000 \mathrm{~cm}^{-1}$.

The spectral pattern exhibited by the difference spectrum in Fig. 8 does not correlate with any known absorption bands for polyethylene which suggests that the prominent absorption bands at $471 \mathrm{~cm}^{-1}$ and $1085 \mathrm{~cm}^{-1}$ as well as the three weaker bands mentioned above are due to the presence of a rather high concentration of additive (or additives) in the $B 1$ film. Although the differential scanning calorimetry experiments reported in Section (E) indicated the presence of an additive (or additives) in the $\mathrm{BI}$ as well as in the Category I-IV films no distinguishable evidénce of absorption bands at $471 \mathrm{~cm}^{-1}$ and $1085 \mathrm{~cm}^{-1}$ 
was detected in the spectra of the latter four films. The occurrence of two weak absorption bands at $1150 \mathrm{~cm}^{-1}$ and $1723 \mathrm{~cm}^{-1}$ in the spectra of Cat. I-IV films may be attributed to another type of additive or additives since these latter spectral features are also not characteristic of polyethylene.

\section{E. Density Measurements.}

The density of each of the five categories of film was determined at 23 $\pm 0.1^{\circ} \mathrm{C}$ using water/ethanol density gradient columns. Appropriate precautions were taken to deaerate the samples prior to immersion in the columns. The results obtained for two samples from each film type are listed in Table 4. The corresponding weight \% crystallinities, $x$, are listed in the same Table. They were calculated from the following expression:

$$
x=100 \frac{\rho_{c}}{\rho} \cdot \frac{\left(\rho-\rho_{a}\right)}{\left(\rho_{c}-\rho_{a}\right)}
$$

where $\rho$ is the measured density of the sample, $\rho_{c}$ is the density of purely crystalline polyethylene (i.e. the unit cell density), and $\rho_{a}$ the density of amorphous polyethylene. The values used for $\rho_{c}$ and $\rho_{a}$ were $1.000 \mathrm{~g} / \mathrm{cc}$ [5] and $0.8547 \mathrm{~g} / \mathrm{cc}$ [6] respectively.

As can be seen from the data in Table 4 the two measurements carried out on each category of film are in good agreement with one another (within the experimental error of $< \pm 0.0005 \mathrm{~g} / \mathrm{cc}$ ), and any differences in density between the films are extremely small. It appears from these data that the Category Bl film is slightly denser than the other four types, and that the Category II film may be marginally denser than the Category I, III, and IV.

\section{F. Differential Scanning Calorimetry (DSC).}

A specimen from each of the Category I to IV films listed in Table 1 and the $\mathrm{B} 1 \mathrm{film}$ was heated at a constant rate of $20^{\circ} \mathrm{C} / \mathrm{min}$ from $-40^{\circ} \mathrm{C}$ to $120^{\circ} \mathrm{C}$ in order to determine the peak melting temperature. The samples were then cooled from $120^{\circ} \mathrm{C}$ at $20^{\circ} \mathrm{C} / \mathrm{m}$ in to below room temperature to determine the location of the peak crystallization temperature. The results of DSC experiments are affected by the heating and cooling rates used, hence data obtained at only one rate are not absolute. The main objectives of the present exploratory experiments using a single heating and cooling rate was to determine whether there exist significant relative differences between the peak melting temperatures and/or the peak crystallization temperatures exhibited by the films. Large differences in peak melting temperatures can be expected to occur, for example, if the thermal and stretching conditions used in the production of the films differed appreciably, and/or if the molecular characteristics (molecular weight, branching) of the starting polymers are significantly 
different from one another. Differences of the latter type might also be reflected in differences in the location of the peak crystallization temperature exhibited by the molten specimens upon cooling.

In the heating experiments, film of all five categories exhibited two melting endotherms, namely a very weak one peaked at a temperature below $60^{\circ} \mathrm{C}$, and a very pronounced one peaked in the narrow temperature range $106.2^{\circ} \mathrm{C}-107.1^{\circ} \mathrm{C}$. The latter endotherm is due to the melting of the bulk of the polymer in the films. The temperatures corresponding to the peaks of the low and high temperature endotherms for each film are listed in Table 5 .

In the cooling experiments all the films exhibited two crystallization exotherms. A very pronounced exotherm, due to the crystallization of the bulk of the polyethylene, and having a peak temperature in the narrow range $93.0^{\circ} \mathrm{C}$ to $94.4^{\circ} \mathrm{C}$, was observed in each case. In addition, a very weak lower temperature exotherm peaked in the range $53.6^{\circ} \mathrm{C}-58.4^{\circ} \mathrm{C}$, was recorded in all the films. The temperatures corresponding to the peaks of the high and low temperature exotherms for each film are listed in Table 5 .

The normalized (to a specimen wt. of $1.0 \mathrm{mg}$ ) DSC curves exhibited by the Category I-IV films upon heating and cooling are illustrated in Figs. $(9-12) a$ and $(9-12) c$ respectively in which the low temperature melting and crystallization peaks are barely if at all visible. The occurrence of these peaks is evident however in Figs. $(9-12) \mathrm{b}$ and Figs $(9-12) \mathrm{d}$ in which parts of the heating and cooling curves are respectively shown with the vertical scale expanded by a factor of six. The heating and cooling DSC curves for the B1 film are shown in Fig. 13a and Fig. 13b respectively.

The DSC experiments described above show that there are only slight differences between the main (high temperature) peak melting temperatures and between the main peak crystallization temperatures exhibited by the Category I-IV and BI film specimens. The experiments also show that all five films contain a small amount of material which melts and crystallizes at much lower temperatures than the bulk of the polymer in the films. The nature of this material(s) is not known, it is however reasonable to speculate that it may be additive, the presence of which in these films was already suggested in Section $D$ in which it was pointed out that infrared spectra of the five films exhibited absorption bands which are not characteristic of polyethylene. The infrared spectroscopy observations also suggested that the additive in the $B 1$ film is different from that in the Category I-IV films.

As can be seen from Table 5 the weak peak melting and crystallization temperatures of the presumed "additive" material occur within the range $47^{\circ} \mathrm{C}-59^{\circ} \mathrm{C}$. It should be noted in this connection that there is considerable overlap between the temperature ranges spanned by the low temperature endotherm and the exotherm exhibited by each film. It is nevertheless surprising at first glance that the low temperature melting peak manifests itself at a lower temperature $\left(47.8{ }^{\circ} \mathrm{C}-54.4^{\circ} \mathrm{C}\right)$ than the 
low temperature crystallization peak $\left(53.6^{\circ} \mathrm{C}-58.4^{\circ} \mathrm{C}\right)$. Whether this is due to a redistribution, during the heating cycle, of the additive in the covered specimen chamber (pan) in the DSC apparatus remains an open question, as does the observation that when the samples were subjected to a second heating cycle no evidence of the low temperature endotherm was observed in the Category I, III, IV and B1 films, however upon being cooled again to below room temperature from $120^{\circ} \mathrm{C}$ all five films exhibited a low temperature exotherm.

\section{(G) Fine Texture and Orientation.}

\section{(i) Fine Texture}

All the films (Category I-IV and B1) appear hazy to the naked eye. When examined in transmission with a light microscope using phase contrast optics they all exhibit a mottled appearance on a fine lateral scale (a few micrometers) as shown in Figures (14-18)a. This appearance may be due to differences in internal fine structure and hence refractive index between the brighter and darker regions seen in Figs.(14-18)a and/or due to differences in film thickness in these regions. In order to determine whether this appearance of the films is associated with variations in the thickness of the films on a small lateral scale, replicas (imprints) were made of the two surfaces of a specimen of each of the five types of film. The specimens were taken from the same rolls (gores) listed in Tables 4,5. The replicas were made by applying a concentrated solution ( $10 \%$ ) of nitrocellulose in amyl acetate to the surfaces of the films and allowing it to dry at room temperature. The resulting nitrocellulose replicas were stripped from the surfaces and examined in transmission in a light microscope using phase contrast optics. If the surfaces of the polyethylene films were perfectly smooth the replicas would appear featureless. This was certainly not the case, as illustrated in Figs. $(14-18) b$ and $(14-18) c$ in which it can be seen that the replicas exhibit fine textural appearances akin to the actual films in Figs.(14-18)a. This confirms the occurrence of variations in film thickness on a small lateral scale (i.e. over distances of a few $\mu \mathrm{m})$ in all the films thus indicating that the haziness of the films is due, in part at any rate, to the surface roughness of the films. Surface roughness in blown films is not an uncommon feature (e.g. see references $[7,8])$. A scanning electron micrograph of one of the surfaces of the Category I film is shown in Fig. 19 in which the uneven character of the surface is directly evident.

The Category B1 film could be distinguished from the other four types of film in the optical microscope (with either normal or phase contrast optics) by its high content of dispersed particles of different sizes and shapes. With phase contrast illumination they appear as very bright objects. Several such objects can be seen in Fig.18a (features denoted X). The occurrence of the particles in the replicas (Figs. 18b,c) of both surfaces of the film indicates that many of the particles are situated on these surfaces or are partially embedded in them and hence easily excised. Whether these objects are particles of the additive detected by infrared spectroscopy (see Section D) is not known. A consideration 
which should be borne in mind is that embedded or partially embedded particles can give rise to uneven stress distributions in a film undergoing deformation and could thus influence the mechanical characteristics of the film.

Differences in haziness to the naked eye were observed between adjoining regions in some portions of the Category I, II and IV films. The diffuse demarcation "line" between the regions which appeared hazy and less hazy was parallel or closely parallel to the machine direction and extended over the length of the samples submitted by NASA. The hazy and less hazy regions exhibited similar appearances when examined under the light microscope using phase contrast optics.

\section{(ii) Orientation}

For the sake of brevity in describing the results of an examination of the birefringent characteristics of the films as well as the results of wide angle $\mathrm{x}$-ray diffraction experiments and infrared spectroscopy we shall refer to the machine and transverse directions as $M$ and $T$ respectively, and to the direction normal to the surface of the films (i.e. normal to the MT plane) as $\mathrm{N}$. In addition the refractive indices for light travelling parallel to $\mathrm{N}$ and polarized with its plane of vibration parallel to $M$ or parallel to $T$ will be denoted $n(M)$ and $n(T)$ respectively.

\section{(a) Birefringence}

The birefringent character of oriented polyethylene films is determined by the distribution of the orientation of the crystalline regions in them, by the film crystallinity, by any optical anisotropy (orientation) in the disordered ('amorphous') regions, and by form birefringence [9]. As pointed out in Section $E$ the crystallinities of the five films are essentially equal. In the absence of any knowledge of the conditions under which the tubular films are extruded (rate of cooling, draw ratio, blow ratio), it can be reasonably presumed, as a starting premise, that the birefringence in the films is due predominantly to crystalline orientation. The birefringence in the MT plane of the films was examined to determine whether there are significant differences between them, i.e. in both the sign ( \pm ) of $\Delta n=n(M)-n(T)$ relative to $M$ and the magnitude of $\Delta \mathrm{n}$ on a scale of $0-0.06$ [10]. As background concerning the upper limit of this scale the following may be noted. The unit cell of polyethylene is orthorhombic [5]. Its parameters are $a=0.74 \mathrm{~nm}$, $b=0.493 \mathrm{~nm}, c=0.254 \mathrm{~nm}, \alpha=\beta=\gamma=90^{\circ}$. The chain molecules are parallel to the c-axis. It is commonly assumed, to a good approximation, that the refractive indices of the unit cell are the same as in single crystals of orthorhombic normal-paraffins (e.g. $n-C_{36} \mathrm{H}_{74}[10]$ ) and that $\mathrm{n}_{\mathrm{a}}=1.514$, $\mathrm{n}_{\mathrm{b}}=1519$, and $\mathrm{n}_{\mathrm{c}}=1.575$ [11]. If one imagines a single crystal of polyethylene oriented relative to the film with the b-axis parallel to $\mathrm{N}$ and the $c$ and $a$ axes parallel to $M$ and $T$ respectively, the crystal would exhibit maximum birefringence, $n_{c}-n_{a}=0.06$, in the MT plane and be positively birefringent with respect to $M$. In reality, of course, films consist of microcrystalline regions interspersed with disordered regions 
which in the case of the films under consideration amount to slightly more than $50 \%$ of the weight of the films (Section E). Furthermore the preferred crystal orientation distributions commonly encountered in blown films differ from the idealized example given above [see Section $G(i i) b]$. Thus, the birefringence of the films in the MT plane would be expected to be less than 0.06 .

Specimens of the five films were examined between crossed polarizer and analyzer with an optical microscope using parallel illumination. The specimens, which lay flat on the microscope stage (i.e. MT plane parallel to the plane of the microscope stage and perpendicular to incident light beam), were cut from the same rolls (gore) as those listed in Table 1. Examination of the extinction characteristics of the various specimens revealed from the outset a distinct difference between the Category I, II, IV and B1 specimens as compared to those of the Category III (roll 非112858, Gore 177). The former four types of specimens exhibited extinction when the nominal machine direction $M$ (based on the inked identification on the films) was parallel or closely parallel to the plane of vibration of the polarizer. In addition, using a first order red retardation plate it was established that in these four types of specimens $n(M)<n(T)$. The magnitude of the birefringence $\Delta n=n(M)-n(T)=\gamma / t$ (where $\gamma$ is the retardation and $t$ the thickness of the specimens), was determined using a Berek compensator to measure $\gamma$. The film thicknesses quoted by the manufacturer were assumed. In each case three specimens approximately $4 \mathrm{~cm} \times 2 \mathrm{~cm}$ were cut from different parts of a $10 \mathrm{~cm} \times 15 \mathrm{~cm}$ sheet of $\mathrm{film}$ and the birefringence in three different regions of each $4 \mathrm{~cm} \times 2 \mathrm{~cm}$ piece was determined. The area sampled in each measurement was $-1 \mathrm{~mm}^{2}$. As can be seen from the results listed in Table 6 $\mathrm{n}(\mathrm{M})<\mathrm{n}(\mathrm{T})$ for Categories I, II, IV and B1 with $\Delta \mathrm{n}$ ranging from -0.0012 to -0.0019 .

In contrast with the four films mentioned above, specimens of the Category III film, roll 非 112858 (Gore 177 excised from the $W 41.47$ balloon) exhibited considerable differences in their extinction characteristics. Extinction between crossed polarizers was observed with the angle $\theta$ between the machine direction and the plane of polarization of the polarizer varying from $0^{\circ}$ to $40^{\circ}$. A first order red retardation plate was used to determine that in all these areas $n(M)$ was greater than $n(T)$ (i.e. $\Delta n$ was positive) in contrast with the other four films. Furthermore the birefringence was found to be extremely weak in the samples which exhibited extinction at angles $\theta \leqq 30$ between $M$ and the plane of polarization of the polarizer. The birefringence of six areas which exhibited extinction at $\theta$ in the range $14^{\circ}-29^{\circ}$ were very close to one another, $(+0.0005$ to +0.0007$)$. It should be emphasized that the latter birefringences do not represent differences between $n_{M}$ and $n_{T}$ but represent the difference in refractive index for light polarized parallel and perpendicular to the direction of extinction.

In order to see whether the extinction and birefringence characteristics of the Cat. III roll 非112858 (Gore 177) were peculiar to that gore, several areas of roll 111958 (Gore 121) from the same balloon were examined. They exhibited similar variations in extinction direction as 
those described above. Similarly, $n(M)$ was also greater $n(T)$. The evident question which arose was whether the features described above, which distinguished the type III specimens excised from gores 177 and 121 from the specimens of the four other films, are characteristics of the Type III film as made, or are a consequence of handling e.g. during the manufacture of the balloon. The possibility that 'handling' might be the reason is suggested by an examination of specimens of Type III (roll \#112877) film which had not been incorporated in a balloon. Film from the same roll had been used in one of the gores (非146) of the balloon from which specimens 112858 (Gore 177) and 111958 (Gore 121) originated. The specimens of roll 非112877 exhibited extinction when the nominal machine direction was parallel to the plane of polarization of the polarizer. Furthermore $n(M)$ was less than $n(T)$ as is the case in the other four Categories of film. Measurements of birefringence, as carried out on the other films, yielded the result listed in Table 6 $(\Delta n=-0.0011)$ which, although lower, seems to be more in keeping with the optical character of the other four films.

As pointed out in Section G(i) there are differences in haziness in different regions of the Category I, II and IV films and the demarcation line between the hazy and less hazy regions in the films runs closely parallel to the machine direction. Some additional birefringence measurements were therefore taken to examine whether there are substantial differences in birefringence between the differently hazy regions in each film. The measurements were made at successive $3 \mathrm{~mm}$ intervals away from the demarcation line between the regions. The results are given in Table 7 .

Neglecting the results for the Category III (非112858, Gore 177) specimens in the light of the measurements on virgin Category III (非112877) film, there are two features of the data in Table 6, 7 which stand out. (1) All the films exhibit negative birefringence relative to $M$. (2) The magnitudes of the birefringences, which are in the range-[0.0009 to

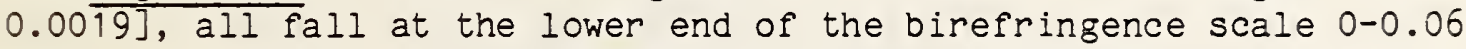
mentioned earlier, and correspondingly any differences in $\Delta n$ between the films are small relative to that scale.

Because of (1) the limited samplings used in the measurements, (2) the assumption that the thickness of each specimen was uniform and equal to the nominal thickness quoted by the manufacturers, and (3) the overlap between the $\Delta n$ values obtained from the different films, it is not possible to derive any definite conclusions regarding differences in $\Delta n$ between the films or between the hazy and less lazy regions in the Category I and II films. The data suggest that the magnitude of $\Delta$ may be smallest in the Category III film. It remains an open question however whether this observation, and e.g. the apparent differences between $\Delta \mathrm{n}$ in the hazy and non-hazy regions in the Category I and II films [Table 7] which are the opposite in the Category II film compared to I, would stand up to measurements on very much larger populations of samples. The same consideration applies to the deviation of the extinction position from $M$ exhibited in the vicinity of the interface between the hazy and less hazy regions in Catagory II film (Table 7). Additional 
comments on the birefringence exhibited by the films are included in Section I in conjunction with the results of the wide angle $x$-ray diffraction and infrared spectroscopy on the orientation of the crystalline regions in the films.

\section{(b) Wide Angle X-ray Diffraction and Infrared Spectroscopy}

As pointed out in the previous section blown films of polyethylene consist of microcrystalline regions interspersed with disordered regions. The microcrystals adopt different preferred orientations relative to the $\mathrm{M}, \mathrm{T}$, and $\mathrm{N}$ directions depending, inter alia, on the rate at which the tubular extrudate is cooled, and on the stretch and blow ratios imposed on it [see e.g. refs. 12-15].

As background to the wide angle $x$-ray diffraction (WAXD) experiments reported in this section it should be pointed out that the quantitative characterization of the crystalline orientation in films requires: (1) The determination of the preferred orientation of the $a, b$, and $c$-axis of the microcrystals relative to the $M, N$ and $T$ axes in the films. A possibility which may occur, and which should be borne in mind in this connection, is that a given set of processing conditions may yield a film having e.g. two populations of microcrystals having distinctly different preferred orientations relative to $\mathrm{M}, \mathrm{T}$, and $\mathrm{N}$; (2) The determination of the distribution(s) or deviations from the preferred orientation(s) among the total population of microcrystals.

Tasks (1) and (2) outlined above require the determination of pole figures [16] which involves the monitoring of the changes in intensity which key reflections undergo when the orientations of the $M, T$ and $N$ axes in the film sample are changed systematically relative to the incident $x$-ray beam by small angular increments over wide angular ranges. These tasks can be achieved with an automated counter $x$-ray diffractometer having a four circle goniometer sample holder and equipped with data collecting, processing and display facilities. Such a system, which is currently being installed in the Polymers Division, was not available during the period covered in this report.

In the comparatively limited exploratory experiments described below, a flat plate camera set-up was used to record photographically the diffraction patterns exhibited by each type of film when it was oriented in three different ways relative to the collimated beam of monochromatic $x$-rays ( $N$ i filtered CuKa radiation), $\lambda=0.15418 \mathrm{~nm}$ ). The three orientations were with the $T$, the $M$ and the $N$ axis of the film set parallel to the incident $x$-ray beam respectively. For the sake of brevity the corresponding diffraction patterns will be referred to below as the $T, M$ and $\mathrm{N}$ patterns. The patterns obtained from the five films are shown in Figs. 20-24. The orientations of the two orthogonal axes in the polyethylene film which lie in the plane normal to the $x$-ray beam are identified in each pattern (e.g. the $M$ and $N$ axes in the $T$ diffraction patterns etc.). The most evident reflections exhibited in all the patterns are (in order of decreasing intrinsic as well as observed intensity) the 110 the 200 and the 020 reflections. The interplanar spacings 
corresponding to these reflections are $0.41 \mathrm{~nm}, 0.37 \mathrm{~nm}$ and $0.246 \mathrm{~nm}$ [5]. These reflections which are identified in all the patterns (Figs. 20-24) occur as arcs which in some cases (particularly the 110 reflections) exhibit considerable azimuthal spread and appear ringlike in character.

An overall feature of the results of the experiments outlined in the previous paragraph is the similarity in the dispositions of reflections (relative to the film reference axes) between the $\mathrm{T}$, between the $M$, and between the $\mathrm{N}$ diffraction patterns of all the films. The following characteristics may be listed in this connection:

T-diffraction patterns, Figs. $(20-24)$ a

020 reflections: arcs spread preferentially about the axis parallel to $\mathrm{N}$

200 reflections: arcs spread preferentially about the axis parallel to M.

110 reflections: two pairs of diametrically opposite arcs spread about $\pm 30^{\circ}$ from $\mathrm{N}$

M-diffraction patterns, Figs. $(20-24) b$.

020 reflections: arcs spread preferentially about the axis parallel to $\mathrm{N}$

200 reflections: arcs spread preferentially about the axis parallel to $\mathrm{T}$

N-diffraction patterns, Figs. $(20-24) c$

020 reflections: faint arcs spread preferentially about the axis parallel to $\mathrm{T}$

200 reflections: arcs spread preferentially about the axis parallel to $M$

The arced or ringlike character of the various $x-r a y$ reflections exhibited by the films indicate that there are broad distributions in or ientation about some preferred orientation or orientations. The preferred dispositions exhibited by the 200 reflections in the $M$, $T$, and $\mathrm{N}$ diffraction patterns indicate that the microcrystalline regions in the films are oriented with the a-axis preferentially parallel to the MT plane and with a preference parallel to $M$. The dispositions of the 020 reflections suggest the b-axis is preferentially oriented parallel to the NT plane and with a preference parallel to $\mathrm{N}$.

A possible working model which suggests itself, and which would be consistent with the preferred a-axis and b-axis orientations indicated above, is one in which the film is envisaged as containing mainly two populations of microcrystals whose respective orientations are distrib- 
uted preferentially about the two idealized orientations depicted in Fig.25. In Fig.25a the microcrystals are envisaged as being oriented with the b-axis parallel to $\mathrm{N}$ and with the a-axis and the c-axis randomly oriented in the MT plane. In the case of Fig. 25b the microcrystals are oriented with the a-axis parallel to $M$, and with the $\mathrm{b}$-axis and the c-axis randomly oriented in the NT plane. Preferred orientations corresponding to those in Fig.25a and Fig.25b would each exhibit $\mathrm{T}$-diffraction patterns in which the preferred dispositions of the 020,200 and 110 reflections relative to the $\mathrm{N}$ and $\mathrm{M}$ directions are the same and would correspond to the actually observed dispositions of these reflections in the $T$ diffraction patterns exhibited by the films which were described earlier.

While the qualitative observations described above have identified features of the $\mathrm{M}, \mathrm{T}$, and $\mathrm{N}$ diffraction patterns which indicate that the crystalline orientation(s) in the five films are similar or related in type, more detailed studies using the automated counter-diffractometer technique mentioned earlier will be necessary to compare their orientation characteristics (preferred orientations and orientation distributions) quantitatively, and to test the suggested working model.

Information on the orientation of the crystalline regions in polyethylene can also be obtained from infrared (IR) spectra. The methylene rocking vibration of crystalline polyethylene gives rise to a doublet the lower frequency $\left(719 \mathrm{~cm}^{-1}\right)$ component of which absorbs IR radiation polarized parallel to the b-crystallographic axis, while the higher frequency $\left(733 \mathrm{~cm}^{-1}\right)$ component absorbs radiation polarized parallel to the a-axis [17]. A complicating factor is that absorption near $719 \mathrm{~cm}^{-1}$ may arise from $-\mathrm{CH}_{2}$ rocking vibrations in the disordered (non-crystalline) regions of polyethylene. This complication notwithstanding, infrared spectra of a sample from each of the five films were recorded with the incident $I R$ beam parallel to $\mathrm{N}$ in the films. Two spectra were recorded in each case, namely with the incident beam polarized either parallel or perpendicular to the $M$ direction (or the extinction direction nearest to M).

The $-\mathrm{CH}_{2}$ rocking region of the spectra exhibited by each film is shown in Fig.26(a-e) in which it can be seen that the intensity of the 733 $\mathrm{cm}^{-1}$ band (a-axis) is always higher when the IR radiation was polarized parallel (dashed line) to $M$ as compared to perpendicular (continuous line) to $M$, and that the reverse is true for the $719 \mathrm{~cm}^{-1}$ band (b-axis). The ratio of the intensity of each band for the two different polarizations is listed in Table 8 . It was pointed out earlier that absorption near $719 \mathrm{~cm}^{-1}$ may also arise from $-\mathrm{CH}_{2}$ rocking vibrations in the disordered regions. Any orientation in these regions will also affect the intensity ratio of the $719 \mathrm{~cm}^{-1}$ band, and could account for the differences between the parallel/perpendicular $\left(733 \mathrm{~cm}^{-1}\right)$ and perpendicular/parallel $\left(719 \mathrm{~cm}^{-1}\right.$ ) ratios exhibited by some of the films (Table 8). The data are nevertheless consistent with the wide angle $x$-ray diffraction patterns obtained with the $\mathrm{x}$-ray beam parallel to $\mathrm{N}$ ( $\mathrm{N}$ diffraction pattern) which indicated that in the MT plane there is a 
preferential orientation of the a-axis parallel to $M$ and the $b$-axis parallel to $T$ (the 200 and 020 arcs are centered about $M$ and $T$ respectively, as pointed out earlier).

(H) Mechanical Properties

(i) Creep Behavior (Categories I-IV)

As background to the investigation of the tensile elongation and tensile strength at break of the films, the tensile creep behavior of the Category I-IV films was examined at $23 \pm 0.5^{\circ} \mathrm{C}$ for specimens which were cut both parallel and transverse to the machine direction. The specimens were cut with a die which conformed closely with the type (II) tensile bar specified in ASTM D638. In order to determine the strain as a function of time fiducial marks were placed approximately five centemeters apart on the straight gage section of each specimen and the separation of the marks was monitored with a cathetometer. The duration of each creep experiment was generally about one hour.

In the first set of experiments the specimens were subjected to an applied engineering stress of $2.5 \mathrm{MPa}$ ( $363 \mathrm{PSI}$ ). This level of stress corresponds to about one fourth of the yield stress for these films as determined in uniaxial extension at a constant rate of strain (discussed in a later section). The results are shown in Figure 27 plotted as 108 strain versus log time. Under the conditions just described the maximum strain after one hour was $2.2 \%$ or less. No significant differences in creep behavior occurred between the machine and transverse directions, nor was there any appreciable difference in behavior from film to film. Most of the observed differences are probably within the experimental errors which can arise from factors such as nonuniformity in the film thickness and creases due to folds which can result in uncertainty in determining the initial unloaded gage length $\ell_{0}$.

A second set of creep experiments was done using a larger applied engineering stress of $10 \mathrm{MPa}$ ( $1450 \mathrm{PSI}$ ) which is very close to the yield stress for these films at $23^{\circ}$ (see later, Table 12). From Figure 28 -it can be seen that at the higher level of stress, strains of from $30 \%$ to $100 \%$ were observed after about one hour. After one minute all of the film specimens except two exceeded the strain at the yield point which is in the range from 18 to $22 \%$ for these films at $23^{\circ} \mathrm{C}$. Beyond the yield point significant differences occurred between the machine and transverse direction as well as from film to film. The Category I film appears to be the most nearly balanced of the four films, and the Category IV film the least. Of the four films the Category II film exhibited the least amount of creep in the machine direction after one hour.

(ii) Elongation to Break, Tensile Strength, Yield Stress (Categories I-IV, B1)

The tensile elongation and tensile strength at break of the Category $\mathrm{I}-\mathrm{IV}$, and $\mathrm{B} 1$ films were investigated at $23 \pm 0.5^{\circ} \mathrm{C}$ and at $-70 \pm 2^{\circ} \mathrm{C}$. Due to the limited amount of actuator travel available in our hydraulic test 
machine fitted with a low temperature chamber, it was found necessary to use specimens which had a gage length of no more than about 1 to $1.5 \mathrm{~cm}$. Specimens were cut with a dumbbell shaped die specially designed so that the ends widened rather gradually in the first $0.1-0.2 \mathrm{~cm}$ beyond the straight portion of the dumbbell. The straight portion of the dumbbell was $0.80 \mathrm{~cm}$ long and the width in that narrow section was $0.315 \mathrm{~cm}$.

For the initial set of experiments, which were carried out at $23 \pm 0.5^{\circ} \mathrm{C}$, the gage length was set at $1.0 \mathrm{~cm}$ so that at each grip about $0.1 \mathrm{~cm}$ of the exposed gage section was slightly wider than the $0.80 \mathrm{~cm}$ long straight section. The results of tests carried out on the Category I and II films are presented in Table 9. The values obtained were found to be significantly smaller than those quoted by either the film manufacturer or the NSBF. Therefore much effort was devoted to examine the effect of different specimen geometries and clamping arrangements on the measurements. This effort involved the testing of approximately 200 specimens having geometries which varied from straight strips of different length to width ratios to the dumbbell shaped specimens described above in which the gage length was varied. Of the different geometries examined the one which consistently yielded in the greatest strain at break was one using the original dumbbell shaped specimen gripped such that only the straight section of the dumbbell was exposed between the grips. Accordingly, all subsequent tests at $23^{\circ} \mathrm{C}$ and $-70^{\circ} \mathrm{C}$ were carried out using specimens with a gage length of $0.60 \mathrm{~cm}$ so that the length to breadth ratio was 1.9 , which compares to a value of 2 used by the NSBF. The specimen grips were made of aluminum. They were covered with one layer of a soft cloth electrical tape to prevent contact of the polyethylene film with the metal. Use of the cloth tape results in greater values of the strain at break. The rate of clamp separation, which was limited by the number of positions available on the function generator of our testing machine, was set so that the specimen was strained at a rate of $991 \%$ per minute as compared to a rate of $1000 \%$ per minute used by the NSBF.

Using the test procedures just described, the tensile properties of the Category I-IV, and B1 films were examined at $23 \pm 0.5^{\circ} \mathrm{C}$ and the results are shown in Table 10. In the machine direction the average strain at break does not differ greatly among the five films, whereas in the transverse direction significant differences do occur. For the Category I and B1 films the average strain at break is slightly greater in the machine direction than in the transverse direction. The reverse is true for the Category II, III, and IV films for which the transverse direction exhibits significantly greater strain before failure. It should be noted that the Category I-IV films exhibited a distinct maximum in the stress-strain curve at low strains (range 18-22\%) when stretched in the transverse direction. A barely perceptible maximum occurred in the B1 film. None of the films exhibited a maximum in the stress at low strains when stretched in the machine direction. Based upon the tensile tests, the Category I-IV films are all consistent with the creep measurements described earlier where the specimens from these films subjected to a stress of $10 \mathrm{MPa}$ (Fig.28) were found to creep significantly more in the transverse than in the machine direction, except for the 
Category I film which exhibited more balanced behavior and also exhibited slightly higher creep in the machine direction than in the transverse direction.

The maximum and minimum values of the strain at break at $23^{\circ} \mathrm{C}$ are listed in Table 11 for each of the five films. For stretching along the machine direction the smallest minimum values occurred in the Category III and IV films, whereas for stretching along the transverse direction they occurred in the Category I and B1 films.

A summary is presented in Table 12 of the yield stress data obtained from the same tensile tests described above. In the present work the yield stress was defined to be either the point at which the

stress-strain curve went through a maximum (transverse direction), or if no maximum occurred (machine direction) it was taken to be the point at which the stress-strain curve exhibited a sharp bend. The maximum average yield stress occurred for the Category I film in the machine direction and the minimum average value occurred for the Category III film in the transverse direction. However, there did not appear any large varlation in yield stress among any of the five films at $23^{\circ} \mathrm{C}$. For all five films the strain at the yield point was in the range from 18 to $22 \%$.

Similar tests were carried out at $-70^{\circ} \mathrm{C}$ on specimens cut from the same sheets of $\mathrm{film}$ used for the $23^{\circ} \mathrm{C}$ tests. The results are summarized in Table 13. The temperature control of the low temperature chamber was such that the actual specimen temperature at the time the test was started is estimated to be $-70 \pm 2^{\circ} \mathrm{C}$. To ensure that the specimen temperature was at least as $10 \mathrm{w}$ as $-70^{\circ} \mathrm{C}$, the chamber was initially cooled to between $-75^{\circ} \mathrm{C}$ and $-80^{\circ} \mathrm{C}$. The chamber was then warmed up to about $-71^{\circ} \mathrm{C}$ and held at that temperature for several minutes. The test was generally started when the temperature in the vicinity of the specimen was between $-71^{\circ} \mathrm{C}$ and $-70^{\circ} \mathrm{C}$. The temperature in the vicinity of the specimen was determined by both a copper-constantan thermocouple placed just below the specimen and a solid state device placed just above the specimen.

As was the case at $23^{\circ} \mathrm{C}$ the Category II, III, and IV films exhibited smaller average strains at break in the machine direction than in the transverse direction, while the Category I film exhibited greater average strain in the machine direction. In the case of the 31 film however the strain to break was larger in the transverse than in the machine direction, whereas the reverse occurred at $23^{\circ} \mathrm{C}$. The average strains to break in both directions are less for all five films at $-70^{\circ} \mathrm{C}$ than they were at $23^{\circ} \mathrm{C}$, by about 33 percent overall. The standard deviations are, however, much larger at $-70^{\circ} \mathrm{C}$ than at $23^{\circ} \mathrm{C}$, particularly in the case of the Category II film. For the five sets of film samples examined, the average strain at break in each case did exceed the current minimum requirement of $250 \%$ stipulated by NSBF, although in several cases individual specimens failed at elongations well below this value. 
Table 14 shows the maximum and minimum values of the strain at break corresponding to the data resented in Table 13. While in each case the average strain at break exceeded $250 \%$, each film, with exception for the Category III film, exhibited at least one specimen which failed at a strain less than 250\%. One specimen of the Category III film exhibited the largest elongation $(609 \%)$ at $-70^{\circ} \mathrm{C}$ of any of the specimens tested.

Table 15 presents a summary of the yield stress data obtained at $-70^{\circ} \mathrm{C}$. A comparison of the data in Tables 12 and 15 shows that at $-70^{\circ} \mathrm{C}$ the $y$ ield stress is from 4 to 5 times greater than it is at $23^{\circ} \mathrm{C}$. Whereas at $23^{\circ} \mathrm{C}$ the variation in yield stress from film to film was less than $12 \%$, at $-70^{\circ} \mathrm{C}$ it is as much as $37 \%$. On average, the Category I film exhibits a higher yield stress than do the other three, while the Category II film in the transverse direction exhibits the smallest average yield stress. At the same time the strain at the yield points exhibited by the films decreases from the $18-22 \%$ range at $23^{\circ} \mathrm{C}$ to the $6-9 \%$ range at $-70^{\circ} \mathrm{C}$. It should be noted that all the films exhibited a maximum in the stress strain curve at $-70^{\circ} \mathrm{C}$ when stretched in the transverse as well as in the machine direction. This contrasts with the deformation at $23^{\circ} \mathrm{C}$ where the manifestation of a maximum occurred only upon stretching in the transverse direction.

Using the data for the 64 specimens of Category I-IV and B1 filmswhose properties are summarized in Table 13, we have plotted in Figure 29 the strain at break versus yield stress at $-70^{\circ} \mathrm{C}$. Of the eleven specimens which failed at a strain of less than $250 \%$, 4 belong to Category II, three to Category B1, two to Category I, and two to Category IV. The two smallest values obtained ( 46 and $72 \%$ ) were from Category II. Of these eleven specimens which failed at less than $250 \%$ strain, all but one exhibited a yield stress of less than $50 \mathrm{MPa}$. However, the overall average yield stress for all 70 specimens tested was only $47.0 \mathrm{MPa}$ ( 6831 PSI ).

\section{(iii) Effect of Strain Rate.}

Another aspect of the low temperature deformation of the films which is of interest is the extent to which the ultimate tensile properties depend upon the rate of strain. The strain rate dependence was examined at $-70^{\circ} \mathrm{C}$ for the Category I, II, and $\mathrm{B} 1$ films and the results are presented in Table 16. The strain rate was varied by a factor of one hundred, the lowest rate being $99.1 \%$ per minute and the highest being $9910 \%$ per minute. It can be seen from Table 14 that in the range of strain rates examined there is little, if any, dependence of the strain to break on the strain rate. Except for the Category B1 film, at each rate of strain the trends are the same as those found earlier. The Category I film extends more in the machine direction than in the transverse direction while for the Category II film the opposite is true. The Category $\mathrm{B} 1 \mathrm{film}$ at the lowest and highest rate of strain shows the opposite behavior to that at the rate of $991 \%$ per minute. At all three strain rates each of the three films meets the minimum requirement of $250 \%$ elongation, although Category $I$ and B1 films do so marginally. Examination of the results on tensile strength indicates that, if averaged over 
all three films, the average stress at break is slightly higher at a rate of $991 \%$ per minute than at the other two rates, however the averages for the two extreme rates of strain are based upon the testing of only three specimens cut along each direction.

\section{(iv) Comparison of Tensile Properties of Different Rolls of Category I FIIm}

Following the tensile tests described earlier in this report on roll 315477 of the Category I film, several additional pieces of Category I film from roll 315421 were received from the NSBF which were cut from areas very near those tested previously by them. The pieces were identified as Sample 2, areas 106-112. We have examined the tensile properties of specimens cut from the two areas identified as 107 and 111 and the results are presented in Table 17. For comparison the results from the earlier tests on roll 315477 are also included. The values quoted represent averages for only three specimens cut in each direction for areas 107 and 111, whereas for roll 315477 the averages are for six specimens.

At both $23^{\circ} \mathrm{C}$ and $-70^{\circ} \mathrm{C}$ the strain at break is greater for roll 315421 than for roll 315477, while the yield stress is greater for roll 315477 . Moreover, there appear to be differences in all three tensile properties between areas 107 and 111 from roll 315421 . At $-70^{\circ} \mathrm{C}$ one specimen from area 107 failed at a strain of less than 250\% (202\%), whereas none from area 111 failed at less than $380 \%$ elongation. Also, at $-70^{\circ} \mathrm{C}$ the specimens from area 111 cut along the transverse direction exhibited the highest tensile stress at break of any of the five film categories tested in this study.

\section{(v) Haziness}

As pointed out in Sections $G(i)$ and $G(i i)$ a films of Category $I$, II and IV exhibit regions which to the eye appeared to vary in haziness. The boundary separating the more hazy from less hazy material was in some instances rather abrupt and it tended to $r$ un more or less parallel to the machine direction in the film. One sheet of film in which this phenomenon was particularly evident was from roll 311071 of Category IV. To investigate the possibility that differences in mechanical performance might be associated with differences in haziness a set of twelve specimens were cut initially from one 8 inch by 8 inch piece from roll 311071 , six from the more hazy region and six from the less hazy region. All twelve were cut parallel to the transverse direction in the film and the tensile tests were carried out at $-70^{\circ} \mathrm{C}$. The results are presented in Table 18. The initial twelve specimens are identified as MH1-MH6 (more hazy) and LH1-LH6 (less hazy). The result was that only one of the six specimens cut from the more hazy region extended more than $100 \%$, whereas all six specimens cut from the less hazy region extended more than $280 \%$. 
As a result of this observation, seven more specimens were cut from areas surrounding the more hazy region from which the original six were cut. The latter seven specimens are identified in Table 18 as MH7-MH13. All seven of these extended at least 388\%. The reason why $f$ ive of the first six specimens from the more hazy region failed at much smalier strains remains unknown. All nineteen specimens were handled and tested under identical conditions. Moreover the first twelve specimens were tested by alternating between specimens cut from the more hazy and less hazy material. It is possible that, by chance, the first six specimens were cut from a small but particularly weak area of the film.

Because of the above observations all the pieces of film from the ten rolls of the Category III film and at least six rolls from each of the Category I, II, and IV films supplied by the NSBF were examined visually for haziness. None of the ten rolls of Category III film were found to exhibit any significant variation in haziness. On the other hand, all the film examined from Categories I, II, and IV did contain at least one region which exhibited more hazy and less hazy areas. The one piece of film from Category B1 which we received did not show any variability in haziness.

After the above mentioned inspection of the various films, it was decided to examine the mechanical behavior of one of the more hazy regions observed in the Category II film. Eight specimens were cut along the transverse direction from roll 313865, gore 53. The results of tensile tests done at $-70^{\circ} \mathrm{C}$ are shown in Table 19. Although two specimens failed at a strain of less than $250 \%$, the strains, on average, are not greatly different from those found earlier for the same roll of film (see Table 13). Both the average stress at break and average yield stress are, however, significantly smaller (compare with data in Table 13 and Table 15 respectively).

\section{(vi) Wide Strip Geometry}

In addition to the tensile tests just described, we have also examined briefly the mechanical properties of film specimens having different geometries or subjected to different deformation modes. The first of these to be discussed involves the extension of a wide strip of film. In the work described above the ratio of the specimen width to the length was 0.52 . In the present case the width was set at $1.87 \mathrm{~cm}$ and the gage length set at $0.2 \mathrm{~cm}$, so that the width to gauge length ratio was 9.35. A width of $1.87 \mathrm{~cm}$ corresponds to the maximum dimension which can be accommodated in our present set of grips. Table 20 summarizes the results of measurements made at $23^{\circ} \mathrm{C}$ on films from Categories $I$, II, and III. All of the specimens were cut so that the transverse film direction was parallel to the tension axis. In each case the average strain at break is significantly greater, from 18 to $31 \%$, than for the narrower tensile specimens used earlier (see Table 10). One specimen from the Category II film elongated by as much as $1030 \%$ before failing. 


\section{(vii) Bubble Inflation}

Another technique which can be used to investigate the mechanical performance of biaxially oriented films is one involving the inflation of a diaphragm to form a bubble. This method is described in reference [18] and is very similar to the "race track" test used by the NSBF. An example is shown in Figure 30. The film is inflated from one side to form a bubble. Provided the film is sufficiently thin and the deformations small the bubble will approximate very closely a spherical shape. Near the pole the deformation is 'equal-biaxial' and the true stress in the region is given by

$$
\sigma_{\mathrm{T}}=\frac{\mathrm{P}}{2} \frac{\mathrm{r}}{\mathrm{h}} \lambda^{2}
$$

where $P$ is the inflation pressure, $r$ is the radius of curvature, $h$ is the initial film thickness, and $\lambda$ is the stretch ratio given by $\lambda=1+\varepsilon, \varepsilon$ being the strain determined along a given radius. If the deformation becomes large enough that the yield point is exceeded, the bubble may become distorted and no longer spherical in shape. Under a constant inflation pressure creep will occur. If either sufficient time is allowed or the pressure is high enough, the material will eventually reach a point of instability and necking followed by cold drawing may occur prior to rupture.

Using this inflation method one sheet of Category III film was gradually inflated by slowly increasing the pressure until yielding and rupture occurred. The area of our diaphragm tester was $46 \mathrm{~cm}^{2}$ and the test was conducted at $23^{\circ} \mathrm{C}$. The example shown in Figure 30 is Category III just prior to rupture. A characteristic of the film was the formation of numerous "necks" or thinned down regions. In Figure 30 more than 10 different necked down regions were observed over the central region of the bubble. In each case the necking originated from one or more thin faintly visible lines which ran nearly parallel to the machine direction in the film. Upon formation of a neck, cold drawing then occurred with the deformation being greater in the transverse direction.

(viii) An Example of the Influence of Molecular Weight and Molecular Weight Distribution on the Tensile Properties of Polyethylene

In Section B of this report it was found that of the five categories of film the Category III film had a somewhat greater proportion of high molecular weight material than did the others, whereas the Category B-1 film had the lowest molecular weight. It is well known that factors such as nolecular weight and molecular weight distribution play an important role in determining the tensile properties of polymers, particularly semicrystalline polymers such as polyethylene. In this section we shall present one example of how molecular weight and molecular weight distribution can influence the uniaxial creep behavior of initially unoriented linear polyethylenes [19] at $23^{\circ} \mathrm{C}$. 
Figures 31,32 , and 33 present what we shall refer to as isochronal stress-strain surfaces obtained from creep experiments on three different samples of linear polyethylenes. Although the particular surfaces shown are for linear polyethylenes in uniaxial creep, a similar set of surfaces will exist for branched polyethylenes under uniaxial or biaxial deformations. The surfaces were obtained in the following way. For each of the three different samples a set of uniaxial creep experiments was carried out at different levels of applied engineering stress. Each creep experiment was continued until fracture occurred. In some cases this meant conducting the experiment for a period of several months. From each of the sets of creep curves a series of isochrones was determined, as shown in the figures. All three samples were linear polyethylenes having very nearly the same number average molecular weight $\left(M_{n}=15,300-15,600\right)$, but different weight average molecular weights $\left(M_{W}=99,000-192,000\right)$. In the present case a greater $M_{W}$ implies a greater proportion of higher molecular weight components.

The fracture behavior of linear polyethylene in uniaxial creep can be described by two distinctly different mechanisms. For relatively large applied stresses the polymer creeps until a material instability occurs beyond which yielding, cold drawing, and eventually fracture occur. As we shall see presently, the amount of cold drawing which occurs prior to fracture depends strongly on the molecular weight distribution. At much smaller applied stresses, or very long failure times, fracture occurs as a result of crack formation and growth. In this region fracture may occur well before the macroscopic yield point is reached. This region is not pertinent to the present discussion.

Figure 31 shows a series of isochrones from the sample having the smal1est $M_{W}$. Line a represents for each value of applied stress the time and strain (plotted as $10 \mathrm{~g}$ strain) at which neck formation occurs. Line $\gamma$ corresponds to the same two measures at the point of fracture. Since in this material the specimens all fractured immediately following neck formation, lines $\alpha$ and $\gamma$ are the same line.

A similar plot is shown in Figure 32 for the polymer having an $M_{W}$ of 160,000 . In this case it can be seen that, depending upon the level of applied stress, a significant amount of cold drawing can occur and correspondingly a substantially greater lifetime. At the optimum stress, this material is capable of elongating as much as 25 times before fracture occurs. In Figure 32 the line $\beta$ represents the strain at which the neck had propagated the entire gage length of the specimen.

By increasing the $M_{W}$ to 192,000 the diagram shown in Figure 33 is obtained. Although similar in shape to Figure 32, two distinct differences appear. Firstly the maximum elongation which can be achieved is somewhat less (18-20\%), and secondly the breadth of the region in stress in which a significant amount of cold drawing can occur is greater. A third difference, and one which possibly may be of importance within the context of film behavior, is the following. At a given stress level the time to fracture depends upon $M_{W}$. For example, at a stress of $20 \mathrm{MPa}$ the polymer having an $M_{w}$ of 160,000 fractured in a time of about one to two 
hours. By increasing the $M_{W}$ to 192,000 the time to fracture has been increased to nearly 10 hours. Therefore a small increase in the proportion of higher molecular weight components can lead to a substantially longer lifetime. The point to be made here is that the principle difference in behavior resulting from the small change in $\mathrm{M}_{\mathrm{w}}$ occurs in the region beyond the yield point. Both materials exhibit yield and necking at approximately the same strain and time under creep.

\section{Summary}

The following features of five polyethylene films (Categories I-IV and B1) have been examined: molecular weight, molecular weight distribution, branching, melting behavior, density (crystallinity), surface texture, birefringence, crystalline orientation, uniaxial deformation in the machine $(M)$ and in the transverse ( $T$ ) directions, and the effect of sample geometry on deformation behavior. In addition, observations concerning additive(s) in the films have been obtained, and a preliminary experiment on biaxial deformation of one of the films has been performed.

Among the features enumerated above clear differences between the films were observed in their molecular weights-molecular weight distributions. The intrinsic viscosity was highest $(1.27 \mathrm{dl} / \mathrm{g})$ for the Cat. III and Cat. II films, lowest for the B1 film $(1.13 \mathrm{dl} / \mathrm{g})$, and was between these extremes in the case of the Cat. I (1.23) and Cat. IV (1.22) films. The size exclusion chromatograms of all the films showed evidence of a bimodal distribution with a hint of a third peak. These features are likely to be the result of a blending of polymers. Comparison of the normalized chromatograms showed that within the calibration limits of the separation columns used (M.Wts. $850-4.6 \times 10^{6}$ ) the Cat. III film contained a larger proportion of high molecular weight species than the other films and, on a relative basis, had the nighest $M_{W}$, followed in decreasing order of molecular weight by the Cat. II, Categories I and IV, and B1 films.

In so far as branching is concerned, the methyl group content as determined by Fourier Transform Infrared Spectroscopy was found to be the same for all the films, i.e. $\sim 2.1$ methyl groups $/ 100$ carbon atoms. The fact that the DSC (Differential Scanning Calorimetry) curves of all the films exhibited a polymer melting endotherm whose peak was in the narrow temperature range $105.5^{\circ} \mathrm{C}-107^{\circ} \mathrm{C}$, and that the crystallinities of the films (based on density measurements) were found to be close to one another ( $46.2 \%-48.2 \%)$, are consistent with the methyl group content being the same for the various films. The DSC experiments revealed the presence in all the films of a small quantity of a component which melts at a much lower temperature than the bulk of the polymer. This low melting component is most probably additive material. The presence of additive was also indicated in FTIR spectra which exhibited extra absorption bands which are not known bands of polyethylene. The extra bands were however different for the Bl film than for the Cat. I-IV films. 
The crystalline orientation in the films was probed by taking wide angle $\mathrm{x}$-ray diffraction patterns with the $\mathrm{x}$-ray beam parallel to the $\mathrm{T}, \mathrm{M}$ and $\mathrm{N}$ (normal to the film) directions. The results indicate that there are qualitative similarities between the preferred orientations of the microcrystalline regions in the various films. The indications are (1) that the a-axis tends to be oriented preferentially parallel to the MT plane and preferentially parallel to $M$ in that plane, and that (2) the b-axis tends to be preferentially oriented parallel to the NT plane and preferentially parallel to $\mathrm{N}$ in that plane. Infrared spectroscopic data were obtained which are consistent with these observations. An idealized working model is suggested in which it is envisaged that crystalline regions in the films consist mainly of two populations of microcrystals having different preferred orientations (Fig. 25) relative to $T, M$ and $N$. This model must remain speculative pending quantitative studies and comparisons of the orientation(s) and orientation distributions in the films using an automated counter-diffractometer system equipped with a four circle goniometer sample holder.

When viewed along the $\mathrm{N}$ direction the Category $\mathrm{I}$, II, IV and B1 films, as well as virgin Cat. III film, exhibited negative birefringence with respect to $M$, i.e. $n(M)<n(T)$. The magnitudes of the birefringences measured for all the films were collectively very small (in the range-[0.0009 to 0.0019$]$ and, correspondingly, any differences between the films were also small. This latter observation is consistent with the similarity in the character of the crystalline orientations in the various films suggested by the WAXD and Infrared spectroscopic examinations of the films, provided it is assumed that the contribution of the disordered regions to the total birefringence in the MT plane is the same for all the films.

In the area of mechanical properties it was established that in uniaxial constant rate of strain experiments the extension to break is dependent on specimen geometry, $i . e$. on the sample length/breadth ratio. Decreasing the length/breadth ratio results in an increase in the extension to break at $23^{\circ} \mathrm{C}$. A length/breadth ratio of 1.9 was used in the experiments which were carried out at $23^{\circ} \mathrm{C}$ and $-70^{\circ} \mathrm{C}$ using a strain rate of $991 \% / m i n$. A summary of the tensile data in Tables $9-15$ is given in Table 21.

Concerning the NSBF criterion that the strain to break should not be less than $250 \%$ in either the $M$ or $T$ directions at $-70^{\circ} \mathrm{C}$, it was found that although the average strain to break of each of the five films met that requirement, the Category III film was the only one for which none of the measurements fell below $250 \%$.

The Cat. II, III and IV films exhibited higher average extensions to break parallel to $\mathrm{T}$ than to $\mathrm{M}$ at both $23^{\circ} \mathrm{C}$ and $-70^{\circ} \mathrm{C}$. In contrast, the average strains to break in both directions for the Cat. I film were essentially the same at $23^{\circ} \mathrm{C}$, furthermore at $-70^{\circ} \mathrm{C}$ the extension to 
break was higher in the $M$ direction. The extension to break behavior of the $B 1 \mathrm{film}$ in the $\mathrm{M}$ relative to the $\mathrm{T}$ direction was similar to that of the Cat. I at $23^{\circ} \mathrm{C}$ and to that of the Cat. II, III and IV at $-70^{\circ} \mathrm{C}$.

The overall haziness exhibited by all the films is due, in part at any rate, to the roughness of both their surfaces at which variations in topography occur on a lateral scale of a few $\mu \mathrm{m}$. Differences in haziness to the naked eye (under appropriate illumination) were observed in adjoining regions in some portions of the Cat I, II and IV films. The boundary between the hazy and less hazy regions was usually roughly parallel to M. A brief examination of whether there are differences in birefringence and/or mechanical behavior between adjoining hazy and less hazy regions was carried out. In view of the scatter in the relatively few measurements which were made, some of the results which might be interpreted as evidencing differences in birefringence and/or mechanical properties between the differently hazy regions in the films must remain tentative at this juncture. The scatter in the measurements is not unlike the scatter experienced in similar measurements made in regions of apparently uniform haziness.

\section{J. Concluding Remarks}

This exploratory study has resulted in the identification of similarities and differences between various features of the films. Close similarities have been found in methyl group content, crystallinity, and peak melting temperature. The preferred orientations in the crystalline regions (i.e. relative to the $M, T$, and $N$ directions) appear to be qualitatively similar. However, due to the limited scope of the orientation studies, the question of whether there are differences in the orientation distributions of the microcrystals between the films remains open pending the determination and comparison of the pole figures of each film.

Differences between the films have been revealed in two features, namely between their molecular weights, and in the balance of the strain to break behavior in the $M$ relative to the $T$ directions. These two types of differences are particularly evident between the Cat. III, Cat. I-and B1 films.

Differences in response to tensile deformation in the $M$ relative to the $T$ directions point to underlying built-in differences in fine structural anisotropies in the films with respect to these directions. One or both of two possibilities suggest themselves in this connection: Differences in the distribution of the orientations of the microcrystalline regions, hence the need for quantitative comparisons of the crystalline orientation characteristics of the films: (2) differences in the nature of and degree of any chain orientation in the disordered regions which are interspersed between the constituent microcrystals in the films. Differences of the latter type [i.e. type (2)] are difficult to determine. In any event determination of the crystalline orientation characteristics of the films would be a necessary first step in this latter connection. Added to these various 
considerations are the differences in molecular weight between the films, the effects of which remain unclear at this stage. The influence which differences in molecular weight can have on the mechanical behavior of initially unoriented polyethylene was illustrated in the example discussed in section H(viii). However, in the case of the films investigated in this study, determination of any effects of molecular weight per se on the mechanical properties of the films is complicated by the fact that the films are not isotropic.

In addition to the determination of the pole figures of the films, it is recommended that future studies include: (a) An examination of

the biaxial (bubble geometry) deformation characteristics of the films at $23^{\circ} \mathrm{C}$ and $-70^{\circ} \mathrm{C}$. Biaxial deformation experiments address themselves more directly than uniaxial ones to the question of the importance of the type of imbalance which exists between the mechanical properties in the $\mathrm{M}$ and $\mathrm{T}$ directions. (b) As background to developing an understanding of the possible intrinsic influence of differences in molecular weight between the films on their mechanical properties, creep to failure experiments of the type described in section H(viii) should be carried out on unoriented sheets of polymer from each film. Such sheets can be prepared by melting and subsequently cooling several compacted layers of film. 
K. References

1. Drott, E.E., and Mendelson, R. A., J. Polymer Sci., Part A-2, 8,559 (1973).

2. Wagner, H. L. and McCrackin, F. L., J. Appl. Polymer Sci., 21, 2833 (1977).

3. Zimm, B. H., and Stockmayer, W. H., J. Chem. Phys. 17, 1301 (1949).

4. Rueda, D. R., Balta'-Calleja, F. J., and Hildalgo, A., Spectrochemica Acta 35A, 847 (1979).

5. Bunn, C. W., Trans. Faraday Soc. 39, 482 (1939).

6. Davis, G. T., Eby, R. K., J. Appl. Phys. 44,4274 (1973).

7. Stehling, F. C., Speed, C. S., and Westerman, L., Macromolecules, 14, 698 (1981).

8. Tabar, R. J., Murray, C. T., and Stein, R. S., J. Polymer Sci. Polym. Phys. Ed. 21, 83 (1984).

9. Stein, R. S., and Wilkes, G. L., in Structure and Properties of Oriented PoIymers (I.M. Ward edit.) Chapt. 3, Wiley N.Y. (1975).

10. Mead, W. T., Desper, C. R. and Porter, R. S., J. Polymer Sci., Polymer Phys. Ed. 17, $859 \cdot(1979)$.

11. Bunn, C. W., and Daubeny, R. De P., Trans. Faraday Soc. 50, 1173 (1954).

12. Lindemeyer, P. H., and Lustig, S., J. Appl. Polymer Sci., 9, 227 (1965).

13. Maddams, W. F. and Preedy, J. E., J. Appl. Polymer Sci. 22, 2721 (1978).

14. Maddams, W. F. and Preedy, J. E., J. Appl. Polymer Sci. 22, 2739 (1978).

15. Maddams, W. F. and PReddy, J. E., J. Appl. Polymer Sci. 22, 2751 (1978).

16. Alexander, L. E., X-Ray Diffraction Methods in Polymer Science, Wiley, N.Y. (1969).

17. Krimm, S. 'Infrared Spectra of Solids: Dichroism and Polymers', in Infrared Spectroscopy and Molecular Structure (Ed. M. Davies) Elsevier, Amsterdam (1963). 
18. Webb, L. D., Engineering Services Final Report, prepared for NSBF, National Center for Atmospheric Research, Palestine, Texas. Contract 非CAR1-73, Project \#TAMRF-921.

19. Zapas, L. J., and Crissman, J. M., ACS Symposium Series \#195, Durability of Macromolecular Materials (R. K. Eby Ed.) 301 (1978). 


\section{List of Tables}

1. Limiting Viscosity Number of Polyethylenes

2. 'Apparent' Molecular Weights (SEC)

3. Comparison of Methyl Group Content of Polyethylene Films from the Analysis of the Infrared Spectral Region $1328-1400 \mathrm{~cm}^{-1}$

4. Density of Polyethylene Films at $23.0 \pm 0.1^{\circ} \mathrm{C}$

5. Differential Scanning Calorimetry of Films

6. Birefringence of Films

7. Birefringence on Either Side of Boundary between Hazy and Less Hazy Regions

8. Intensity Ratios of $-\mathrm{CH}_{2}$ Rocking Bands

9. Summary of Ultimate Properties for the Category I and II Films at $23^{\circ}$

10. Tensile Properties of Ballon Films at $23^{\circ} \mathrm{C}$.

11. Maximum and Minimum Values of Strain at Break at $23^{\circ} \mathrm{C}$

12. Summary of Yield Stress Data Obtained from Tensile Tests at $23^{\circ} \mathrm{C}$

13: Tensile Properties of Balloon Film at $-70^{\circ} \mathrm{C}$

14. Maximum and Minimum Values of Strain at Break at $-70^{\circ} \mathrm{C}$

15: Summary of Yield Stress Data obtained from Tensile Tests at $-70^{\circ} \mathrm{C}$

16. Summary of Tensile Properties of Balloon Film as a Function of Strain Rate at $-70^{\circ} \mathrm{C}$

17. Summary of Tensile Properties of Category I Film

18: Summary of Tensile Properties of Specimens Cut from both Hazy and less Hazy Category IV Film at $-70^{\circ} \mathrm{C}$. (Transverse Direction Only).

19. Summary of Tensile Properties at $-70^{\circ} \mathrm{C}$ for Specimens Cut From One Hazy Region of Category II Film. (Transverse Direction Only).

20. Ultimate Properties at $23^{\circ} \mathrm{C}$ for Specimens $1.87 \mathrm{~cm}$ wide and a Gage Length of $0.20 \mathrm{~cm}$. (Transverse Direction Only).

21. Summary of Tensile Properties at $23^{\circ} \mathrm{C}$ and $-70^{\circ} \mathrm{C}$ (from Tables 10-15) 
List of Figures

Fig. 1. Normalized Size Exclusion Chromatographs of the Category I and Category II films (Table 2, Series A).

Fig. 2. Normalized Size Exclusion Chromatographs of the Category I and Category III films (Table 2, Series A).

Fig. 3. Normalized Size Exclusion Chromatographs of the Category I and Category IV films (Table 2, Series A).

Fig. 4. Normalized Size Exclusion Chromatographs of the B1 film, and the raw polymer pellets from which it was produced (Table 2, Series B).

Fig. 5. Normalized Size Exclusion Chromatographs of the B1 and Category I films (Table 2, Series B).

Fig. 6. Normalized Size Exclusion Chromatographs of the B1 and Category III film (Table 2, Series B).

Fig. 7. Room temperature Infrared Spectra in the frequency range $1328 \mathrm{~cm}^{-1}-1400 \mathrm{~cm}^{-1}$, obtained from the five categories of film after they had been melted and then cooled to room temperature (see text).

Fig. 8. Difference Spectrum B1 - Category I.

Fig. 9a. DSC heating curve, Category I film.

Fig. 9b. DSC heating curve, Category I film (expanded vertical scale).

Fig. 9c. DSC cooling curve, Category I film.

Fig. 9d. DSC cooling curve, Category I (expanded vertical scale).

Fig. 10a. DSC heating curve, Category II film.

Fig. 10b. DSC heating curve, Category II film (expanded vertical scale).

Fig. 10c. DSC cooling curve, Category II film.

Fig. 10d. DSC cooling curve, Category II film (expanded vertical scale).

Fig. 11a. DSC heating curve, Category III film.

Fig. 11b. DSC heating curve, Category III film (expanded vertical scale).

Fig. 11c. DSC cooling curve, Category III film.

Fig. 11d. DSC cooling curve, Category III film (expanded vertical scale).

Fig. 12a. DSC heating curve, Category IV film. 
Fig. 12b. DSC heating curve, Category IV film (expanded vertical scale).

Fig. 12c. DSC cooling curve, Category IV film.

Fig. 12d. DSC cooling curve, Category IV film (expanded vertical scale).

Fig. 13a. DSC heating curve, B1 film.

Fig. 13b. DSC cooling curve, B1 film.

Fig. 14. Phase Contrast Micrographs of Category I film (非315477).

(a) Actual film, (b) and (c) are replicas of areas on opposite surfaces.

Fig. 15. Phase Contrast Micrographs of Category II film (非313865-53). (a) Actual film, (b) and (c) are replicas of areas on opposite surfaces.

Fig. 16. Phase Contrast Micrographs of Category III film (非12858-177). (a) Actual film, (b) and (c) are replicas of areas on opposite surfaces.

Fig. 17. Phase Contrast Micrographs of Category IV film (非11071). (a) Actual film, (b) and (c) are replicas of areas on opposite surfaces.

Fig. 18. Phase Contrast Micrographs of Category $B 1$ film (非67006). (a) Actual film, (b) and (c) are replicas of areas on opposite surfaces. Particles marked $X$ are discussed in the text.

Fig. 19. Scanning Electro Micrograph of one of the surfaces of Category I (非315420) film.

Fig. 20. Wide angle x-ray diffraction patterns of Category I film (\#315420). (a) x-ray beam parallel to $T$, (b) $x$-ray beam parallel to $\mathrm{M}$, (c) $\mathrm{x}$-ray beam parallel to $\mathrm{N}$.

Fig. 21. Wide angle x-ray diffraction patterns of Category II film -

(非13865, Gore 53). (a) x-ray beam parallel to T, (b) $x$-ray beam parallel to $M$, (c) $\mathrm{x}$-ray beam parallel to $\mathrm{N}$.

Fig. 22. Wide angle x-ray diffraction patterns of Category III film (非12877). (a) x-ray beam parallel to $\mathrm{T}$, (b) x-ray beam parallel to $M,(c) x-r a y$ beam parallel to $N$.

Fig. 23. Wide angle x-ray diffraction patterns of Category IV film (非11071). (a) $\mathrm{x}$-ray beam parallel to $\mathrm{T}$, (b) $\mathrm{x}$-ray beam parallel to $M,(c)$ x-ray beam parallel to $\mathrm{N}$.

Fig. 24. Wide angle x-ray diffraction patterns of B1 film (非67006). (a) $\mathrm{x}$-ray beam parallel to $\mathrm{T}$, (b) $\mathrm{x}$-ray beam parallel to $\mathrm{M}$, (c) $\mathrm{x}$-ray beam parallel to $\mathrm{N}$. 
Fig. 25. Schematic representation of two idealized microcrystal orientations in a film. (a) The microcrystals are oriented with the b-axis parallel to $\mathrm{N}$, and the a-axis (and hence the c-axis also) oriented randomly in the MT plane, (b) the microcrystals are oriented with the a-axis parallel to $M$, and the b-axis (and c-axis) oriented randomly in the NT plane (see text).

Eig. 26. Polarized Infrared Spectra of films in the region $675 \mathrm{~cm}^{-1}-775 \mathrm{~cm}^{-1}$. Dotted lines and full lines correspond to the plane of polarization parallel and perpendicular to $M$ respectively. (a) Category I, (b) Category II, (c) Category III, (d) Category IV, (e) B1.

Fig. 27. Creep strain (\%) versus time for specimens of balloon film at $23^{\circ} \mathrm{C}$ and an applied stress of $2.5 \mathrm{MPa}$ (364 psi). Solid symbols - transverse direction, open symbols - machine direction; squares - Category I, inverted triangles - Category II, circles - Category III, triangles - Category IV.

Fig. 28. Creep strain (\%) versus time for specimens of balloon film at $23^{\circ} \mathrm{C}$ and an applied stress of $10 \mathrm{MPa}$ (1450 psi). Solid symbols - transverse direction, open symbols - machine direction; squares - Category I, inverted triangles - Category II, circles - Category III, triangles - Category IV.

Fig. 29. \% strain at break versus yield stress for 64 specimens of balloon film at $-70^{\circ} \mathrm{C}$. Strain rate $991 \%$ per minute; circles Category I, inverted triangles - Category II, squares - Category III, triangles - Category IV, crosses - Category B1.

Fig. 30. An example of biaxially oriented film under inflation.

Fig. 31. Failure envelope at $23^{\circ} \mathrm{C}$ for linear polyethylene with $M_{n}=$ 15,300 and $\mathrm{M}_{\mathrm{W}}=99,000$. Log percent elongation versus engineering stress for various isochrones obtained from uniaxial creep data. Line $\alpha$ corresponds to necking and $l$ ine $\gamma$ to fracture.

Fig. 32. Failure envelope at $23^{\circ} \mathrm{C}$ for 1 inear polyethylene with $M_{n}=$ 15,000 and $M_{W}=160,000$. Log percent elongation versus engineering stress for various isochrones obtained from uniaxial creep data. Line $\alpha$ corresponds to necking line $\beta$ to the fully necked condition, and $\gamma$ to fracture.

Fig. 33. Failure envelope at $23^{\circ} \mathrm{C}$ for linear polyethylene with $\mathrm{M}_{\mathrm{W}}=$ 15,600 and $M_{W}=192,000$. Symbols have the same meaning as in Fig. 24 . 
Table 1

LIMITING VISCOSITY NUMBER OF POLYETHYLENES

(TRICHLOROBENZENE AT $130 \mathrm{C}$ )

$\begin{array}{lcc}\text { Category } & \text { Roll 非 (Gore) } & \text { Limiting Viscosity Number }(n) d 1 / g \\ \text { I (Set 13) } & 315420 & 1.23 \\ \text { II (Set 15) } & 313865(53) & 1.27 \\ \text { III (W41.47-3) } & 112858(177) & 1.27 \\ \text { IV }(6 / 3 / 82) & 311071 & 1.22 \\ \text { B1 - film } & 367006 \text { Series 03 } & 1.13 \\ \text { B1 - pellets } & & \end{array}$



Table 2

'APPARENT' MOLECULAR WEIGHTS (SEC)

Category

$\frac{\text { Roll \# (Gore) }}{\underline{M w}} \frac{\text { 'Apparent' Molecular Wt.* }}{\underline{M n}}$

I (Set 13)

315420

216000

22300

(Series A)

202000

23100

(Series B)

II (Set 15)

$313865(53)$

243000

23200

(Series A)

III $(W 41.47-3)$

$112858(177)$

253000

29000

(Series A)

255000

30100

(Series B)

IV $(6 / 3 / 82)$

311071

209000

21700

(Series A)

B1 film

367006

154600

22400

(Series B)

B1 pellets

147800

21500

(Series B)

* The 'apparent' Mn and Mw values given in this table were derived from the analysis of the size exclusion chromatograms (Figs. 1-6) using the assumption that the polyethylene chains are linear. Actual Mn and $\mathrm{Mw}$ values are likely to be higher than those listed here due to the effects of branching and because material with molecular weight greater than $-4.5 \times 10^{6}$ is beyond the range of the separation capabilities of the SEC columns used. Both these limitations are discussed in section $B$ (ii) of the report. 

Table 3

COMPARISON OF METHYL GROUP CONTENT OF POLYETHYLENE FILWS FROM THE ANALYSIS OF THE INFRARED SPECTRAL REGION $1328-1400 \mathrm{CM}^{-1}$

\begin{tabular}{|c|c|c|}
\hline Category & Roll (Gore) & $\begin{array}{c}\text { Area } \begin{array}{c}1328-1400 \mathrm{~cm}^{-1} \\
(\mathrm{~A}) \mathrm{cm}^{-1}\end{array} \\
\end{array}$ \\
\hline I (Set 13) & 315420 & 5.376 \\
\hline II (Set 15) & $313865(53)$ & 6.01 \\
\hline $\operatorname{III}(141.47-3)$ & $112858(177)$ & 5.65 \\
\hline IV $(6 / 3 / 82)$ & 311071 & 6.11 \\
\hline$B 1$ (F11K) & 376006 & 6.38 \\
\hline
\end{tabular}

Resolved Methyl Band Peak Intensity at $1378 \mathrm{~cm}^{-1}$

(P)

0.15

$\operatorname{Rat} 10 P / A$

$0.165 \cdot 0.0275$

$0.1554 \quad 0.0275$

0.171

0.0280

0.184

0.0288 

Table 4 DENSITY OF POLYETHYLENE FILMS AT $23.0 \pm 0.1^{\circ} \mathrm{C}$

Weight :

Category

Rol1 \# (Gore)

Density $(g / c c)^{+}$

Crystallinity $(X)$

I (Set 13)

315420

0.9165

0.9170

46.4

46.8

II (Set 15)

$313865(53)$

0.9175

0.9185

47.1

47.8

III $(\$ 41.47-3)$

$112858(177)$

0.9163

46.2

0.9170

46.8

IV $(6 / 3 / 82)$

311071

0.9165

46.4

0.9170

46.8

367006

0.9190

48.2

0.9190

48.2

tError less than $\pm 0.0005 \mathrm{~g} / \mathrm{cc}$. 

Table 5

DIFFERENTIAL SCANING CALORIMETRY OF FILMS

\begin{tabular}{|c|c|c|c|c|c|}
\hline F11m Category & Ro11 Af (Gore) & $\frac{\text { Main Melting }^{*}}{\text { Peak, }{ }^{\circ} \mathrm{C}}$ & $\frac{\text { Main Crystn }}{\text { Peak, }{ }^{\circ} \mathrm{C}}$ & $\frac{\text { Low Temp. }}{\text { Pelting Peak, }{ }^{\circ} \mathrm{C}}$ & $\begin{array}{c}* * \\
\text { Low Temp. } \\
\text { Crysta Peak, }{ }^{\circ} \mathrm{C}\end{array}$ \\
\hline$I($ Set 13) & 315420 & 106.8 & 94.4 & 54.4 & 58.3 \\
\hline II (Set 15) & $3113865(53)$ & 107.1 & 94.1 & 51.6 & 58.4 \\
\hline III (W41.47-3) & $122858(177)$ & 106.2 & 93.0 & 51.8 & 57.2 \\
\hline IV $(6 / 3 / 82)$ & 311071 & 106.6 & 93.3 & 51.5 & 56.7 \\
\hline B1 & 367006 & 105.5 & 91.1 & 47.8 & 53.6 \\
\hline
\end{tabular}

* Heatins cycle: Rate of heating $20^{\circ} \mathrm{C} / \mathrm{min}$.

* Cooling Cycle: Rate of cooling $-20^{\circ} \mathrm{C} / \mathrm{min}$. 



\section{Table 6}

BIREERINGENCE OF FILMS $\triangle \mathrm{n}$

(Film Thickness)

I $(0.7 \mathrm{mil})$

II $(0.8 \mathrm{mil})$

IV $(6 / 3 / 82)(0.8 \mathrm{mil})$

$\mathrm{Bl}(0.8 \mathrm{mil})$

$\operatorname{III}(0.8 \mathrm{mil})$

III $(0.8 \mathrm{mil})$
Rol1 \# (Gore)

315420

$313865(53)$

311071

367006

$112858(177)$

112877

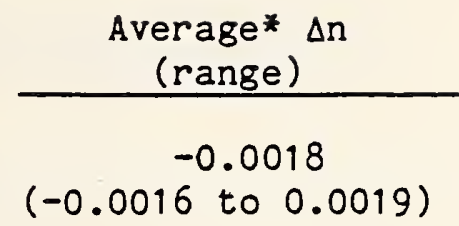

$-0.0015$

$(-0.0013$ to -0.0018$)$

-0.0013
$(-0.0012$ to -0.0015$)$

$-0.0017$

$(-0.0015$ to -0.0019$)$

$n(M)>(T)$

See text

$-0.0011$

$(-0.0009$ to -0.0012$)$

* Average of nine measurements

$\Delta \mathrm{n}=\mathrm{n}(\mathrm{M})-\mathrm{n}(\mathrm{T})=\mathrm{Y} / \mathrm{t}$ is the birefringence in the MT plane.

$\gamma=$ retardation

$t=$ nominal thickness of film (I, $0.7 \mathrm{mil}=17780 \mathrm{~nm}$; II, III, IV, $\mathrm{B1}, 0.8 \mathrm{mil}=20320 \mathrm{~nm})$

Precision in measuring $\gamma= \pm 1 \mathrm{~nm}$ which for films $0.7-0.8 \mathrm{mil}$ thick corresponds to a difference in birefringence of less than \pm 0.0001 . 

Table 7

BIREFRINGENCE $\triangle \mathrm{n}$ ON EITHER SIDE OF BOUNDARY

BETWEEN HAZY AND LESS HAZY REGIONS

Cat I

非315420

$\Delta \mathrm{n}$

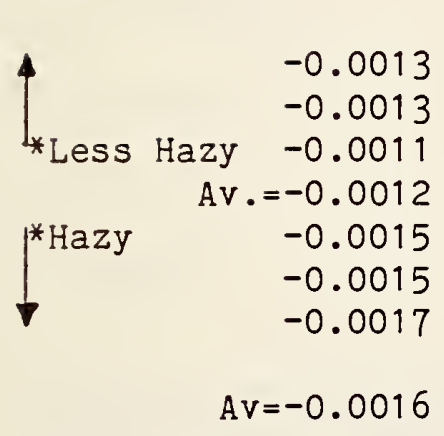

Cat II

非313865（53）

$\Delta \mathrm{n}\left(\theta^{\circ}\right)$

$-0.0018\left(19.5^{\circ}\right)$

$-0.0012\left(19.4^{\circ}\right)$

$-0.0016\left(19.1^{\circ}\right)$

$-0.0015\left(18^{\circ}\right)$

$\mathrm{AV}=-0.0015$

$-0.0013\left(20^{\circ}\right)$

$-0.0013\left(17.2^{\circ}\right)$

$-0.0009\left(16.5^{\circ}\right)$

$-0.0010\left(15.5^{\circ}\right)$

$\mathrm{Av}=-0.0011$
Cat IV

非311071

$\Delta \mathrm{n}$

$$
\begin{array}{r}
-0.0015 \\
-0.0013 \\
-0.0014 \\
-0.0015 \\
A v=-0.0014 \\
-0.0011 \\
-0.0013 \\
-0.0013 \\
-0.0013 \\
A v=-0.0013
\end{array}
$$

* The boundary between the less hazy and the hazy regions runs closely parallel to the machine direction. The birefringence measurements in the two regions were made at $3 \mathrm{~mm}$ increments away from the boundary.

* In the case of Category II, extinction between crossed polarizer and analyzer in the hazy and less hazy regions occurred when the machine direction deviated from the plane of polarization of the polarizer by an angle $\theta\left(15.5^{\circ}=20^{\circ}\right)$ appreciably larger than uncertainties associated in identifying the machine direction exactly. The birefringence in this column represents the difference in refractive index for light polarized parallel and perpendicular to the extinction direction. 

Table 8

INTENSITY RATIOS OF $-\mathrm{CH}_{2}$ ROCKING BANDS

*

* Parallel/Perpendicular

Category $733 \mathrm{~cm}^{-1}$

Perpendicular/Parallel $719 \mathrm{~cm}^{-1}$

I 非315420

1.37

1.38

II 非313865(53)

1.49

1.51

III 非112858(177)

1.17

1.24

IV 非311071

1.60

1.72

B1 非367006

1.26

1.25

* Parallel and perpendicular refer to polarization parallel and perpendicular to the machine direction $M$ or to the extinction direction closest to $\mathrm{M}$. 

Table 9

SUMMARY OF ULTIMATE PROPERTIES FOR THE CATEGORY I AND II FILMS AT $23^{\circ} \mathrm{C}$

\begin{tabular}{|c|c|c|c|c|c|}
\hline Category & $\begin{array}{c}\text { Stretching } \\
\text { Direction(a) }\end{array}$ & 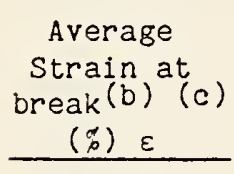 & $\begin{array}{l}\text { Standard } \\
\text { Deviation } \\
(\%) \\
\end{array}$ & $\begin{array}{c}\text { Tensile Stress } \\
\text { at Break } \\
(\mathrm{MPa}) \\
\end{array}$ & $\begin{array}{l}\text { Standard } \\
\text { Deviation } \\
\text { (MPa) } \\
\end{array}$ \\
\hline$I(d)$ & M & 286 & 31 & $19.2(2800 \mathrm{PSI})$ & 1.0 \\
\hline$I(d)$ & $\mathrm{T}$ & 339 & 28 & $21.5(3120$ PSI $)$ & 1.9 \\
\hline II (e) & M & 250 & 17 & $18.0(2610$ PSI $)$ & 1.8 \\
\hline$I I(e)$ & $\mathrm{T}$ & 410 & 35 & $18.9(2740$ PSI $)$ & 1.2 \\
\hline
\end{tabular}

(a) M - Machine Direction, $T$ - Transverse Direction

(b) $\varepsilon=100\left(l-l_{0}\right) / l_{0}$

(c) average for six specimens

(d) Category I (Set 13), Roll \#315420

(e) Category II (Set 15), Roll $\$ 313865$ (Gore 53) 

Table 10

TENSILE PROPERTIES OF BALLOON FILM AT $23^{\circ} \mathrm{C}$

\begin{tabular}{|c|c|c|c|c|c|c|c|}
\hline Category & $\begin{array}{l}\text { Roll } \\
\text { Number } \\
\end{array}$ & $\begin{array}{l}\text { Gore } \\
\text { Number } \\
\end{array}$ & $\begin{array}{l}\text { Cutting } \\
\text { Direction (a) }\end{array}$ & $\begin{array}{l}\text { Average } \\
\text { Strain at } \\
\text { Break }(b, c) \\
(\not) \varepsilon \\
\end{array}$ & $\begin{array}{l}\text { Standard } \\
\text { Deviation } \\
\left(\begin{array}{l}0 \\
0\end{array}\right. \\
\end{array}$ & $\begin{array}{l}\text { Average } \\
\text { Stress } \\
\text { at Break } \\
(\mathrm{MPa})(\mathrm{d}) \\
\end{array}$ & $\begin{array}{l}\text { Standard } \\
\text { Deviation } \\
\text { (MPa) } \\
\end{array}$ \\
\hline I & 315477 & - & M & 462 & 33 & 25.4 & 1.3 \\
\hline I & 315477 & - & $T$ & 454 & 19 & 29.0 & 1.6 \\
\hline II & 313865 & 53 & M & 482 & 39 & 22.5 & 0.7 \\
\hline II & 313865 & 53 & $T$ & 559 & 27 & 25.6 & 1.4 \\
\hline III & 111958 & 121 & M & 445 & 50 & 26.7 & 1.4 \\
\hline II I & 111958 & 121 & $T$ & 624 & 27 & 26.5 & 1.3 \\
\hline IV & 311071 & - & M & 483 & 88 & 22.2 & 3.0 \\
\hline IV & 311071 & - & $T$ & 577 & 75 & 23.5 & 2.4 \\
\hline B1 & 367006 & - & M & 491 & 40 & 27.7 & 1.8 \\
\hline B1 & 3167006 & - & $T$ & 470 & 33 & 34.0 & 2.8 \\
\hline
\end{tabular}

Strain Rate $991 \% / \mathrm{min}$.

(a) M - machine direction, $T$ - transverse direction.

(b) Averages are for 6 specimens, gage length $=0.60 \mathrm{~cm}$, width $=0.315 \mathrm{~cm}$.

(c) $\varepsilon=100\left(l-l_{0}\right) / l_{0}$.

(d) $1 \mathrm{MPa}=145.03 \mathrm{psi}$. 

Table 11

MAXIMUM AND MINIMUM VALUES OF STRAIN AT BREAK AT $23^{\circ} \mathrm{C}$

\begin{tabular}{|c|c|c|c|c|c|}
\hline Category & $\begin{array}{l}\text { Roll } \\
\text { Number } \\
\end{array}$ & $\begin{array}{l}\text { Gore } \\
\text { Number } \\
\end{array}$ & $\begin{array}{l}\text { Cutting } \\
\text { Direction }\end{array}$ & $\begin{array}{c}\varepsilon(\operatorname{Max}) \\
(\%) \\
\end{array}$ & $\begin{array}{c}\varepsilon(\operatorname{Min}) \\
\left(\begin{array}{l}\infty \\
p\end{array}\right)\end{array}$ \\
\hline I & 315477 & - & $M$ & 498 & 408 \\
\hline I & 315477 & - & $\mathrm{T}$ & 477 & 428 \\
\hline II & 313865 & 53 & $M$ & 516 & 418 \\
\hline II & 313865 & 53 & $\mathrm{~T}$ & 593 & 521 \\
\hline III & 111958 & 121 & $M$ & 500 & 371 \\
\hline III & 111958 & 121 & $\mathrm{~T}$ & 655 & 588 \\
\hline IV & 311071 & - & $M$ & 568 & 325 \\
\hline IV & 311071 & - & $\mathrm{T}$ & 671 & 495 \\
\hline B1 & 367006 & - & $M$ & 565 & 457 \\
\hline B1 & 367006 & - & $\mathrm{T}$ & 508 & 415 \\
\hline
\end{tabular}



Table 12

SUMMARY OF YIELD STRESS DATA OBTAINED FROM TENSILE TESTS AT $23^{\circ} \mathrm{C}$

\begin{tabular}{|c|c|c|c|c|c|}
\hline $\begin{array}{l}\text { Film } \\
\text { Category } \\
\end{array}$ & $\begin{array}{l}\text { Cutting } \\
\text { Direction }\end{array}$ & $\begin{array}{l}\text { Average } \\
\text { Yield (a) } \\
\text { Stress } \\
\text { (MPa) } \\
\end{array}$ & $\begin{array}{c}\text { Standard } \\
\text { Deviation } \\
\text { (MPa) }\end{array}$ & $\begin{array}{l}\text { Maximum } \\
\text { Yield } \\
\text { Stress } \\
\text { (MPa) } \\
\end{array}$ & $\begin{array}{l}\text { Minimum } \\
\text { Yield } \\
\text { Stress } \\
\text { (MPa) } \\
\end{array}$ \\
\hline $\begin{array}{l}I \\
I\end{array}$ & $\begin{array}{l}M(b) \\
T(b)\end{array}$ & $\begin{array}{l}11.5 \\
10.7\end{array}$ & $\begin{array}{l}0.3 \\
0.5\end{array}$ & $\begin{array}{l}12.0 \\
11.3\end{array}$ & $\begin{array}{l}11.2 \\
10.2\end{array}$ \\
\hline $\begin{array}{l}\text { II } \\
\text { II }\end{array}$ & $\begin{array}{l}M \\
T\end{array}$ & $\begin{array}{l}10.8 \\
10.4\end{array}$ & $\begin{array}{l}0.3 \\
0.1\end{array}$ & $\begin{array}{l}11.1 \\
10.5\end{array}$ & $\begin{array}{l}10.6 \\
10.4\end{array}$ \\
\hline $\begin{array}{l}\text { III } \\
\text { III }\end{array}$ & $\begin{array}{l}M \\
T\end{array}$ & $\begin{array}{l}11.3 \\
10.3\end{array}$ & $\begin{array}{l}0.4 \\
0.4\end{array}$ & $\begin{array}{l}11.9 \\
11.1\end{array}$ & $\begin{array}{l}11.1 \\
10.0\end{array}$ \\
\hline $\begin{array}{l}\text { IV } \\
\text { IV }\end{array}$ & $\begin{array}{l}M \\
T\end{array}$ & $\begin{array}{l}10.7 \\
10.7\end{array}$ & $\begin{array}{l}0.3 \\
0.6\end{array}$ & $\begin{array}{l}11.1 \\
11.1\end{array}$ & $\begin{array}{l}10.3 \\
10.0\end{array}$ \\
\hline $\begin{array}{l}\text { B1 } \\
\text { B1 }\end{array}$ & $\begin{array}{l}M \\
T\end{array}$ & $\begin{array}{l}10.6 \\
10.7\end{array}$ & $\begin{array}{l}0.4 \\
0.2\end{array}$ & $\begin{array}{l}11.1 \\
11.1\end{array}$ & $\begin{array}{l}10.1 \\
10.6\end{array}$ \\
\hline
\end{tabular}

(a) Averages are for six specimens.

(b) M-machine direction, T-transverse direction. 

Table 13

TENSILE PROPERTIES OF BALLOON FILM AT $-70^{\circ} \mathrm{C}$

\begin{tabular}{|c|c|c|c|c|c|c|c|}
\hline Category & $\begin{array}{l}\text { Roll } \\
\text { Number }\end{array}$ & $\begin{array}{l}\text { Gore } \\
\text { Number }\end{array}$ & $\begin{array}{l}\text { Cutting } \\
\text { Direction (a) }\end{array}$ & $\begin{array}{l}\text { Average } \\
\text { Strain at } \\
\text { Break (b) } \\
(\not) \varepsilon \\
\end{array}$ & $\begin{array}{l}\text { Standard } \\
\text { Deviation } \\
(\%)\end{array}$ & $\begin{array}{l}\text { Average } \\
\text { Stress } \\
\text { at Break } \\
(\mathrm{MPa})(\mathrm{C}) \\
\end{array}$ & $\begin{array}{l}\text { Standard } \\
\text { Deviation } \\
\text { (MPa) }\end{array}$ \\
\hline I & 315477 & - & M & 319 (d) & 59 & 60.0 & 3.4 \\
\hline I & 315477 & - & $T$ & 259 (e) & 75 & 56.0 & 5.3 \\
\hline II & 313865 & 53 & M & 295 (e) & 144 & 48.4 & 3.4 \\
\hline II & 313865 & 53 & $\mathrm{~T}$ & 345 (e) & 143 & 48.7 & 6.4 \\
\hline III & 112861 & 173 & M & 327 (d) & 44 & 54.5 & 4.2 \\
\hline III & 112861 & 173 & $T$ & $434(e)$ & 135 & 54.7 & 3.4 \\
\hline IV & 311071 & - & M & 350 (d) & 117 & 47.4 & 5.1 \\
\hline IV & 311071 & - & $T$ & 428 (e) & 29 & 53.9 & 2.1 \\
\hline B1 & 367006 & - & M & 263 (d) & 107 & 52.0 & 3.6 \\
\hline B1 & 367006 & - & $\mathrm{T}$ & 382 (d) & 67 & 64.0 & 5.0 \\
\hline
\end{tabular}

Strain rate $991 \% / \mathrm{min}$.
(a) $M$ - machine direction, $T$ - transverse direction.
(b) $\varepsilon=100\left(l-l_{0}\right) / 2_{0}$, gage length $=0.60 \mathrm{~cm}$, width $=0.315 \mathrm{~cm}$.
(c) $1 \mathrm{MPa}-145.03 \mathrm{psi}$.
(d) Average for 6 specimens.
(e) Average for 8 specimens. 

Table 14

MAXIMUM AND MINIMUM VALUES OF STRAIN AT BREAK AT $-70{ }^{\circ} \mathrm{C}$

\begin{tabular}{|c|c|c|c|c|c|}
\hline Category & $\begin{array}{l}\text { Roll } \\
\text { Number }\end{array}$ & $\begin{array}{l}\text { Gore } \\
\text { Number }\end{array}$ & $\begin{array}{l}\text { Cutting } \\
\text { Direction }\end{array}$ & $\begin{array}{l}\text { Strain at } \\
\text { Break (max) } \\
\left(\begin{array}{c}q \\
p\end{array}\right) \varepsilon\end{array}$ & 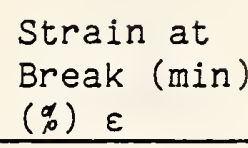 \\
\hline I & 315477 & - & M & 413 & 248 \\
\hline I & 315477 & - & $T$ & 377 & 110 \\
\hline II & 313865 & 53 & $M$ & 449 & 46 \\
\hline II & 313865 & 53 & $T$ & 462 & 72 \\
\hline III & 112861 & 173 & M & 369 & 255 \\
\hline III & 112861 & 173 & $T$ & 609 & 258 \\
\hline IV & 311071 & - & $M$ & 488 & 165 \\
\hline IV & 311071 & - & $T$ & 480 & 217 \\
\hline B1 & 367006 & - & $M$ & 426 & 114 \\
\hline B1 & 367006 & - & $T$ & 470 & 304 \\
\hline
\end{tabular}



Table 15

SUMMARY OF YIELD STRESS DATA OBTAINED FROM TENSILE TESTS AT $-70{ }^{\circ} \mathrm{C}$

\begin{tabular}{|c|c|c|c|c|c|}
\hline $\begin{array}{l}\text { Film } \\
\text { Category }\end{array}$ & $\begin{array}{l}\text { Cutting } \\
\text { Direction }\end{array}$ & $\begin{array}{l}\text { Average } \\
\text { Yield } \\
\text { Stress (a) } \\
\text { (MPa) } \\
\end{array}$ & $\begin{array}{c}\text { Standard } \\
\text { Deviation } \\
\text { (MPa) } \\
\end{array}$ & $\begin{array}{l}\text { Maximum } \\
\text { Yield } \\
\text { Stress } \\
\text { (MPa) } \\
\end{array}$ & $\begin{array}{l}\text { Minimum } \\
\text { Yield } \\
\text { Stress } \\
\text { (MPa) } \\
\end{array}$ \\
\hline $\begin{array}{l}I \\
I\end{array}$ & $\begin{array}{l}M(b) \\
T^{(b)}\end{array}$ & $\begin{array}{l}57.8 \\
51.8\end{array}$ & $\begin{array}{l}4.0 \\
2.4\end{array}$ & $\begin{array}{l}61.3 \\
54.9\end{array}$ & $\begin{array}{l}51.8 \\
49.5\end{array}$ \\
\hline $\begin{array}{l}\text { II } \\
\text { II }\end{array}$ & $\begin{array}{l}M \\
T\end{array}$ & $\begin{array}{l}42.9 \\
42.2\end{array}$ & $\begin{array}{l}3.0 \\
3.4\end{array}$ & $\begin{array}{l}48.9 \\
48.3\end{array}$ & $\begin{array}{l}39.4 \\
38.4\end{array}$ \\
\hline $\begin{array}{l}\text { III } \\
\text { III }\end{array}$ & $\begin{array}{l}\mathrm{M} \\
\mathrm{T}\end{array}$ & $\begin{array}{l}46.4 \\
45.7\end{array}$ & $\begin{array}{l}2.5 \\
4.7\end{array}$ & $\begin{array}{l}49.5 \\
54.6\end{array}$ & $\begin{array}{l}42.2 \\
38.7\end{array}$ \\
\hline $\begin{array}{l}\text { IV } \\
\text { IV }\end{array}$ & $\begin{array}{l}\mathrm{M} \\
\mathrm{T}\end{array}$ & $\begin{array}{l}42.9 \\
47: 3\end{array}$ & $\begin{array}{l}2.9 \\
4.2\end{array}$ & $\begin{array}{l}46.4 \\
50.5\end{array}$ & $\begin{array}{l}37.8 \\
39.1\end{array}$ \\
\hline $\begin{array}{l}\text { B1 } \\
\text { B1 }\end{array}$ & $\begin{array}{l}M \\
T\end{array}$ & $\begin{array}{l}45.4 \\
47.9\end{array}$ & $\begin{array}{l}3.6 \\
3.6\end{array}$ & $\begin{array}{l}49.5 \\
51.8\end{array}$ & $\begin{array}{l}40.3 \\
42.9\end{array}$ \\
\hline
\end{tabular}

(a) Averages are for six or more specimens.

(b) M-machine direction, T-transverse direction. 

Table 16

SUMMARY OF TENSILE PROPERTIES OF BALLOON FILM AS A FUNCTION OF STRAIN RATE AT $-70^{\circ} \mathrm{C}$

\begin{tabular}{|c|c|c|c|c|}
\hline $\begin{array}{l}\text { Film Category } \\
\text { Roll 非 (Gore) }\end{array}$ & $\begin{array}{l}\text { Rate of } \\
\text { Strain } \\
(\phi / m i n .)\end{array}$ & $\begin{array}{l}\text { Cutting } \\
\text { Direction }\end{array}$ & $\begin{array}{l}\text { Average } \\
\text { Strain } \\
\text { at Break } \\
(\%) \varepsilon \\
\end{array}$ & $\begin{array}{l}\text { Average } \\
\text { Stress } \\
\text { at Break } \\
\text { (MPa) }\end{array}$ \\
\hline$I, 3154177$ & $\begin{array}{r}9910 \\
9910 \\
991 \\
991 \\
99.1 \\
99.1\end{array}$ & $\begin{array}{l}\mathrm{M} \\
\mathrm{T} \\
\mathrm{M} \\
\mathrm{T} \\
\mathrm{M} \\
\mathrm{T}\end{array}$ & $\begin{array}{l}372 \\
260 \\
319 \\
259 \\
301 \\
296\end{array}$ & $\begin{array}{l}41.4 \\
44.3 \\
60.0 \\
56.0 \\
39.9 \\
48.1\end{array}$ \\
\hline II, 313915 (22) & $\begin{array}{r}9910 \\
9910 \\
991 \\
991 \\
99.1 \\
99.1\end{array}$ & $\begin{array}{l}\mathrm{M} \\
\mathrm{T} \\
\mathrm{M} \\
\mathrm{T} \\
\mathrm{M} \\
\mathrm{T}\end{array}$ & $\begin{array}{l}358 \\
490 \\
295 \\
346 \\
297 \\
332\end{array}$ & $\begin{array}{l}42.3 \\
58.4 \\
48.4 \\
48.7 \\
48.5 \\
42.3\end{array}$ \\
\hline B1,367006 & $\begin{array}{r}9910 \\
9910 \\
991 \\
991 \\
99.1 \\
99.1\end{array}$ & $\begin{array}{l}\mathrm{M} \\
\mathrm{T} \\
\mathrm{M} \\
\mathrm{T} \\
\mathrm{M} \\
\mathrm{T}\end{array}$ & $\begin{array}{l}363 \\
328 \\
263 \\
382 \\
303 \\
263\end{array}$ & $\begin{array}{l}52.9 \\
55.3 \\
52.0 \\
64.0 \\
54.6 \\
56.5\end{array}$ \\
\hline
\end{tabular}

Averages are for three specimens with the exception of the specimens tested at a strain rate of $991 \% / m i n$ for which the averages are for six specimens. 



\section{Table 17 \\ SUMMARY OF TENSILE PROPERTIES \\ OF CAT. I., FILM}

\begin{tabular}{|c|c|c|c|c|c|}
\hline $\begin{array}{c}\text { Rol1 } \\
\text { Number } \\
\text { Area } \\
\end{array}$ & $\begin{array}{l}\text { Temperature } \\
\left({ }^{\circ} \mathrm{C}\right) \\
\end{array}$ & $\begin{array}{c}\text { Cutting } \\
\text { Direction } \\
\end{array}$ & $\begin{array}{l}\text { Average (a) } \\
\text { Strain } \\
\text { at } \\
\text { Break }(\%) \varepsilon\end{array}$ & $\begin{array}{c}\text { Average } \\
\text { Stress } \\
\text { at } \\
\text { Break } \\
\text { (MPa) } \\
\end{array}$ & $\begin{array}{c}\text { Averages } \\
\text { Yield } \\
\text { Stress }(a) \\
\text { (MPa) } \\
\end{array}$ \\
\hline $\begin{array}{l}315477 \\
315477\end{array}$ & $\begin{array}{l}23 \\
23\end{array}$ & $\begin{array}{l}M \\
T\end{array}$ & $\begin{array}{l}462 \\
454\end{array}$ & $\begin{array}{l}25.4 \\
29.0\end{array}$ & $\begin{array}{l}11.5 \\
10.7\end{array}$ \\
\hline $\begin{array}{l}315421(107) \\
315421(107)\end{array}$ & $\begin{array}{l}23 \\
23\end{array}$ & $\begin{array}{l}\mathrm{M} \\
\mathrm{T}\end{array}$ & $\begin{array}{l}498 \\
546\end{array}$ & $\begin{array}{l}21.0 \\
23.1\end{array}$ & $\begin{array}{l}9.3 \\
8.9\end{array}$ \\
\hline $\begin{array}{l}315421(111) \\
315421(111)\end{array}$ & $\begin{array}{l}23 \\
23\end{array}$ & $\begin{array}{l}M \\
T\end{array}$ & $\begin{array}{l}631 \\
568\end{array}$ & $\begin{array}{l}26 \cdot 5 \\
27 \cdot 5\end{array}$ & $\begin{array}{l}10.4 \\
10.6\end{array}$ \\
\hline $\begin{array}{l}315477 \\
315477\end{array}$ & $\begin{array}{l}-70 \\
-70\end{array}$ & $\begin{array}{l}M \\
T\end{array}$ & $\begin{array}{l}319 \\
259\end{array}$ & $\begin{array}{l}60.0 \\
56.0\end{array}$ & $\begin{array}{l}57.8 \\
51.8\end{array}$ \\
\hline $\begin{array}{l}315421(107) \\
315421(107)\end{array}$ & $\begin{array}{l}-70 \\
-70\end{array}$ & $\begin{array}{l}M \\
T\end{array}$ & $\begin{array}{l}341 \\
375\end{array}$ & $\begin{array}{l}48.5 \\
51.5\end{array}$ & $\begin{array}{l}35.0 \\
42.1\end{array}$ \\
\hline $\begin{array}{l}315421(111) \\
315421(111)\end{array}$ & $\begin{array}{l}-70 \\
-70\end{array}$ & $\begin{array}{l}M \\
T\end{array}$ & $\begin{array}{l}446 \\
453\end{array}$ & $\begin{array}{l}65.1 \\
66.6\end{array}$ & $\begin{array}{l}50.8 \\
48.9\end{array}$ \\
\hline
\end{tabular}

(a) Averages are for 3 specimens except for Roll 315477 from which 6 specimens were tested. Strain Rate $=991 \%$ per minute. 

Table 18

SUMMARY OF TENSILE PROPERTIES OF SPECIMENS CUT FROM BOTH HAZY AND LESS HAZY CATEGORY IV FILM*

TRANSVERSE DIRECTION ONLY

$-70^{\circ} \mathrm{C}$

\begin{tabular}{|c|c|c|c|}
\hline $\begin{array}{l}\text { Specimen } \\
\text { Number }(a)\end{array}$ & $\begin{array}{l}\text { Strain } \\
\quad \text { at } \\
\text { Break } \\
(\%) \varepsilon \\
\end{array}$ & $\begin{array}{c}\text { Stress at } \\
\text { Break } \\
(\mathrm{MPa}) \\
\end{array}$ & $\begin{array}{l}\text { Yield } \\
\text { Stress } \\
\text { (MPa) }\end{array}$ \\
\hline MH1 & 8 & 54.4 & 54.4 \\
\hline MH2 & 99 & 46.5 & 49.4 \\
\hline MH3 & 74 & 44.5 & 52.4 \\
\hline MH 4 & 495 & 53.4 & 46.4 \\
\hline MH5 & 37 & 34.6 & 39.5 \\
\hline MH6 & 74 & 36.6 & 35.6 \\
\hline MH7 & 392 & 43.5 & 42.5 \\
\hline MH8 & 445 & 41.5 & 39.5 \\
\hline MH9 & 549 & 47.4 & 35.6 \\
\hline MH1O & 487 & 46.5 & 43.5 \\
\hline MH11 & 437 & 44.5 & 40.5 \\
\hline MH12 & 388 & 42.5 & 41.5 \\
\hline MH13 & 598 & 57.3 & 42.5 \\
\hline
\end{tabular}

$\begin{array}{llll}\text { LH1 } & 417 & 53.4 & 52.4 \\ \text { LH2 } & 524 & 51.9 & 51.9 \\ \text { LH3 } & 412 & 55.4 & 55.4 \\ \text { LH4 } & 565 & 48.4 & 39.5 \\ \text { LH5 } & 594 & 49.4 & 36.6 \\ \text { LH6 } & 281 & 43.5 & 32.6\end{array}$

$\begin{array}{lll} & \underline{\text { Hazy }} & \text { Clear } \\ \text { Average Strain at Break (\%) } & 314 & 466 \\ \text { Average Stress at Break (MPa) } & 45.6 & 50.3 \\ \text { Average Yield Stress (MPa) } & 43.3 & 44.7\end{array}$

(a) $\mathrm{MH}=$ More Hazy, LH = Less Hazy

*Rol1 311071 

Table 19

SUMMARY OF TENSILE PROPERTIES FOR SPECIMENS CUT FROM ONE HAZY REGION OF THE CATEGORY II EILM*

TRANSVERSE DIRECTION ONLY

$$
-70^{\circ} \mathrm{C}
$$

\begin{tabular}{|c|c|c|c|}
\hline $\begin{array}{l}\text { Specimen } \\
\text { Number }\end{array}$ & $\begin{array}{c}\text { Strain } \\
\quad \text { at } \\
\text { Break } \\
(\%) \varepsilon \\
\end{array}$ & $\begin{array}{c}\text { Stress at } \\
\text { Break } \\
(\mathrm{MPa}) \\
\end{array}$ & $\begin{array}{l}\text { Yield } \\
\text { Stress } \\
\text { (MPa) } \\
\end{array}$ \\
\hline 1 & 280 & 31.6 & 29.6 \\
\hline 2 & 66 & 31.6 & 27.7 \\
\hline 3 & 540 & 41.5 & 29.7 \\
\hline 4 & 561 & 40.5 & 24.7 \\
\hline 5 & 487 & 39.5 & 27.7 \\
\hline 6 & 507 & 42.5 & 30.6 \\
\hline 7 & 429 & 31.6 & 27.2 \\
\hline 8 & 248 & 30.6 & 27.7 \\
\hline
\end{tabular}

Average strain at break $=390 \%$

Average stress at break $=36.2 \mathrm{MPa}$

Average yield stress $\quad=28.0 \mathrm{MPa}$

*Rol1 313865 , Gore 53 

Table 20

ULTIMATE PROPERTIES AT $23^{\circ} \mathrm{C}$ FOR SPECIMENS 1.87 CM WIDE AND A GAGE LENGTH OF $0.20 \mathrm{CM}$ TRANSVERSE DIRECTION ONLY

\begin{tabular}{|c|c|c|c|c|}
\hline $\begin{array}{l}\text { Film Category } \\
\text { \& } \\
\text { Roll Number } \\
\end{array}$ & $\begin{array}{l}\text { Average* } \\
\text { Strain at } \\
\text { Break (\%) }\end{array}$ & $\begin{array}{c}\text { Standard } \\
\text { Deviation } \\
\% \\
\end{array}$ & $\begin{array}{l}\text { Average } \\
\text { Stress } \\
\text { at Break } \\
\text { (MPa) } \\
\end{array}$ & $\begin{array}{c}\text { Standard } \\
\text { Deviation } \\
\quad(\mathrm{MPa}) \\
\end{array}$ \\
\hline$I-135477$ & 595 & 96 & 21.0 & 1.34 \\
\hline $\begin{array}{l}\text { II - } 313865 \\
\text { gore } 53\end{array}$ & 717 & 94 & 17.5 & 1.08 \\
\hline III - 112861 & 736 & 213 & 17.9 & 1.65 \\
\hline $\begin{array}{c}I-315421 \\
\text { area } 106\end{array}$ & 640 & & 19.9 & \\
\hline
\end{tabular}

*averages for six specimens 



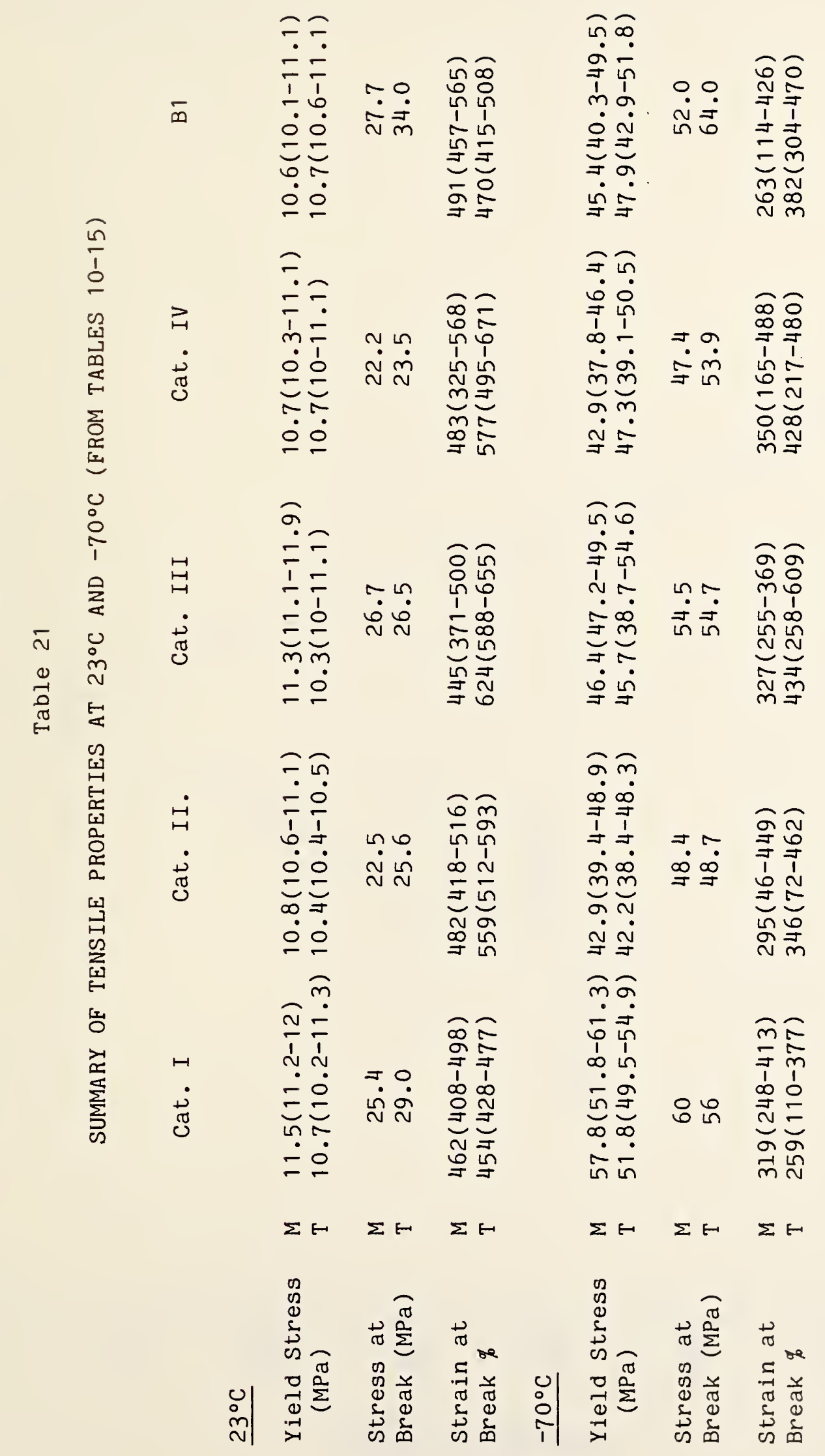





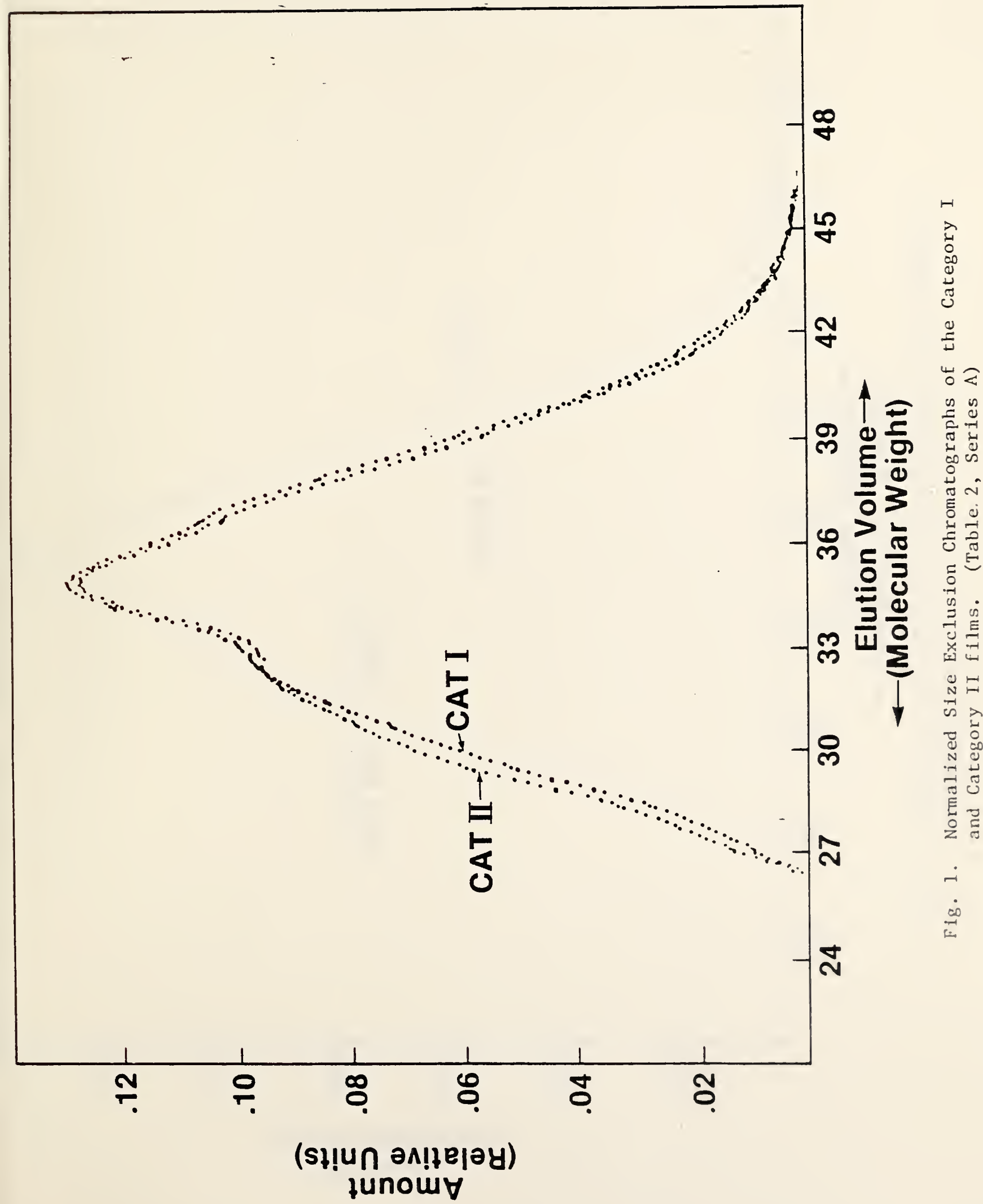





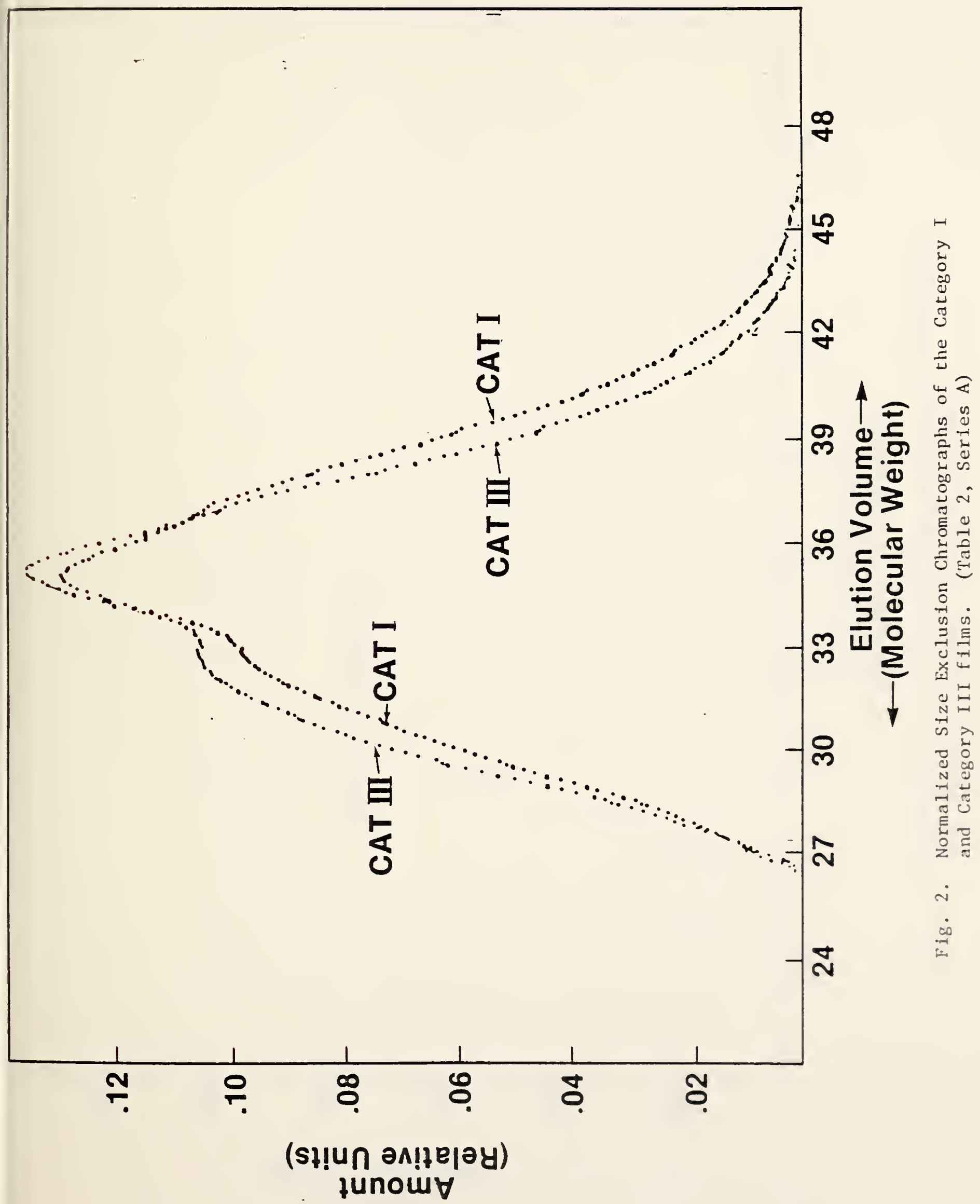





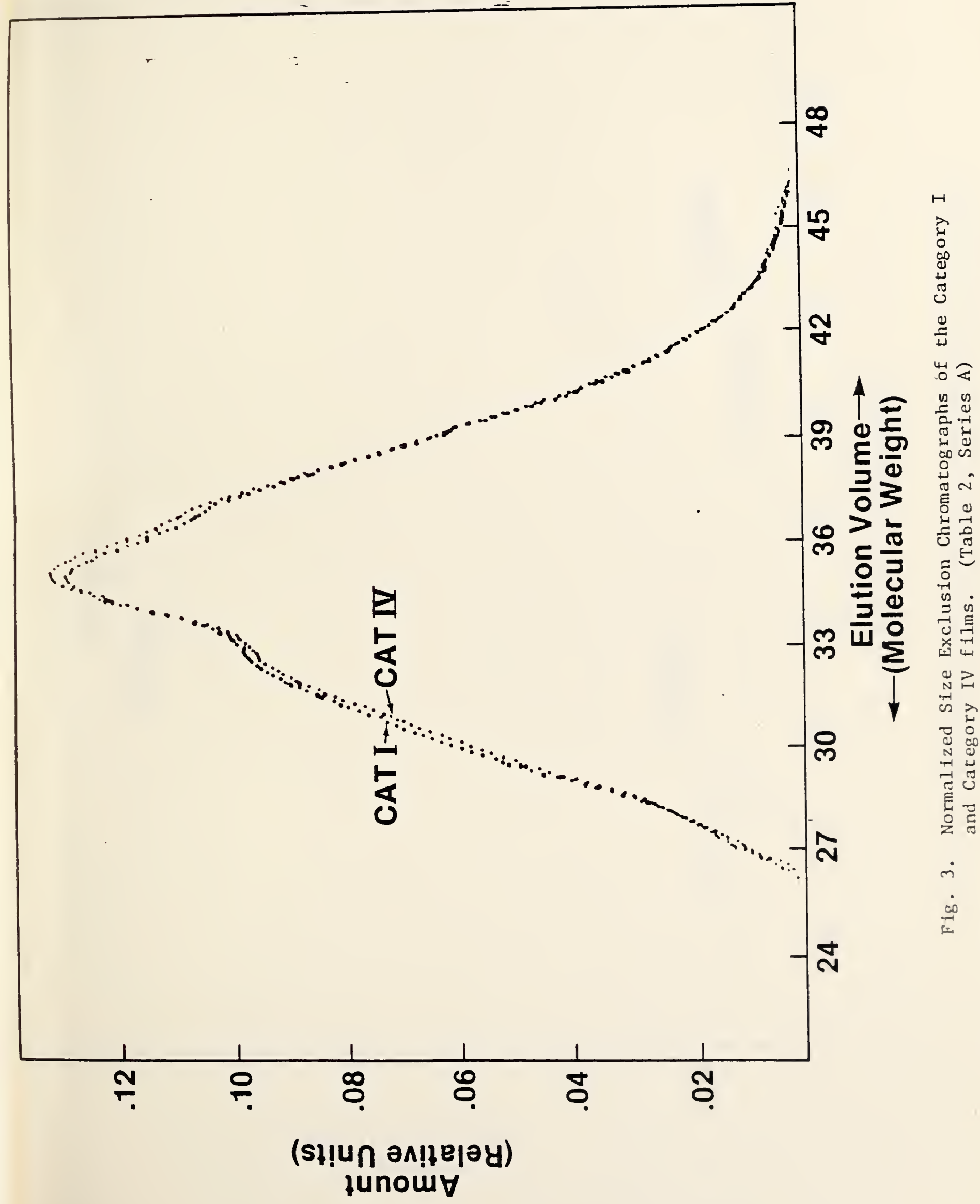







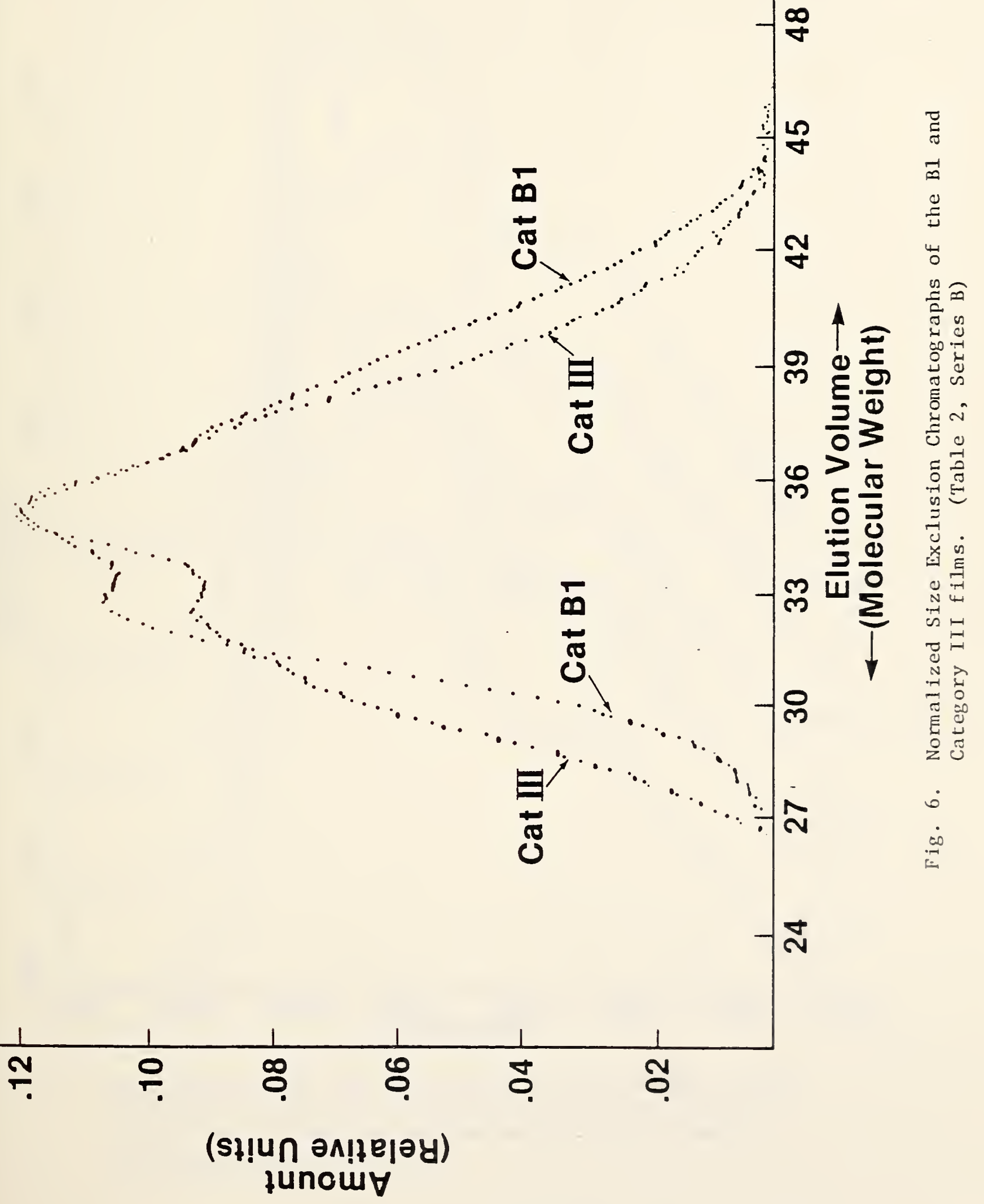






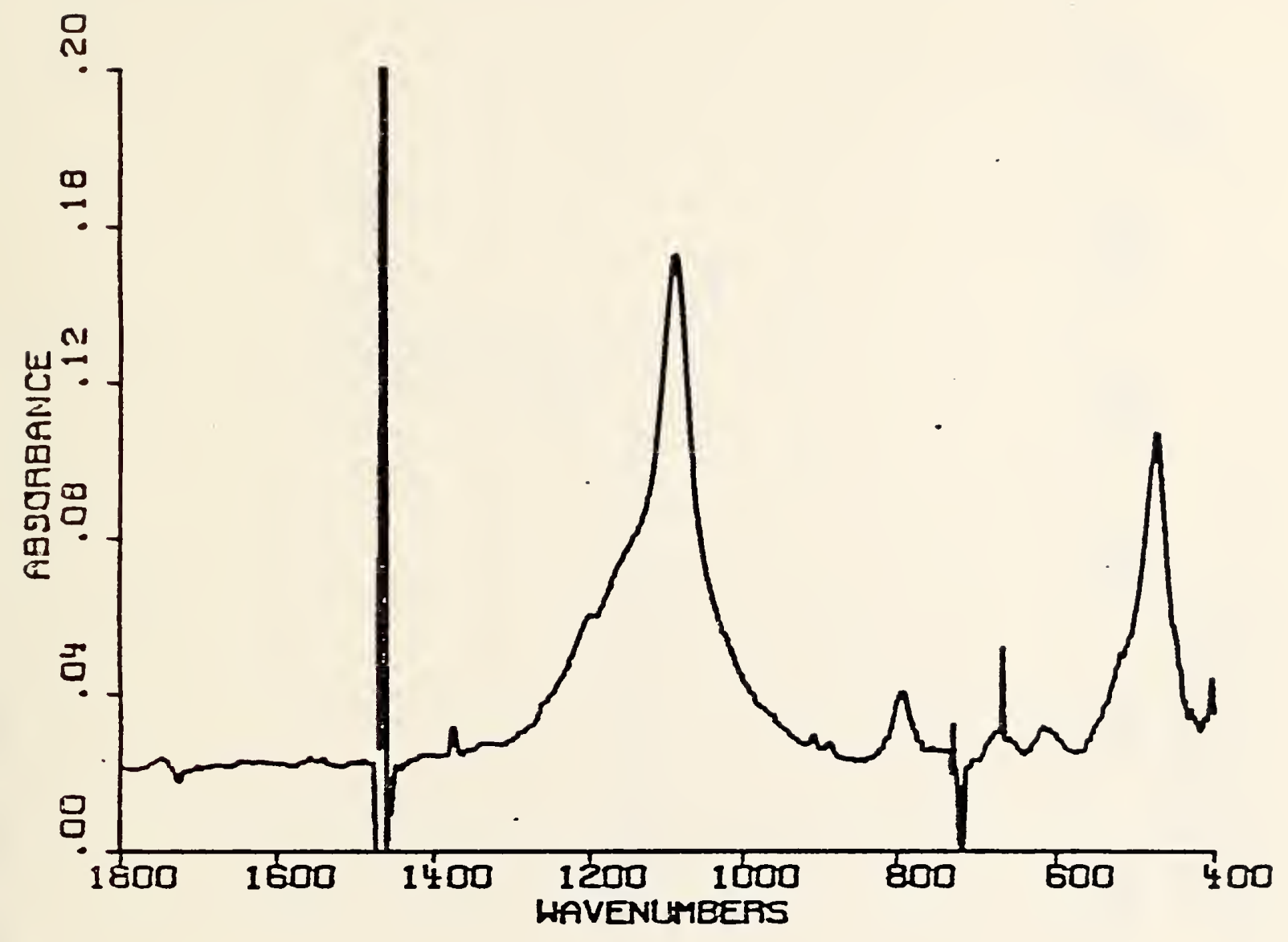

Fig. 8. Difference Spectrum BI - Category I. 



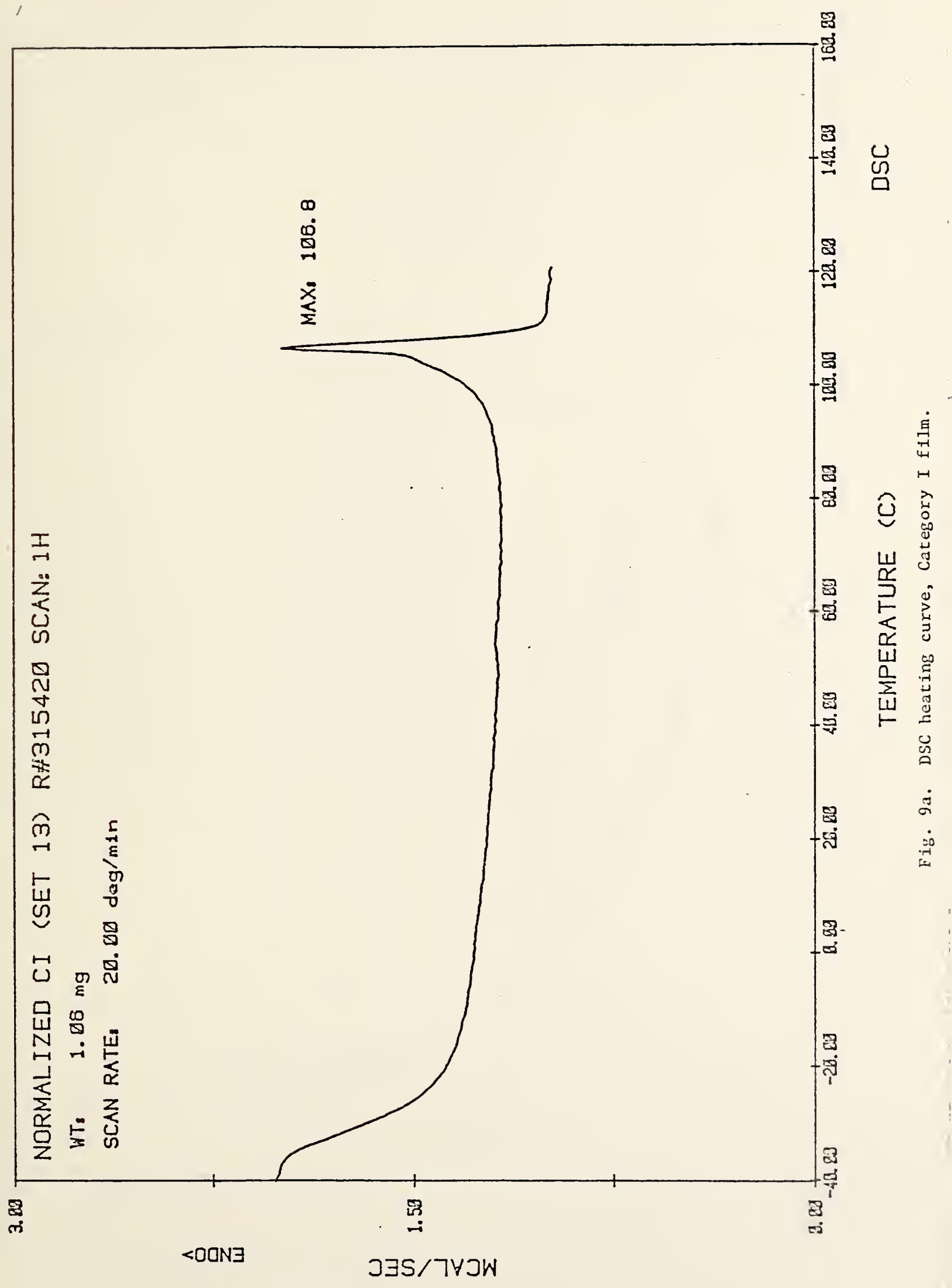





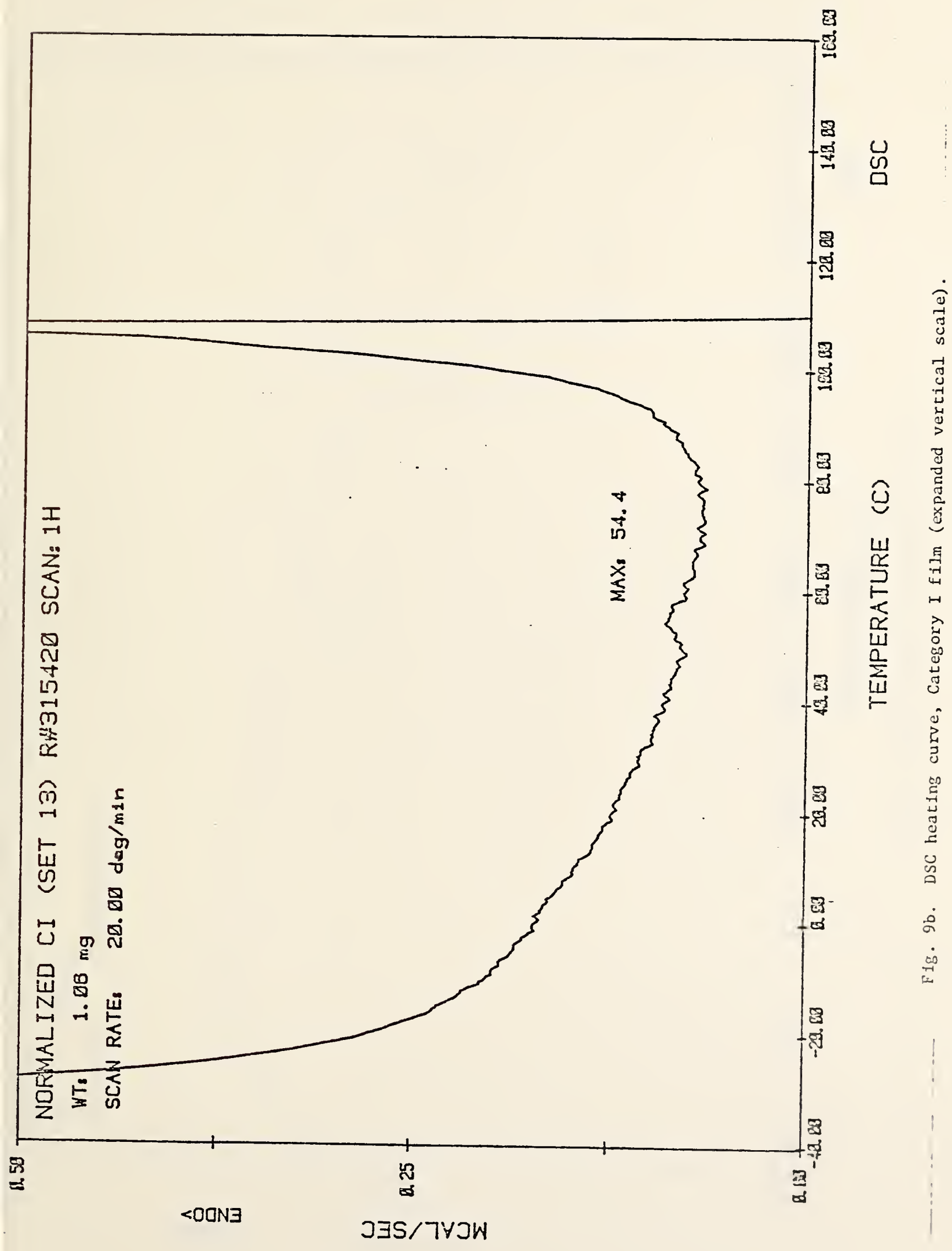





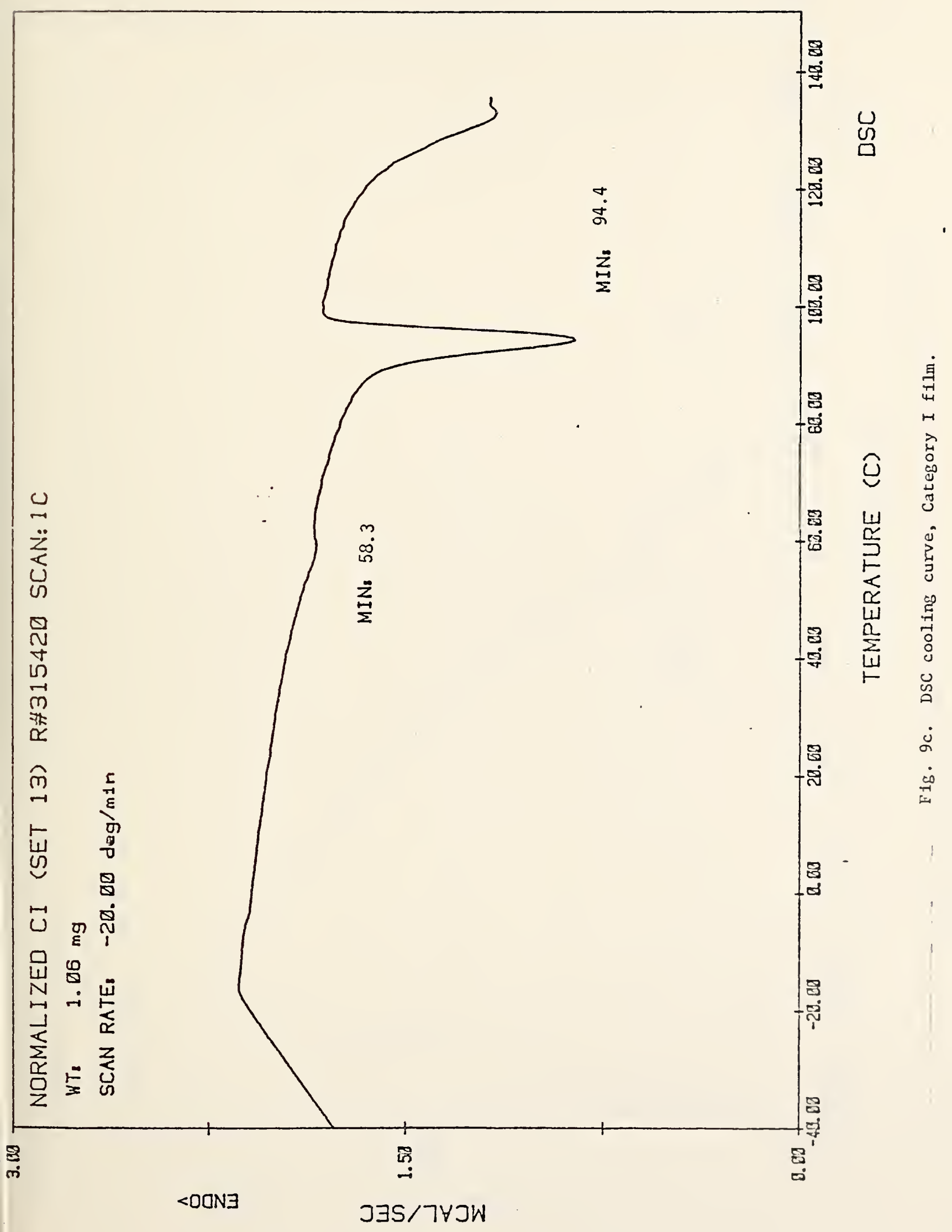






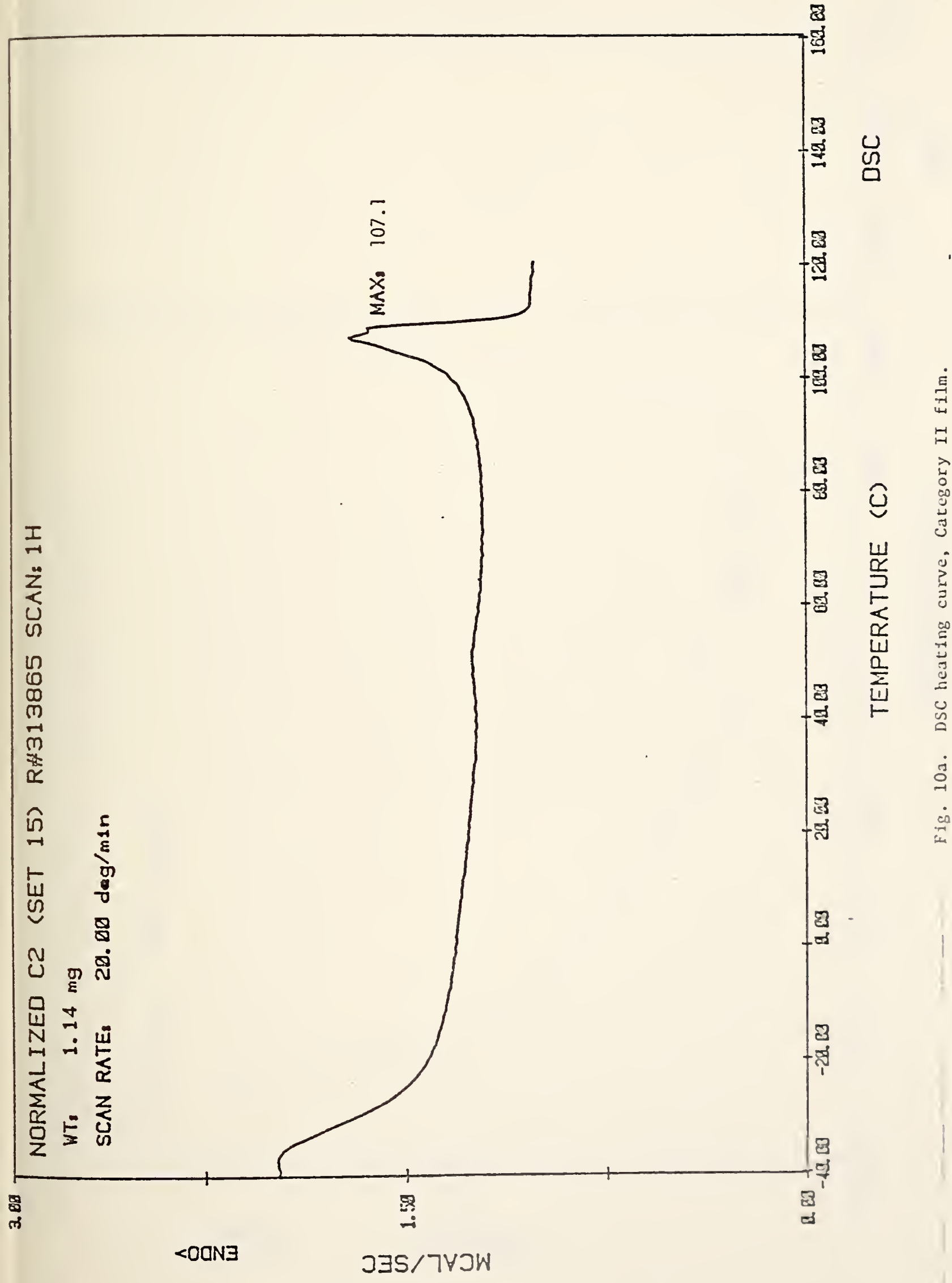





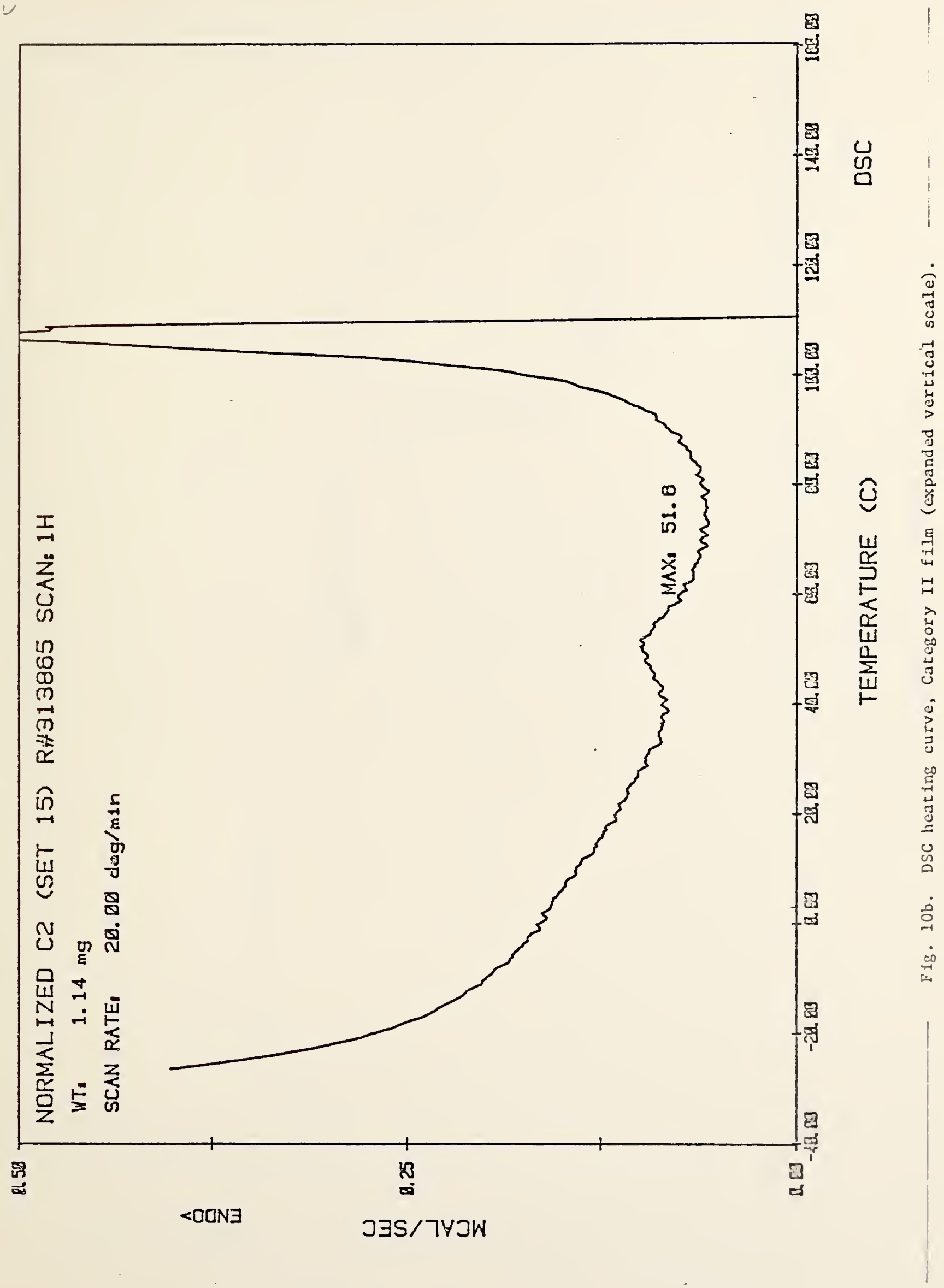





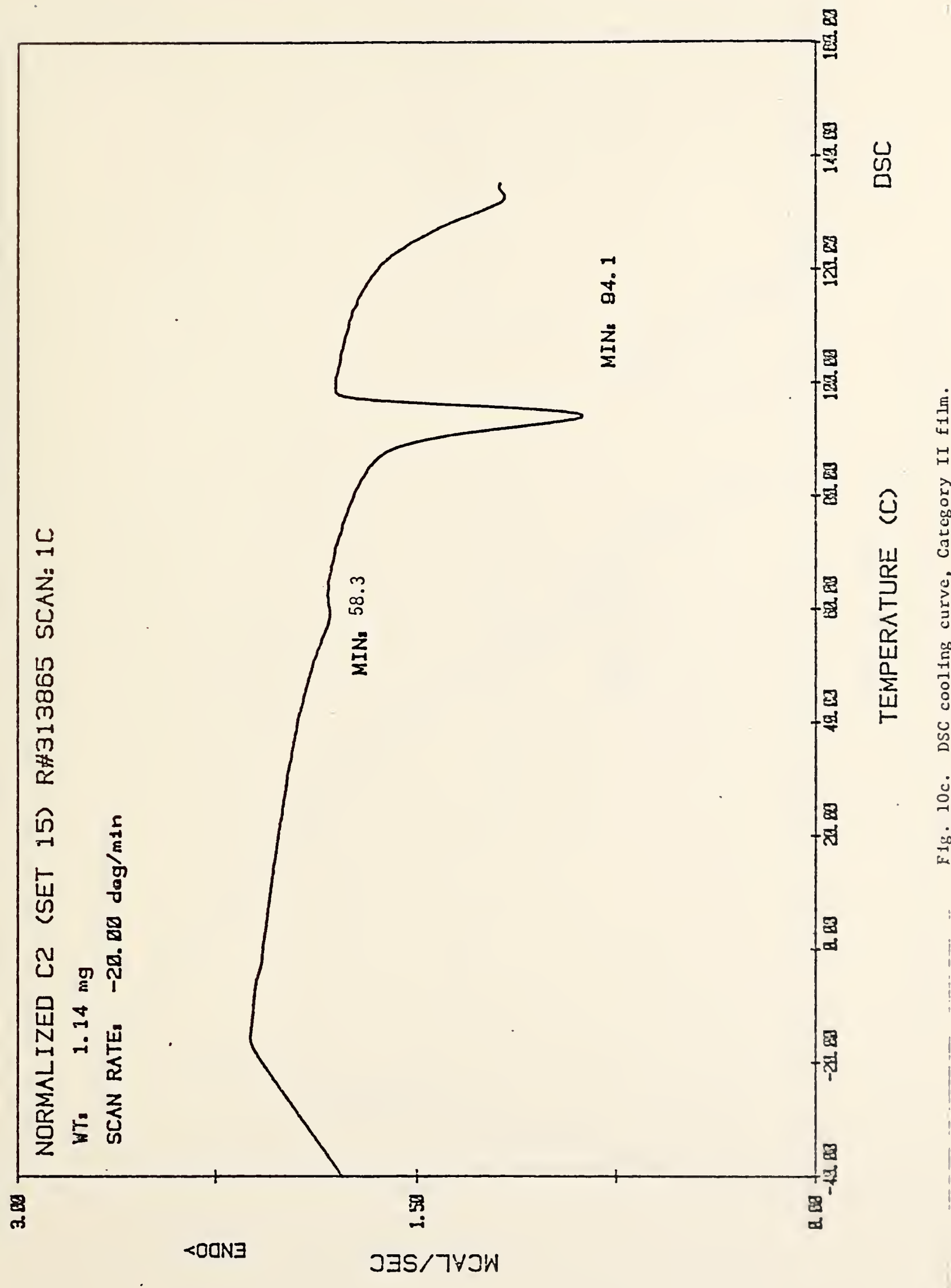





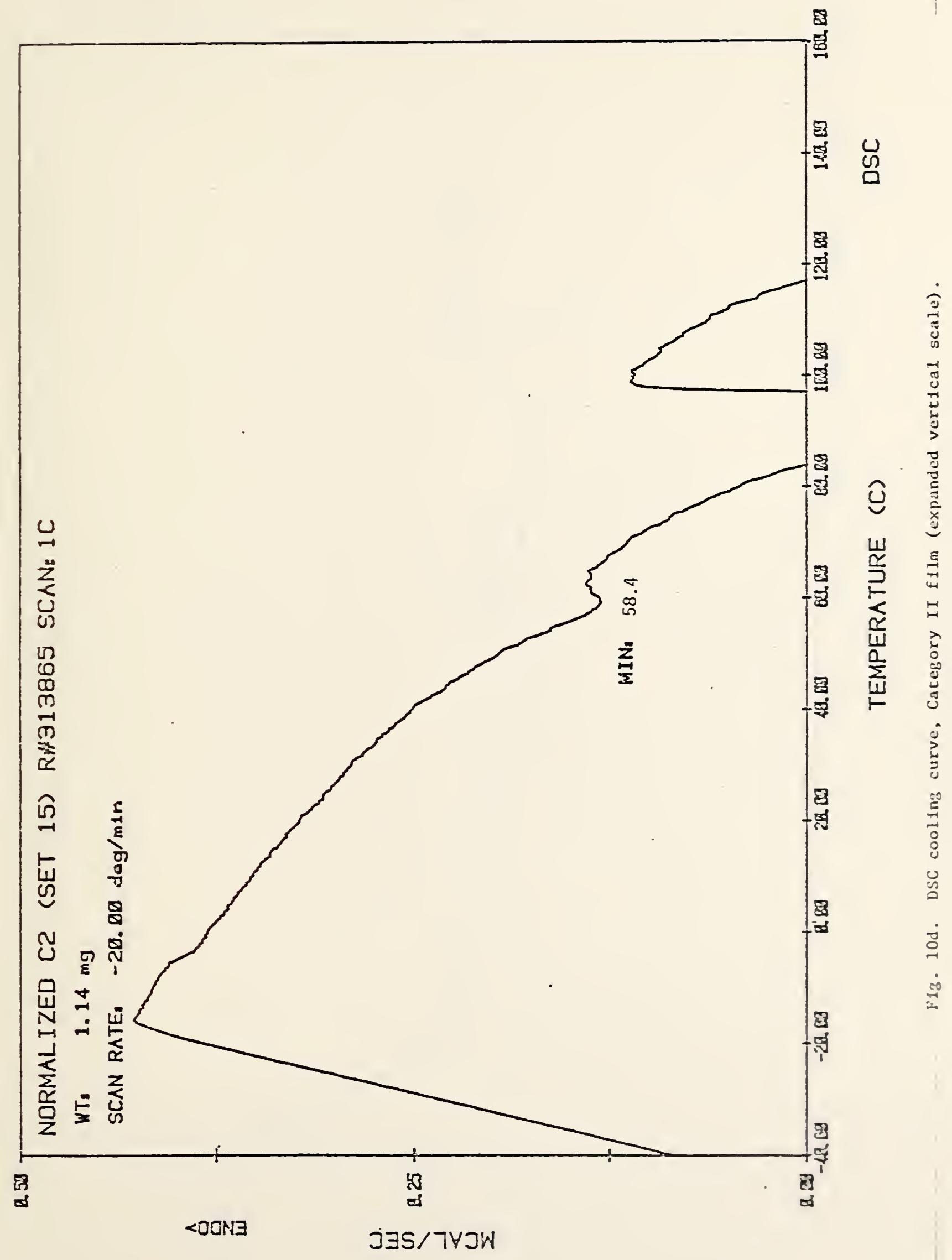





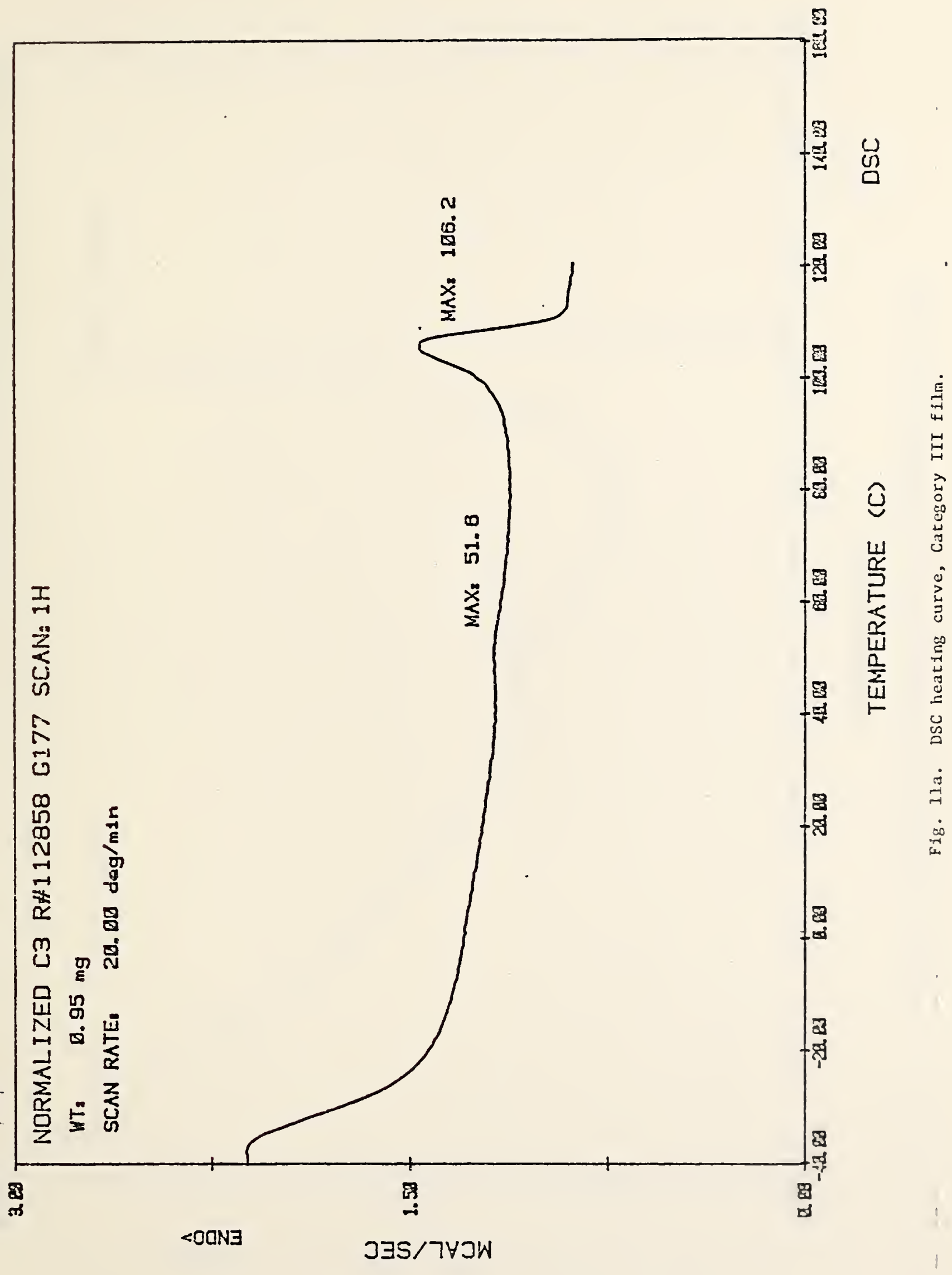





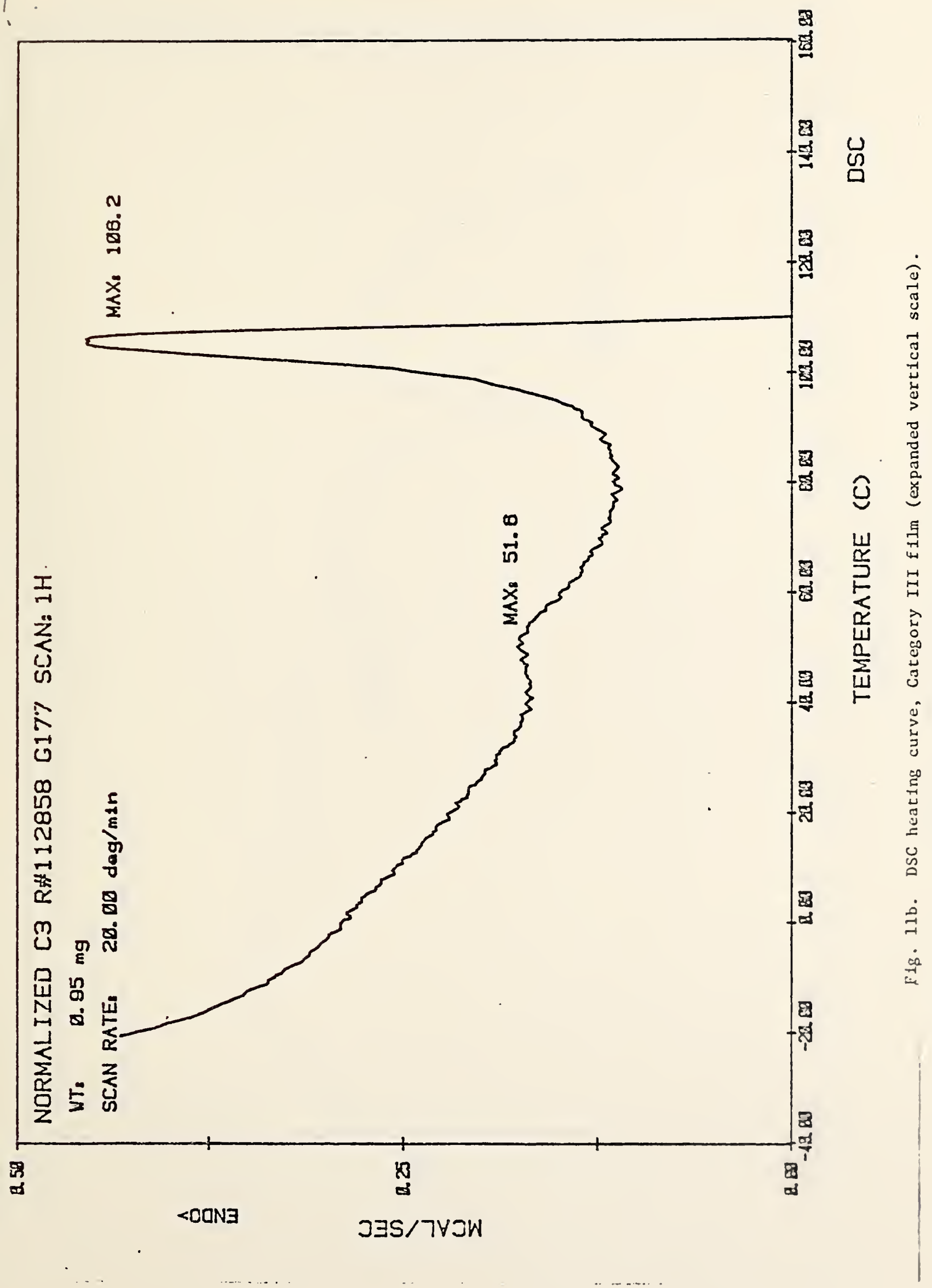





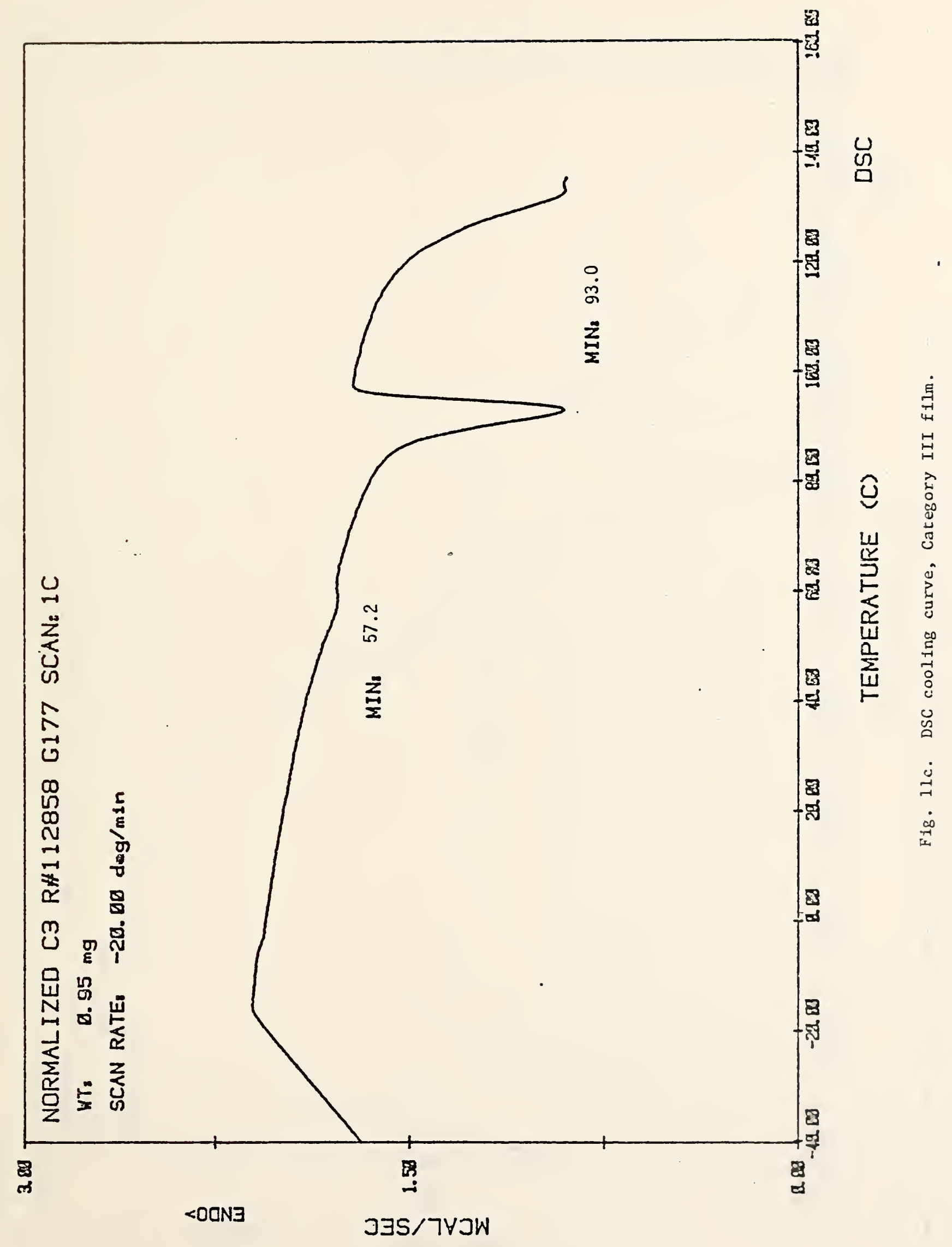





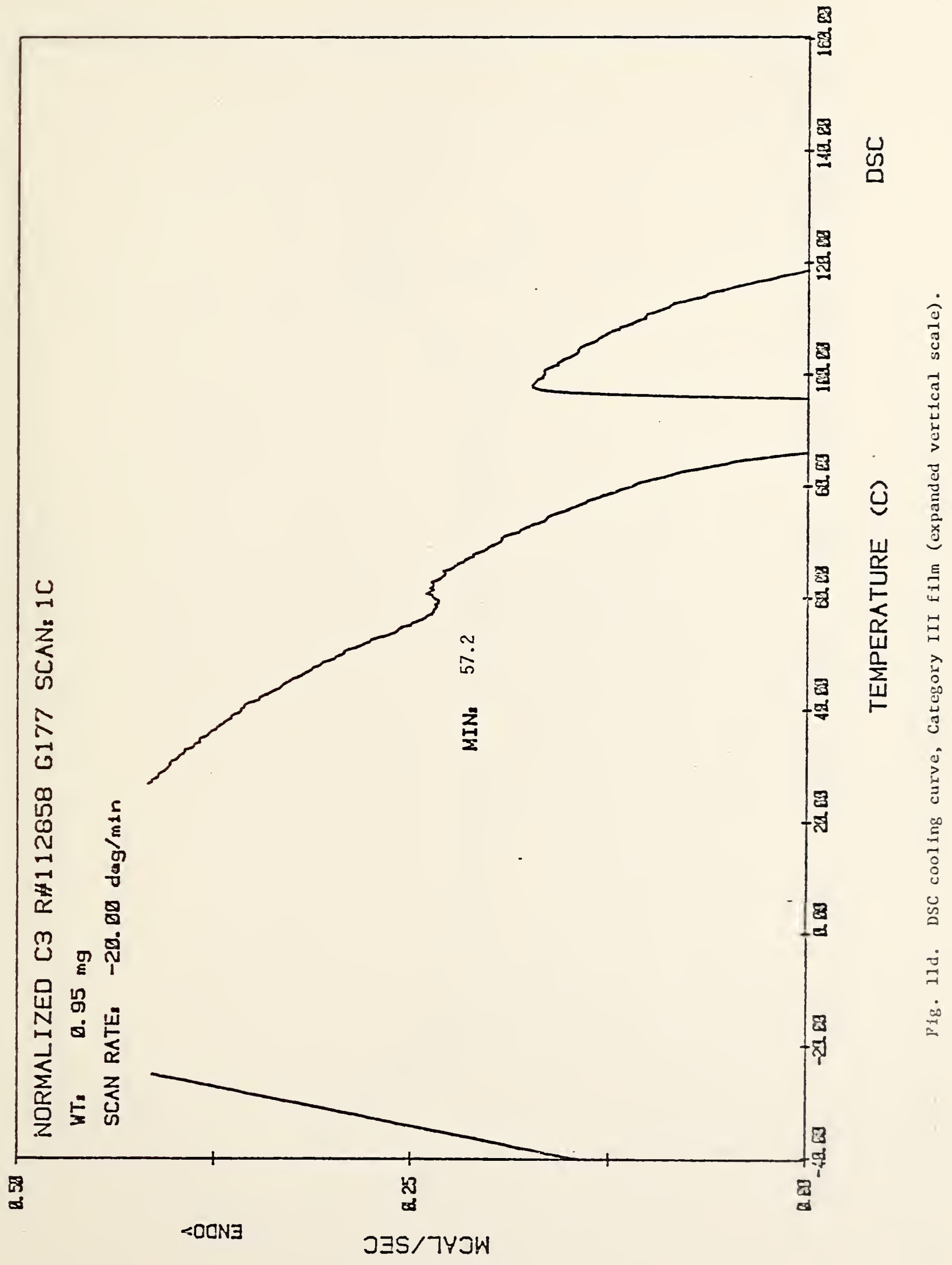





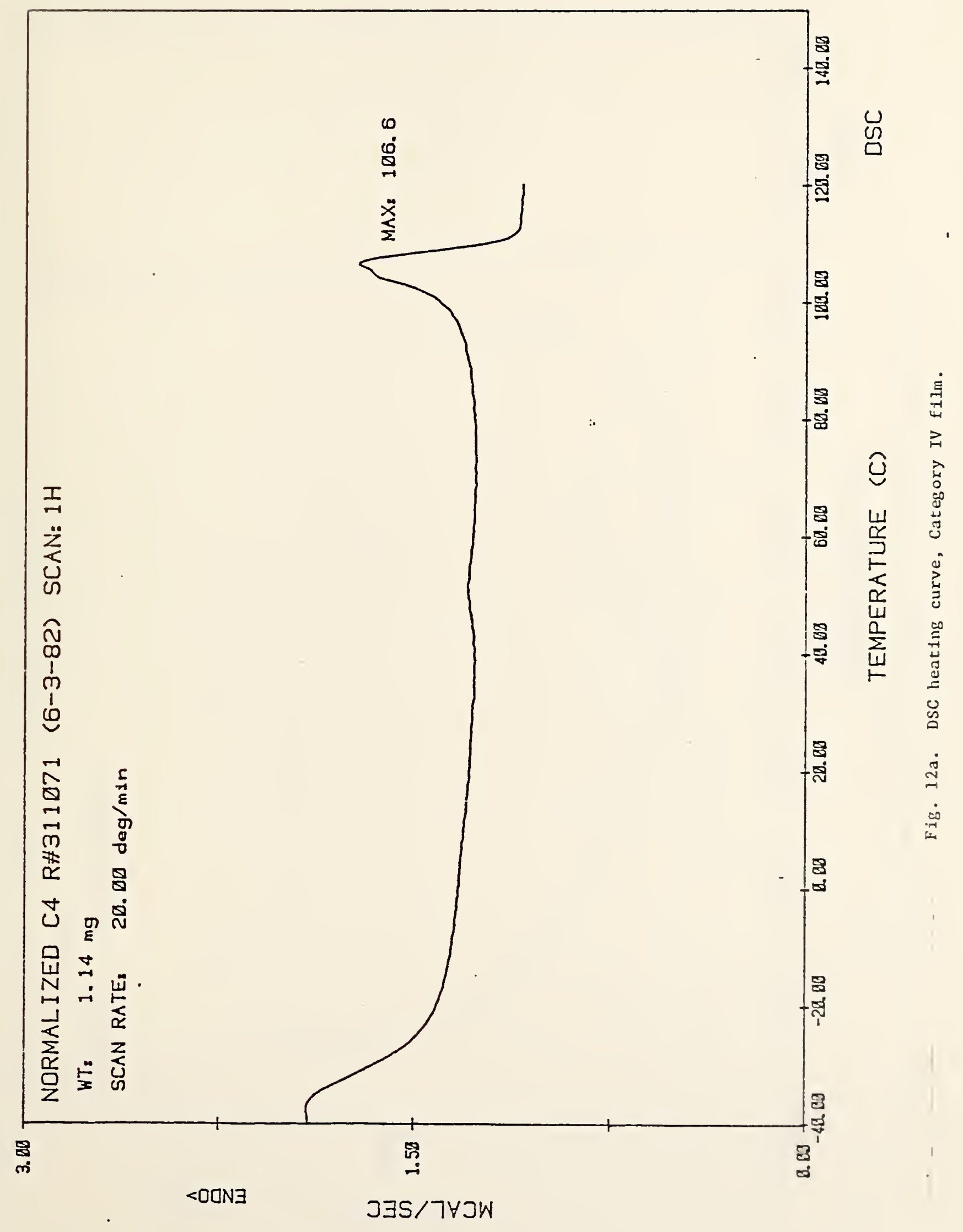





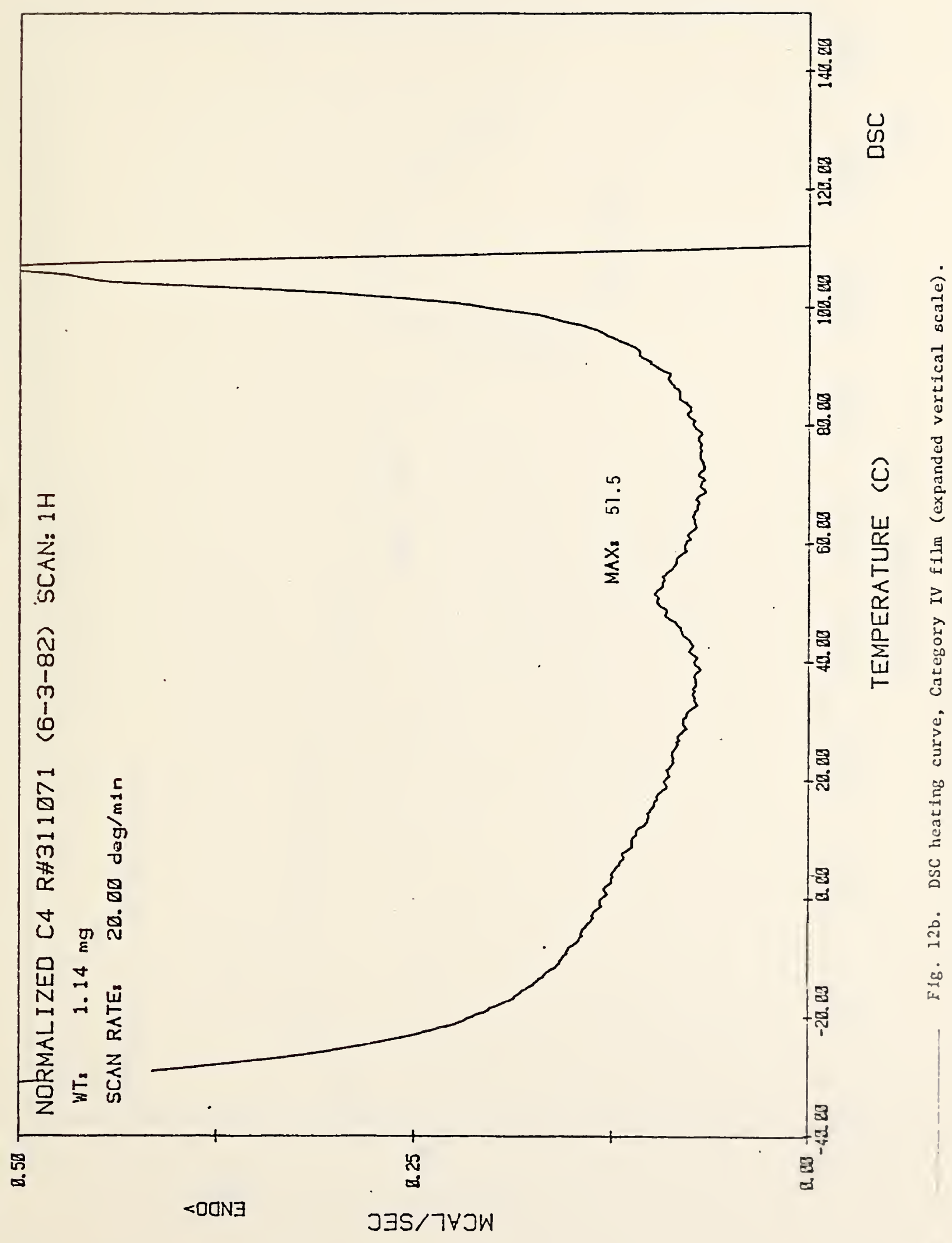





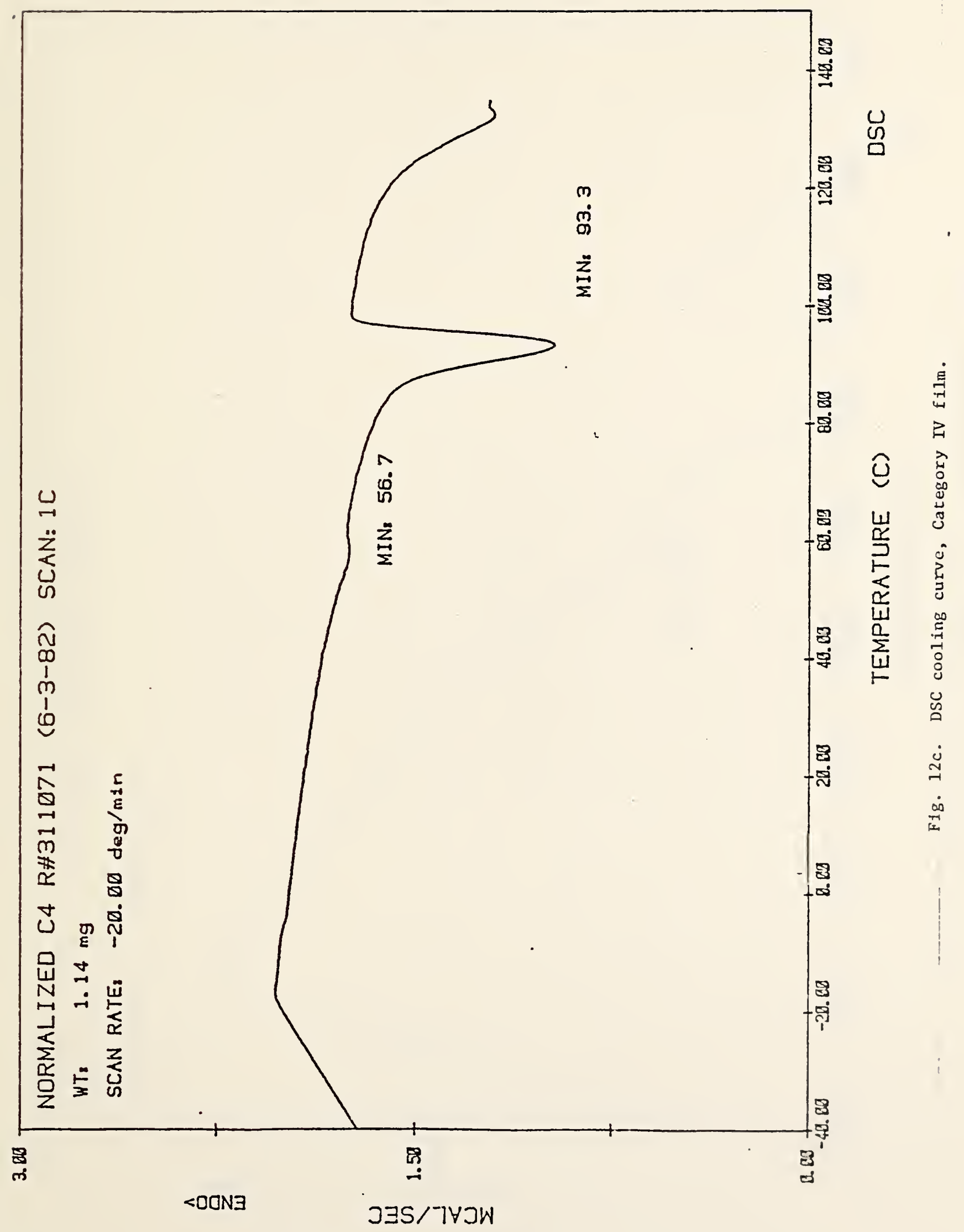





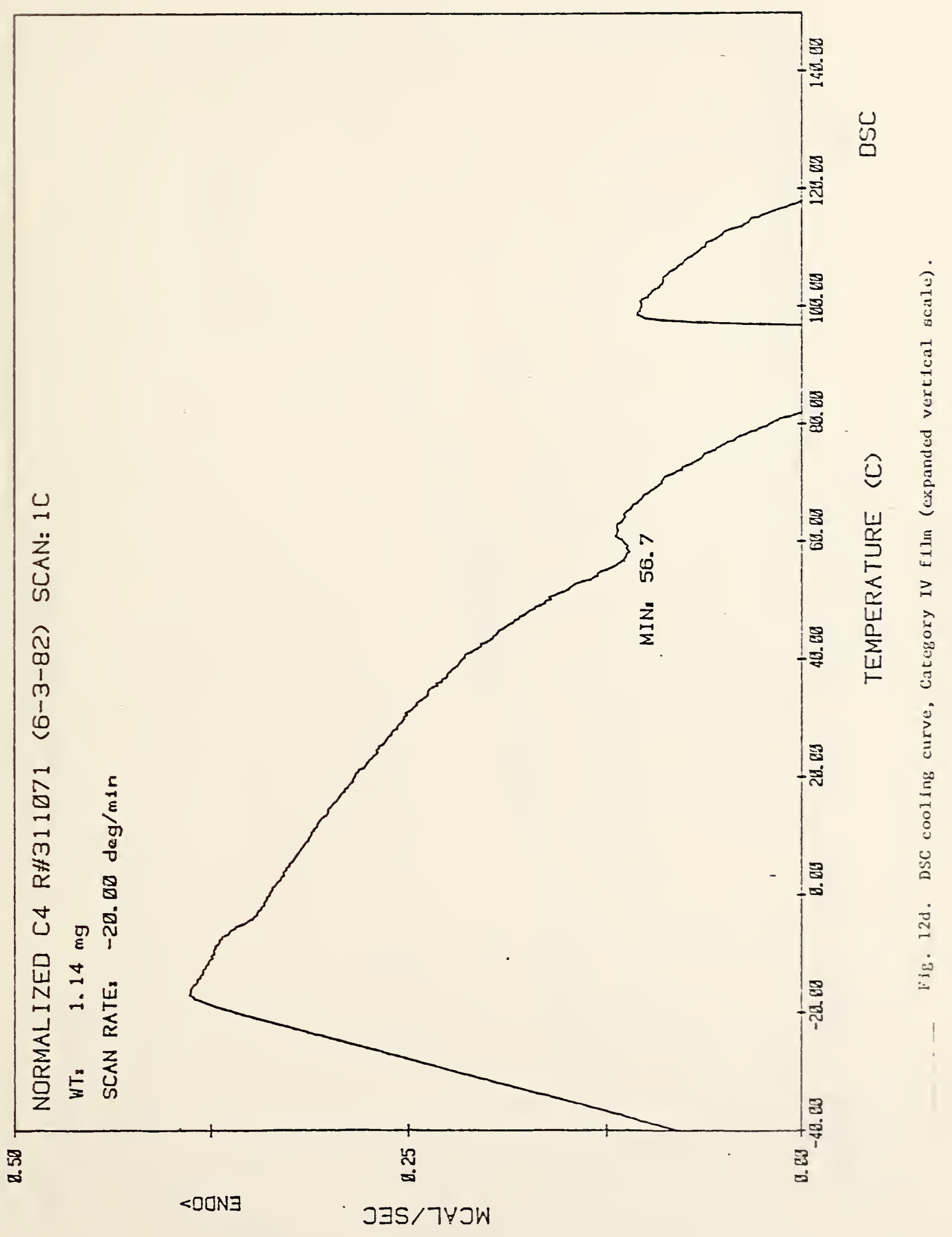





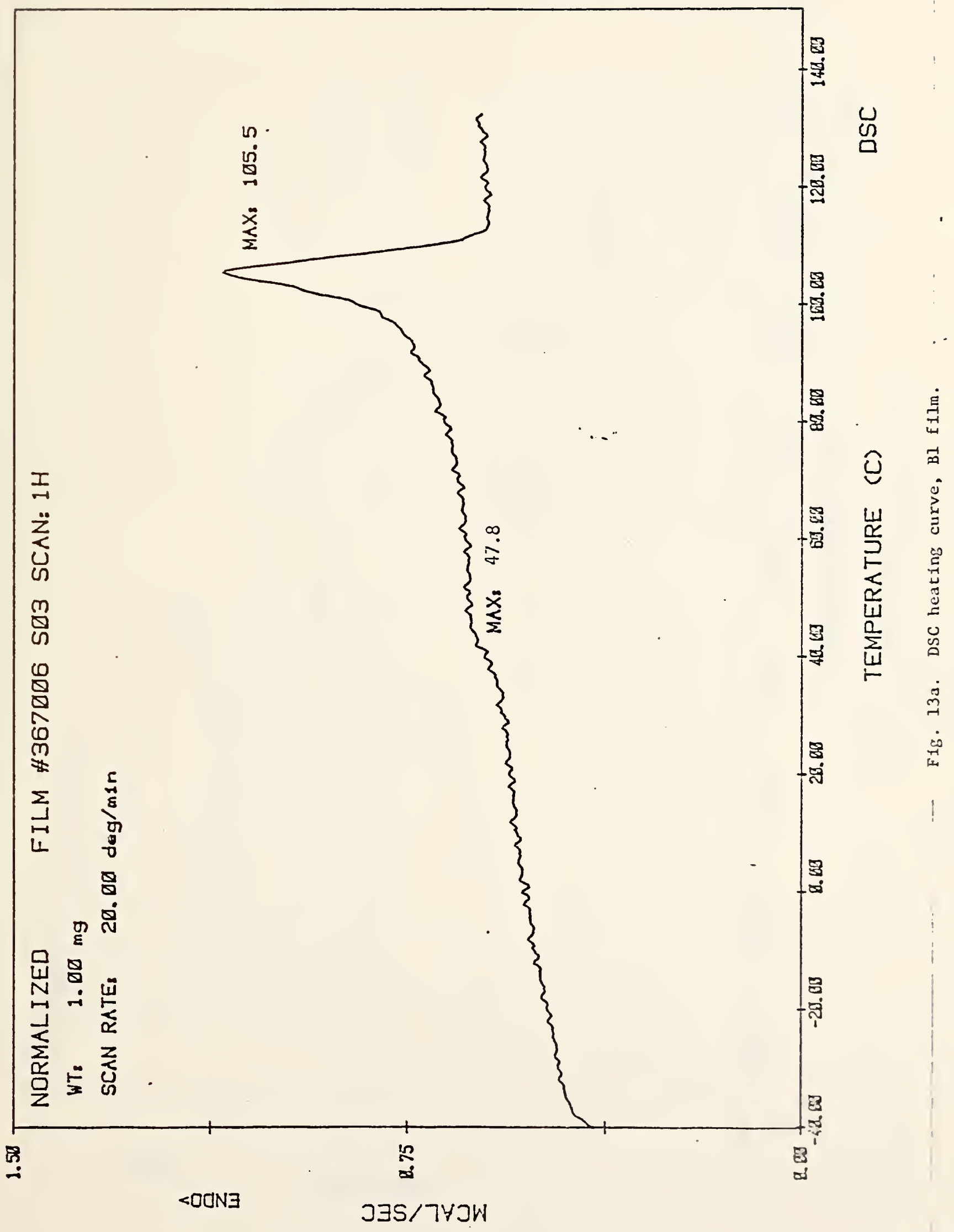





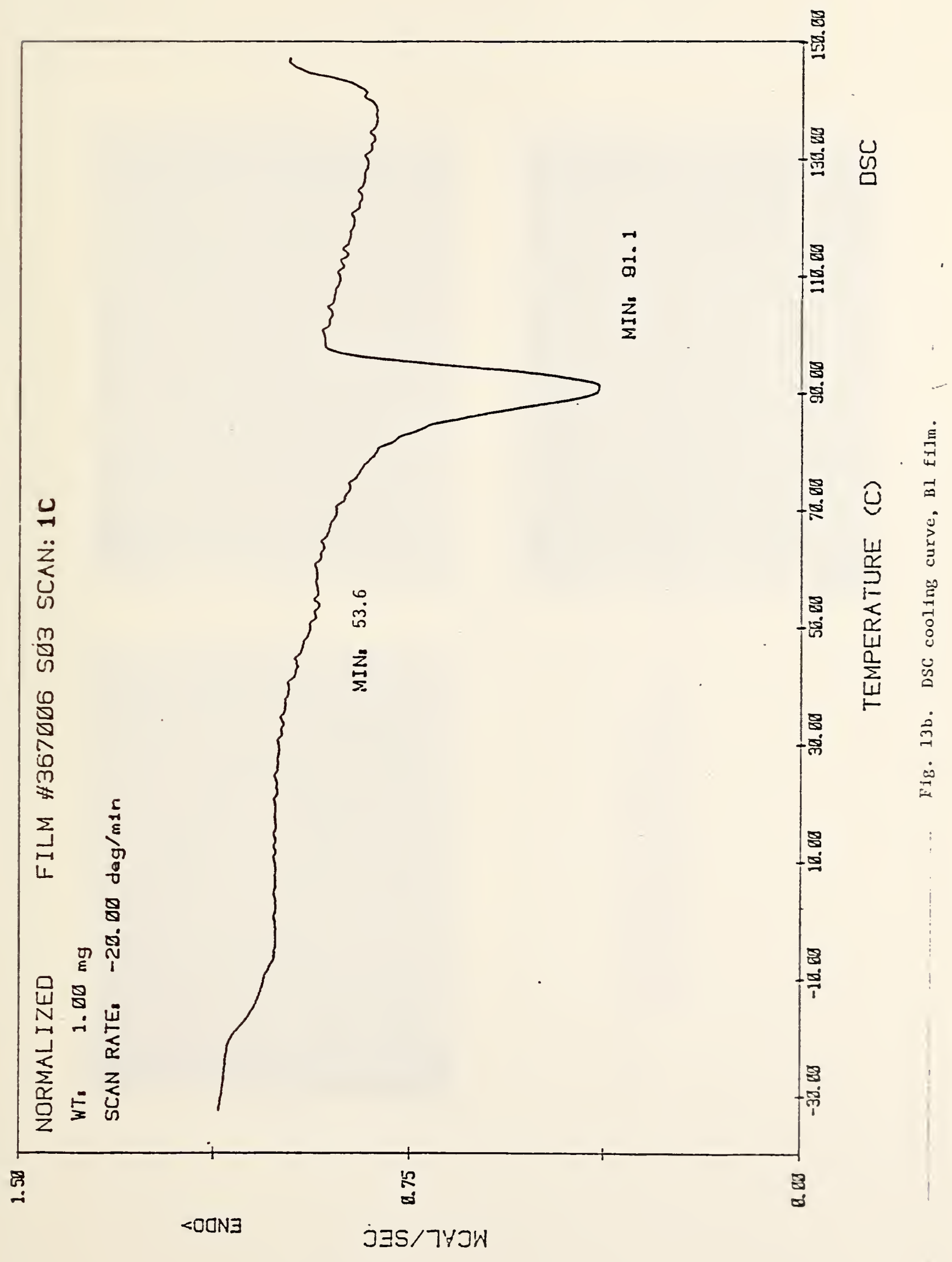




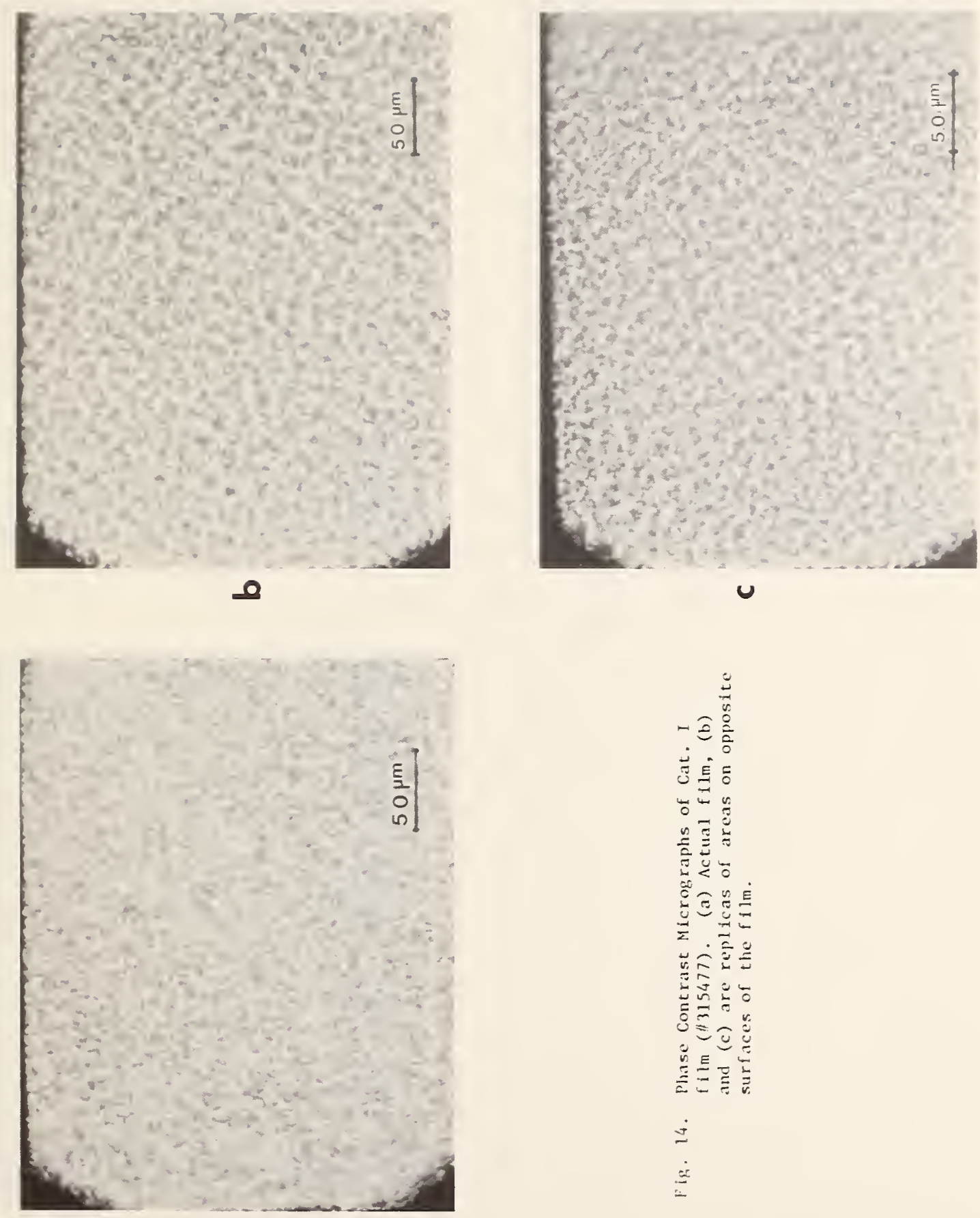

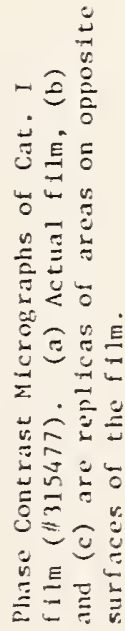

ป

$\underline{-1}$ 


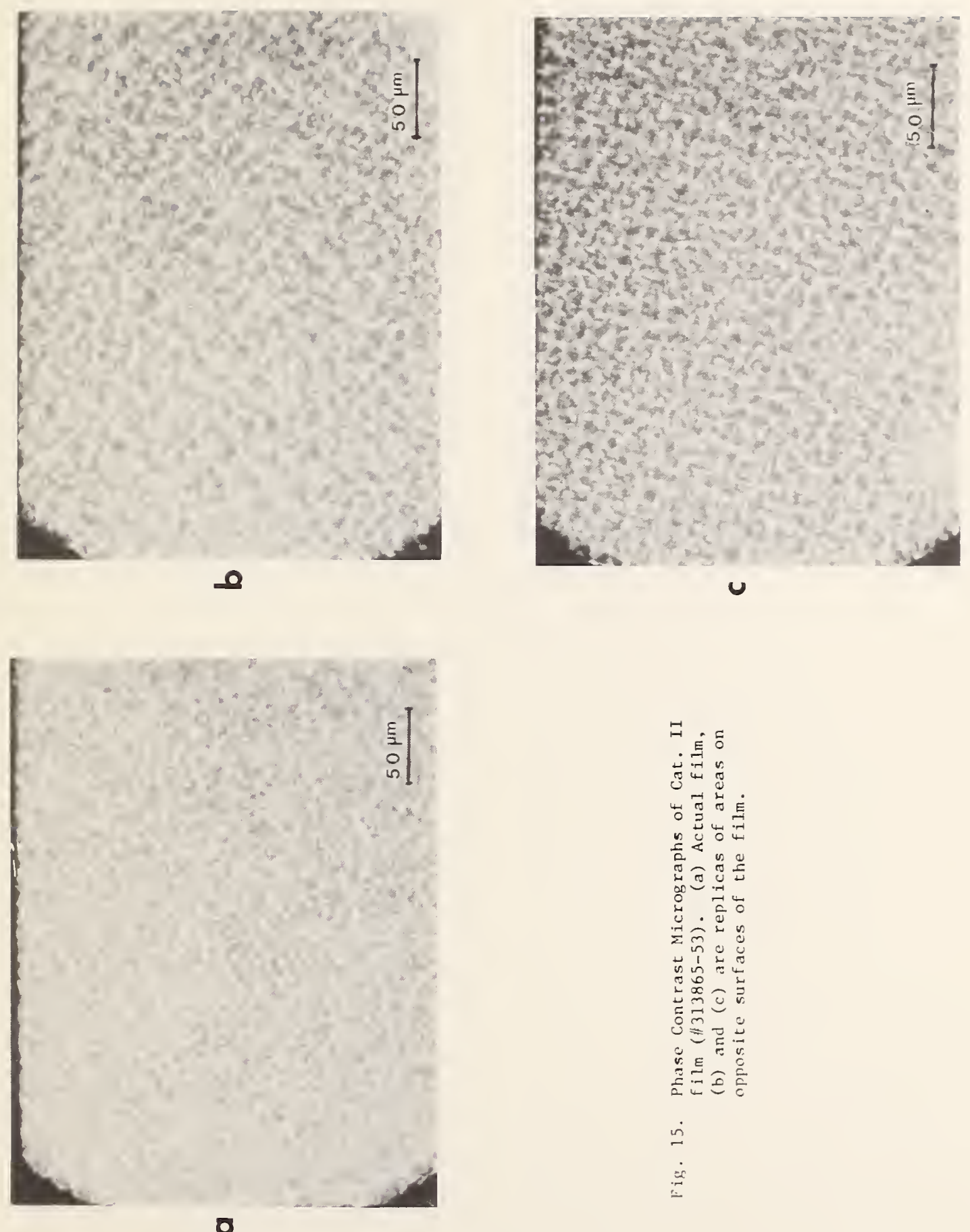


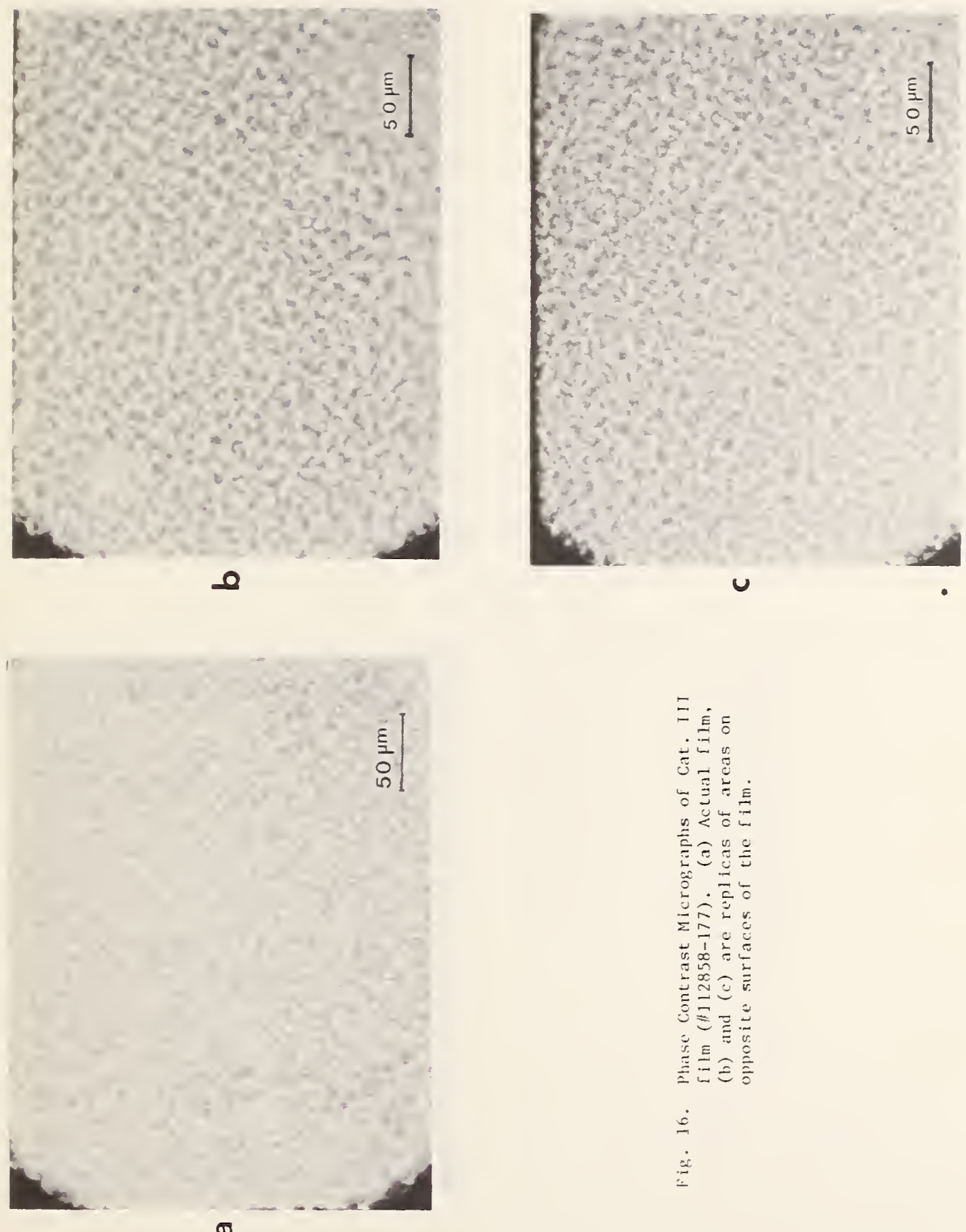


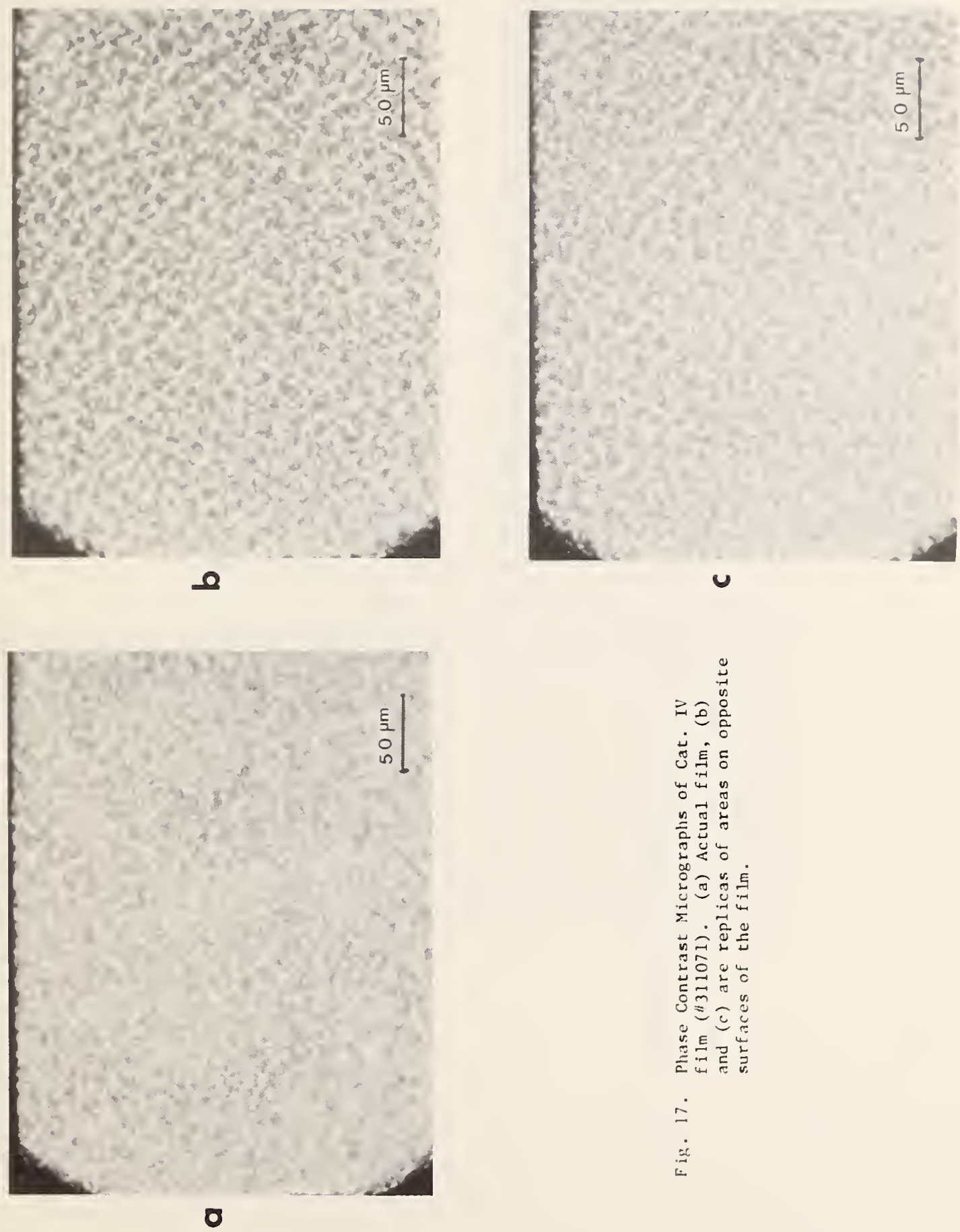


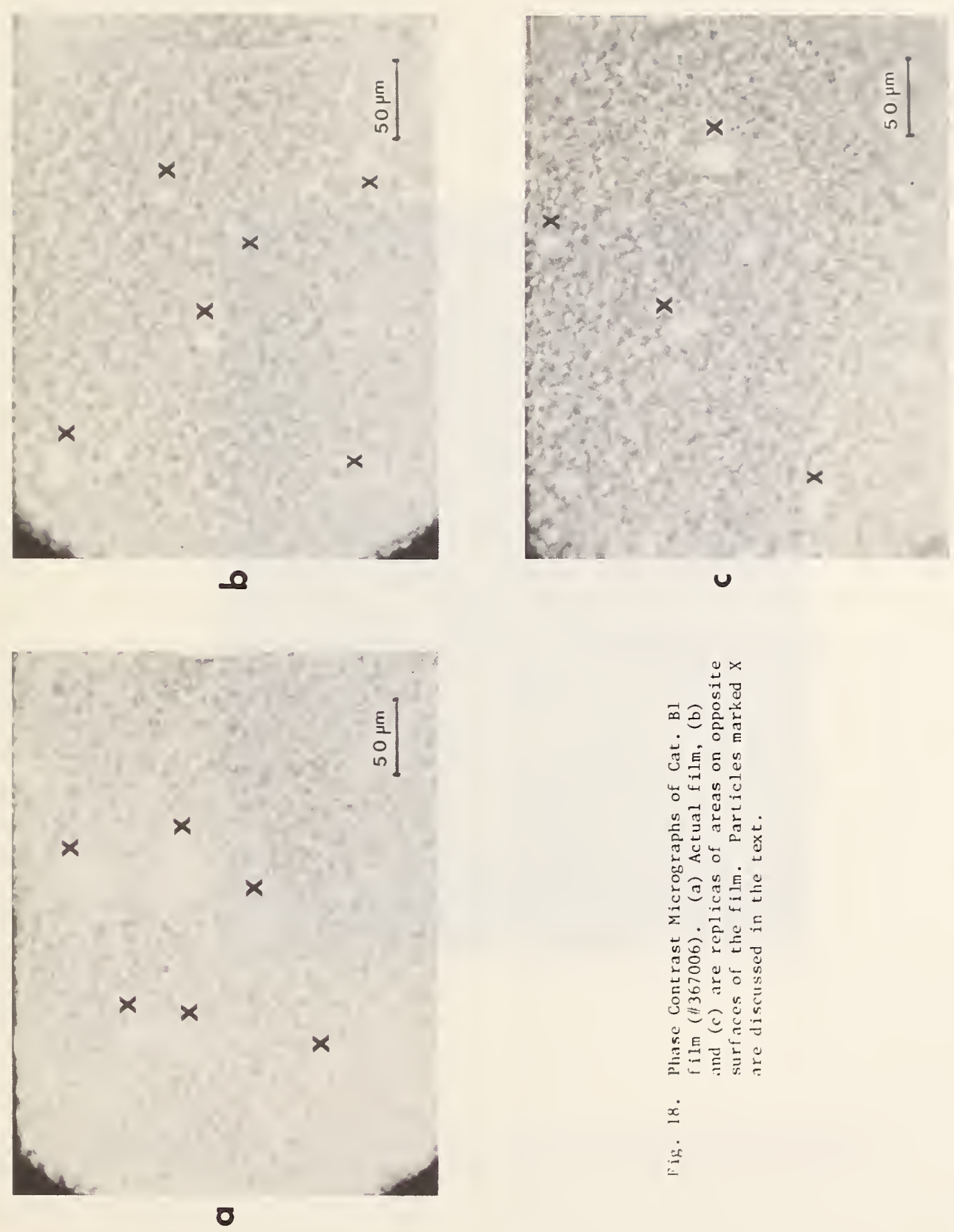



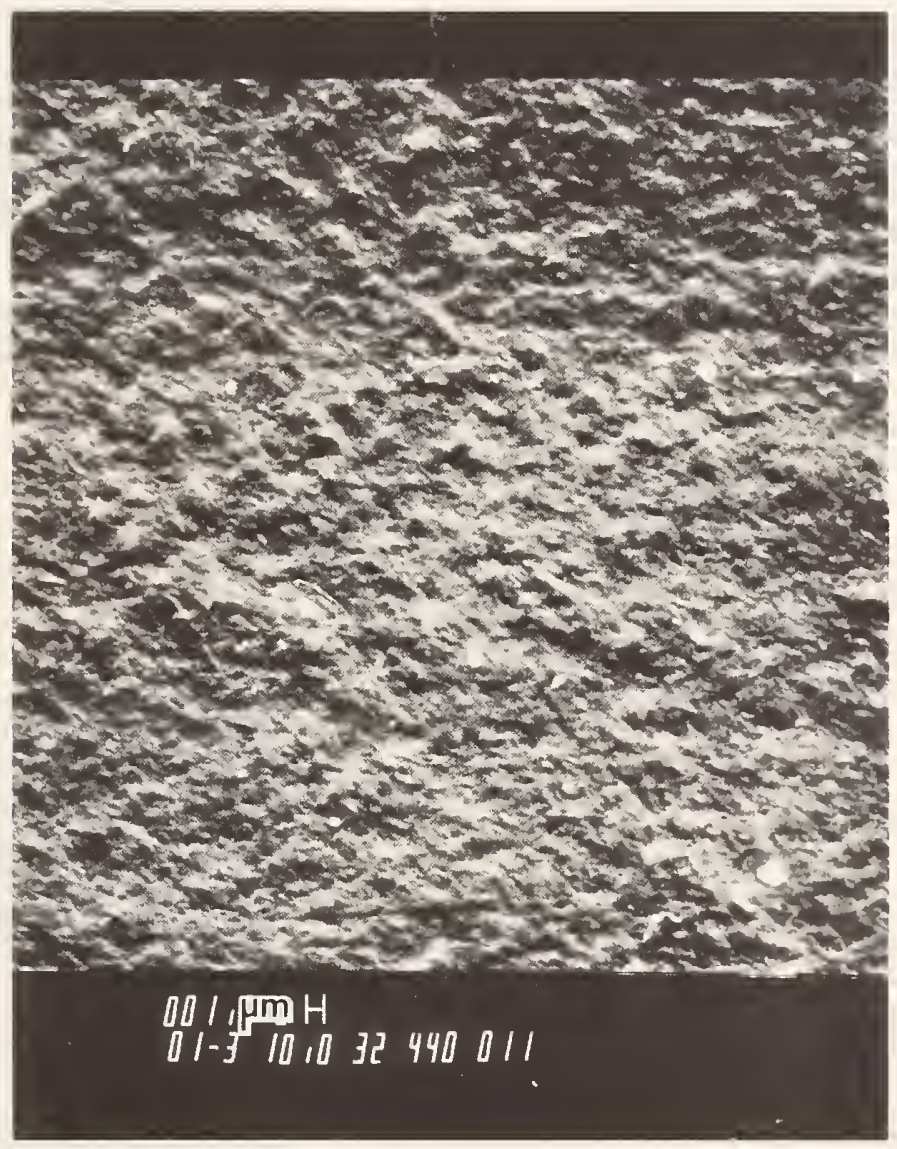

Fig. 19. Scanning Electron Micrograph of one of the surfaces of Category I (非15420) film. 

(a)
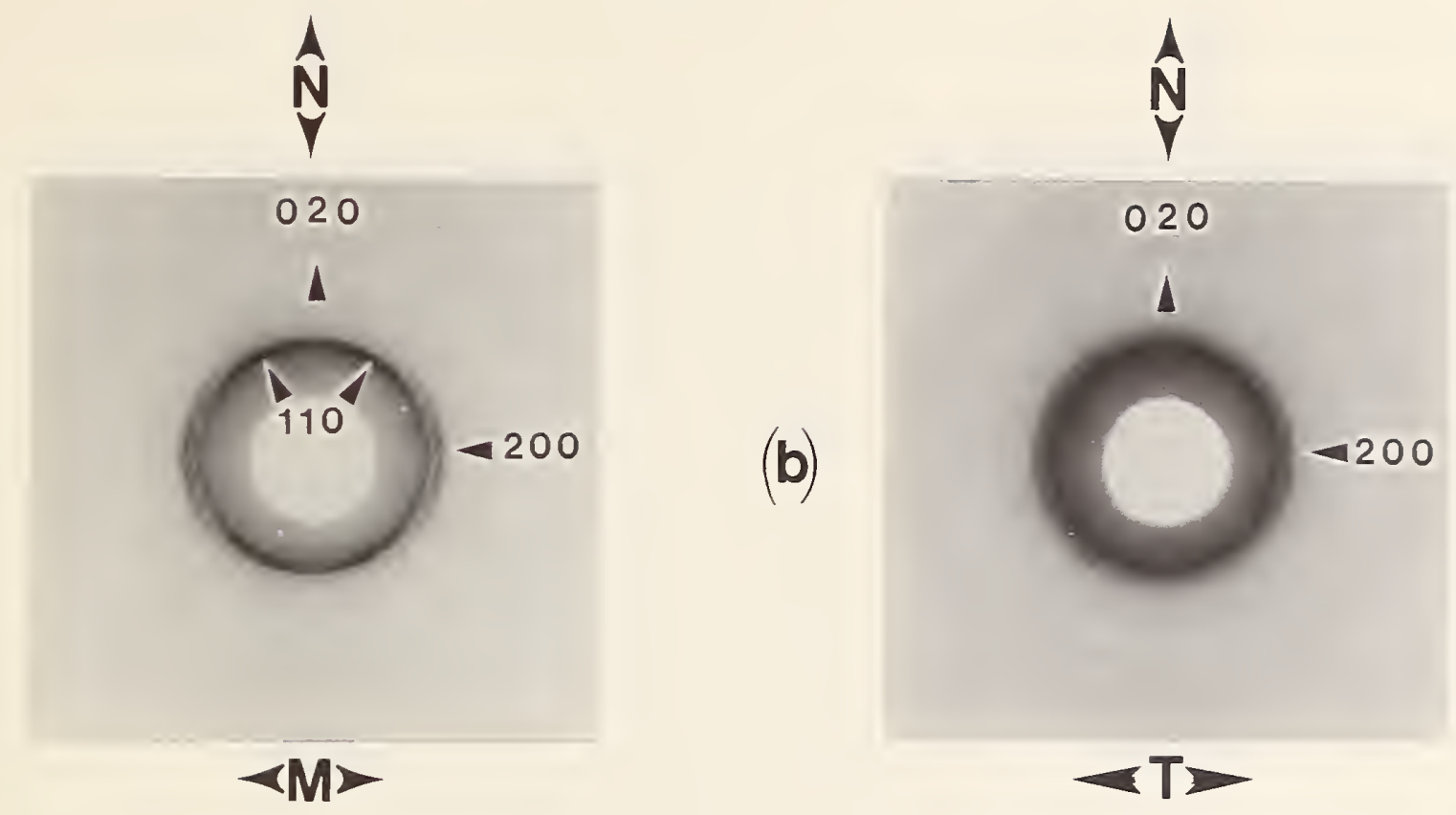

(c)

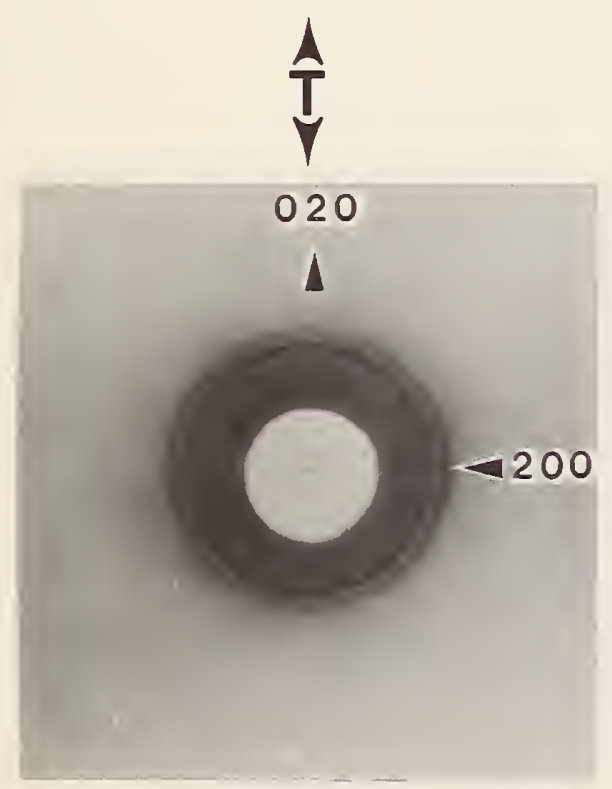

$<M>$

Fig. 20. Wide angle x-ray diffraction patterns of Category I film (非15420). (a) X-ray beam parallel to $\mathrm{T}$.

(b) X-ray beam parallel to M. (c) X-ray beam parallel to $\mathrm{N}$. 



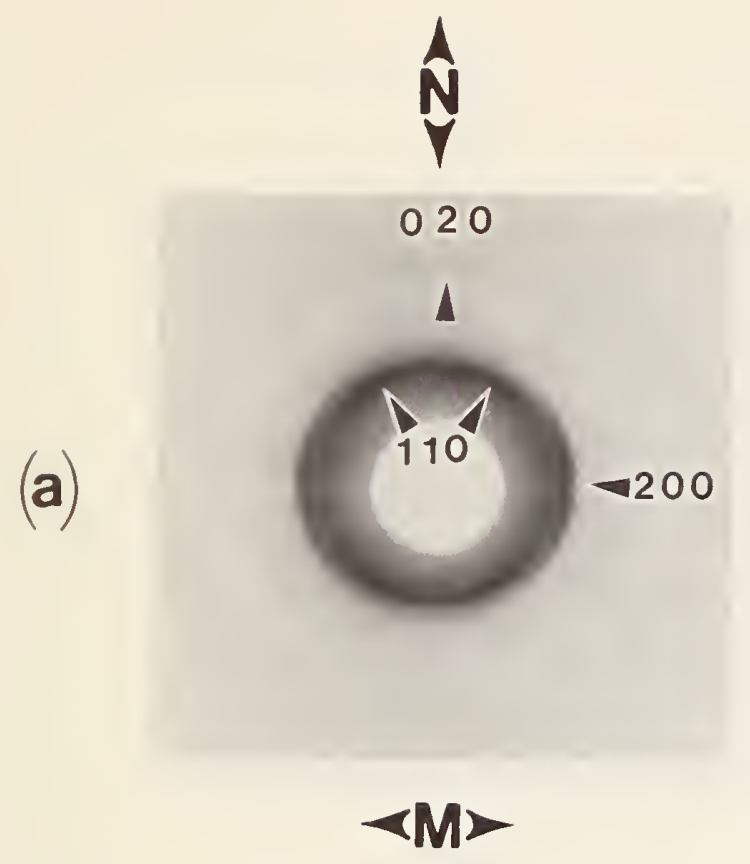

87

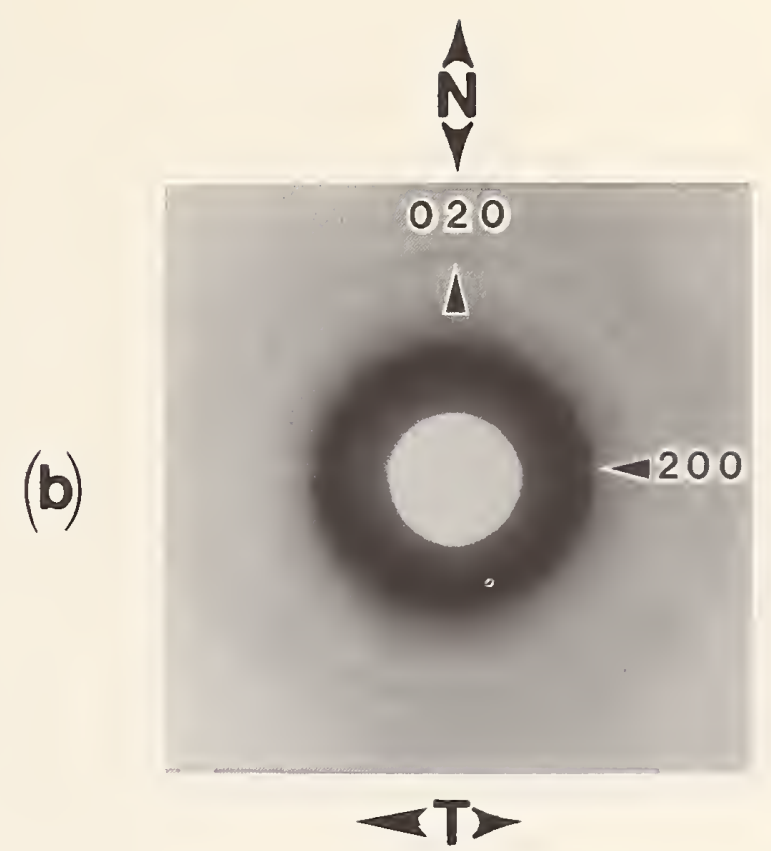

(c)

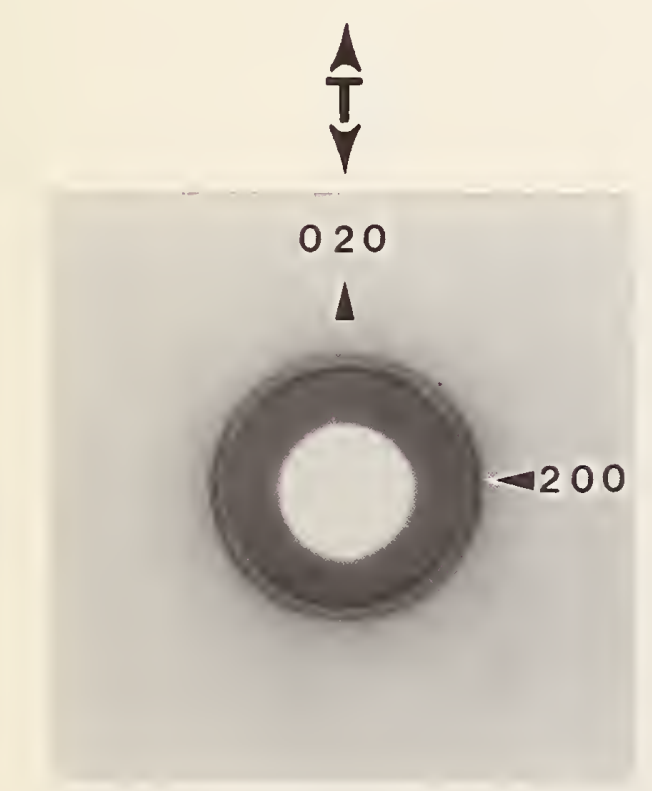

\section{$<M$}

Fig. 21. Wide angle $x$-ray diffraction patterns of Category II film (非13865, gore 53). (a) X-ray beam parallel to T. (b) X-ray beam parallel to $M$. (c) X-ray beam parallel to $\mathrm{N}$. 



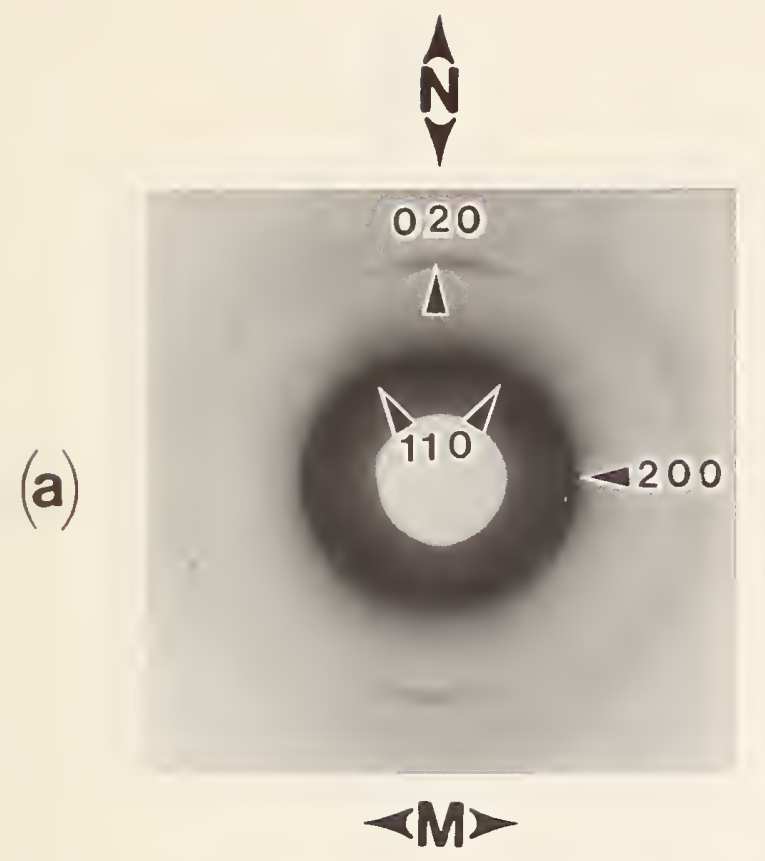

88

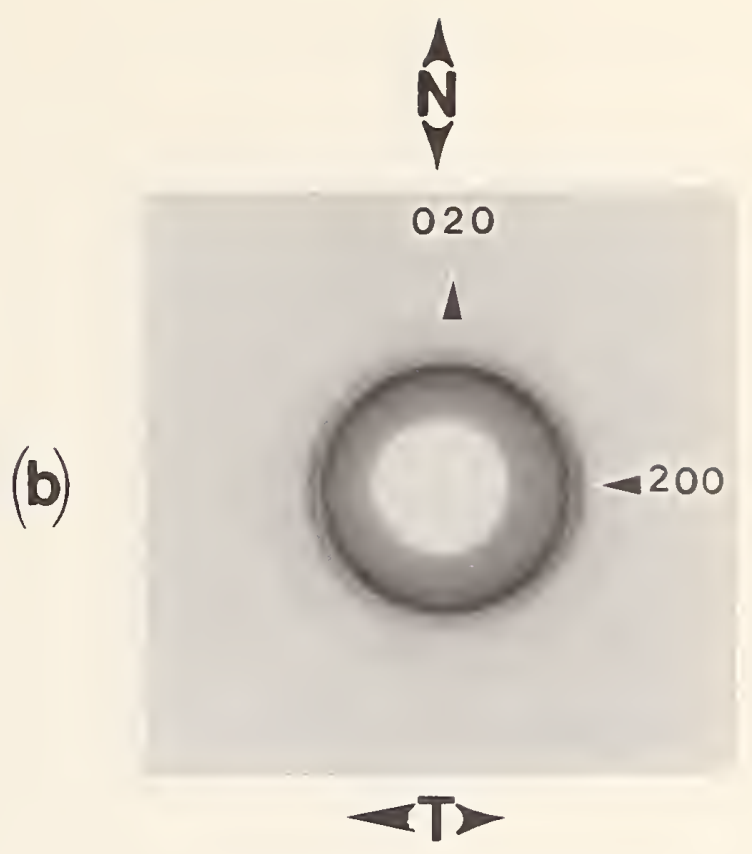

(c)

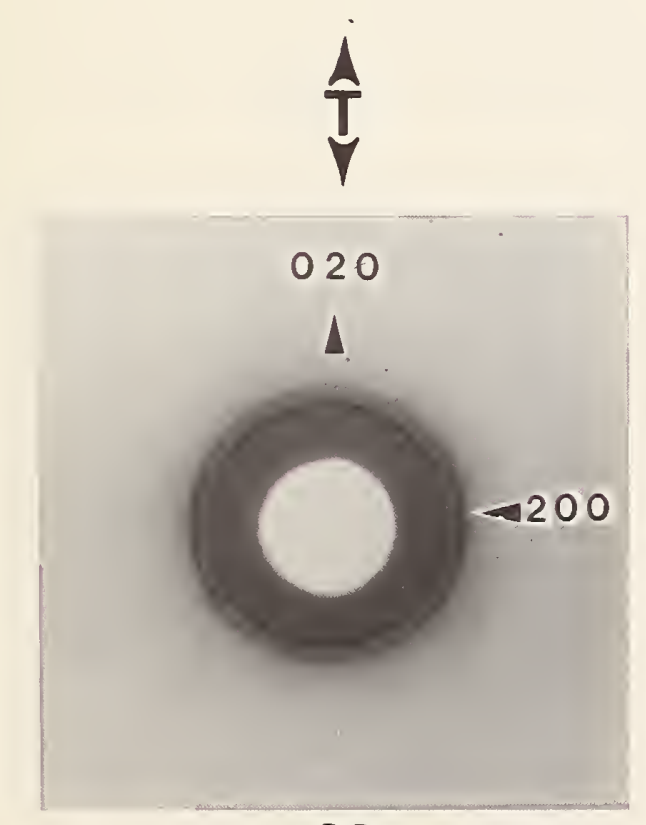

$<M>$

Fig. 22. Wide angle x-ray diffraction patterns of Category III film (非12877). (a) X-ray beam parallel to $\mathrm{T}$.

(b) X-ray beam parallel to $M$. (c) X-ray beam parallel to $\mathrm{N}$. 


(a)
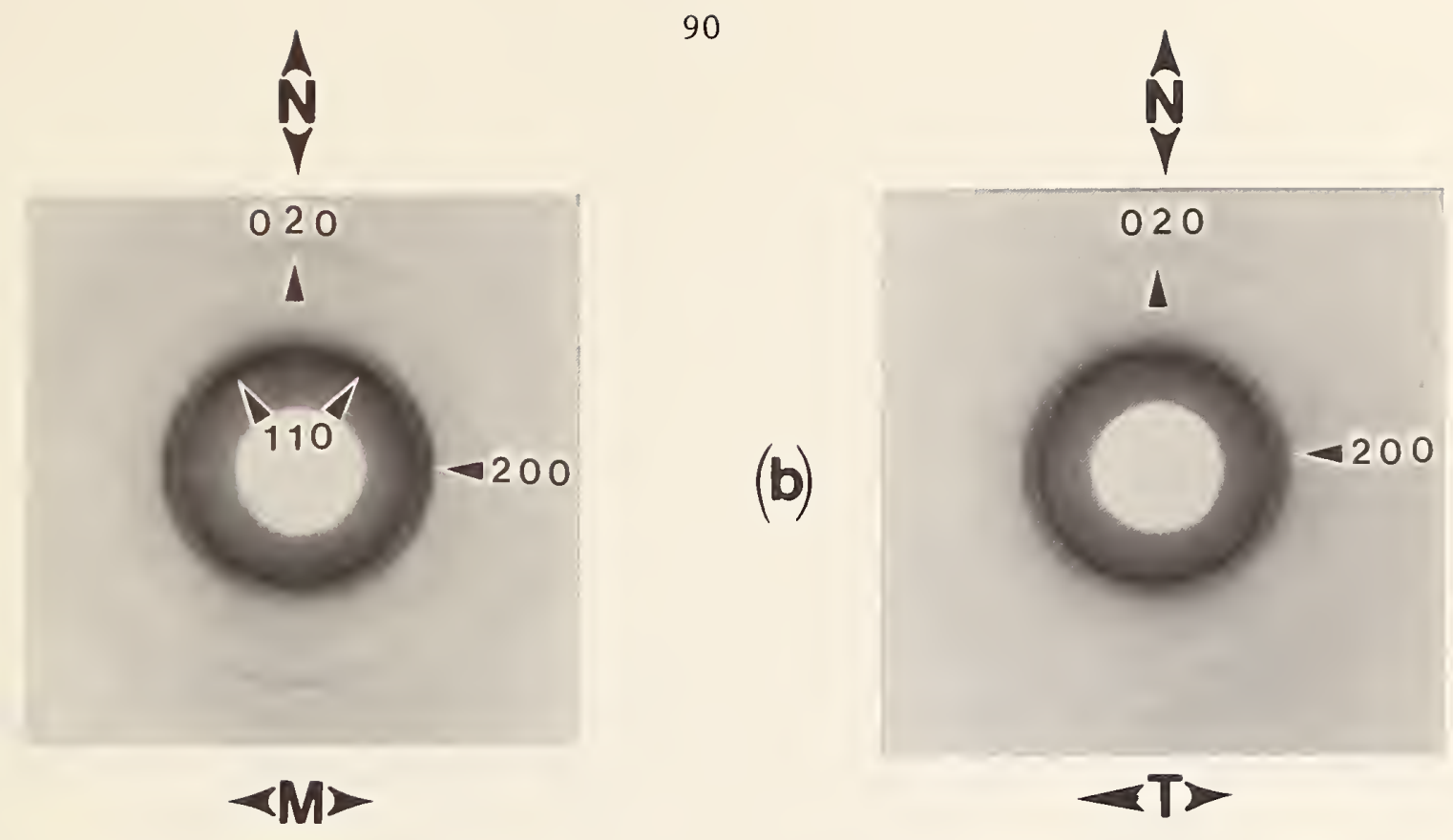

(c)

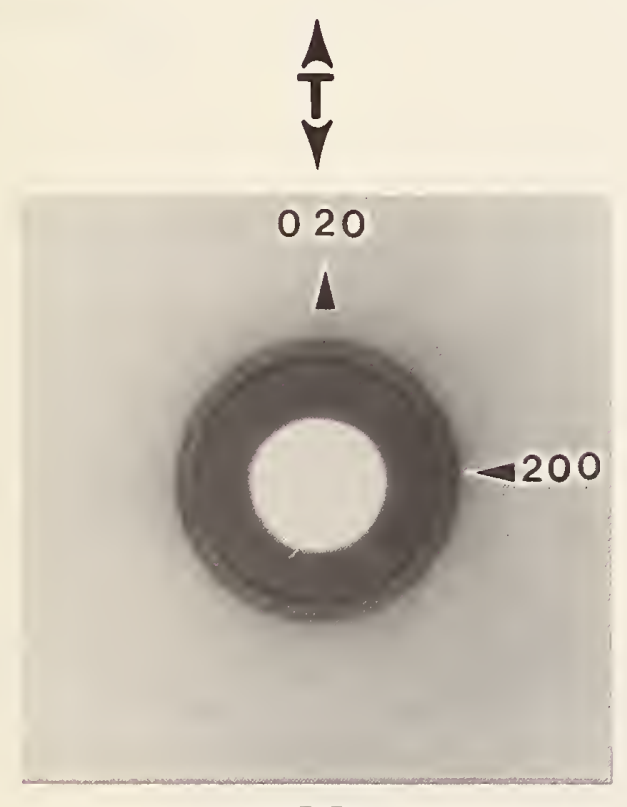

$4 M>$

Fig. 24. Wide angle $x$-ray diffraction patterns of Bl film (非67006). (a) X-ray beam parallel to T. (b) X-ray beam parallel to M. (c) X-ray beam parallel to $\mathrm{N}$. 


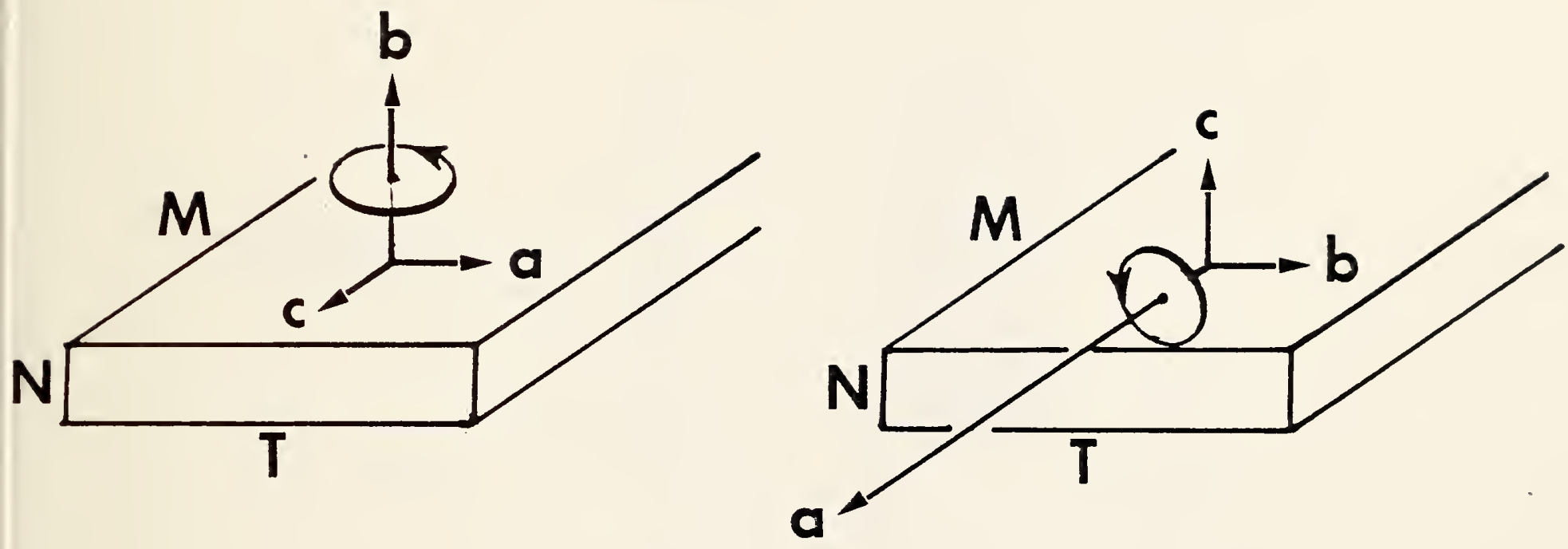

(a)

(b)

Fig. 25. Schematic representation of two idealized microcrystal orientations in a film. (a) The microcrystals are oriented with the b-axis parallel to $\mathrm{N}$, and the a-axis (and hence the c-axis also) oriented randomly in the MT plane. (b) The microcrystals are oriented with the $a$-axis parallel to $M$, and the $b$-axis (and $c$-axis) oriented randomly in the NT plane. (see text) 


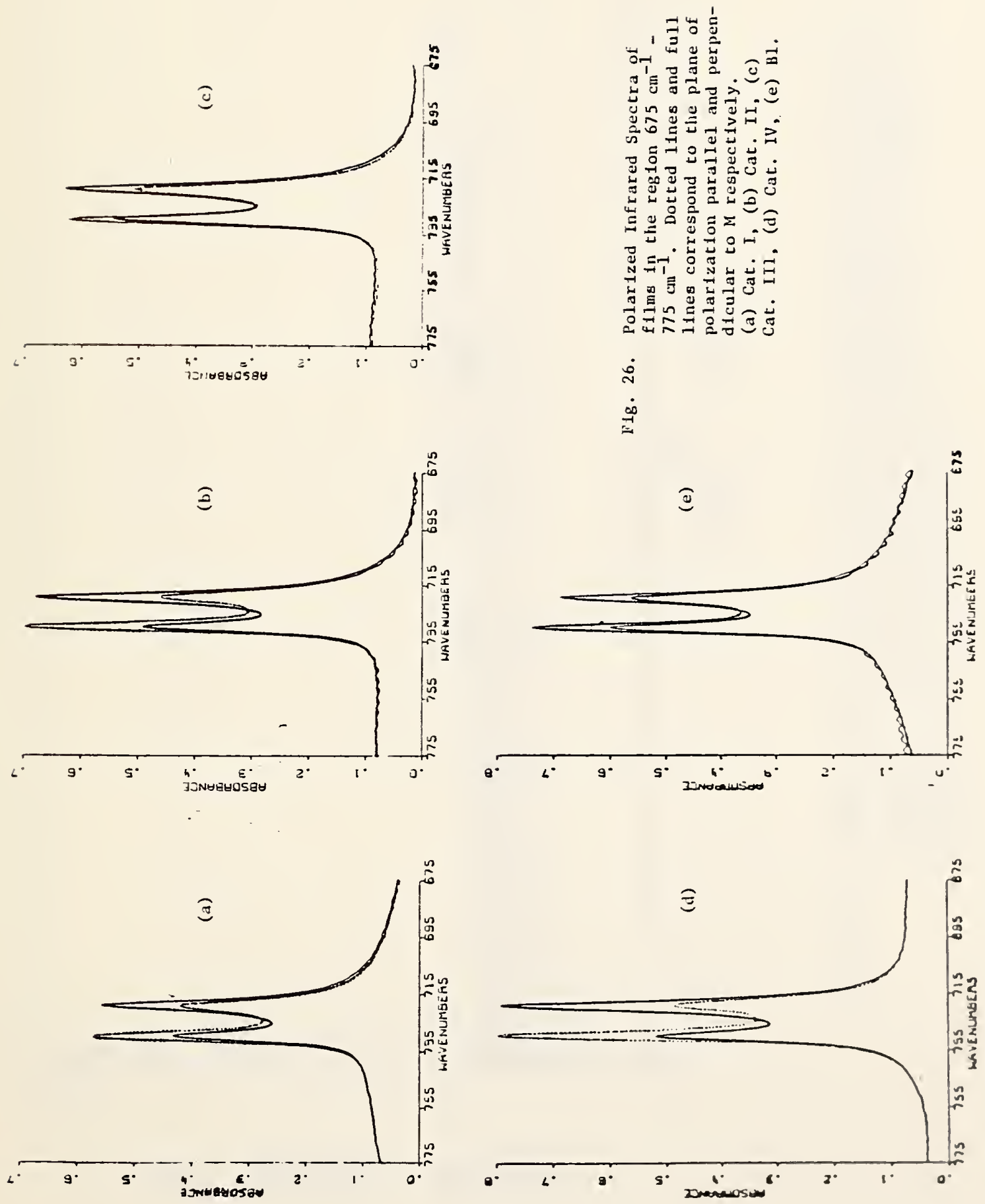



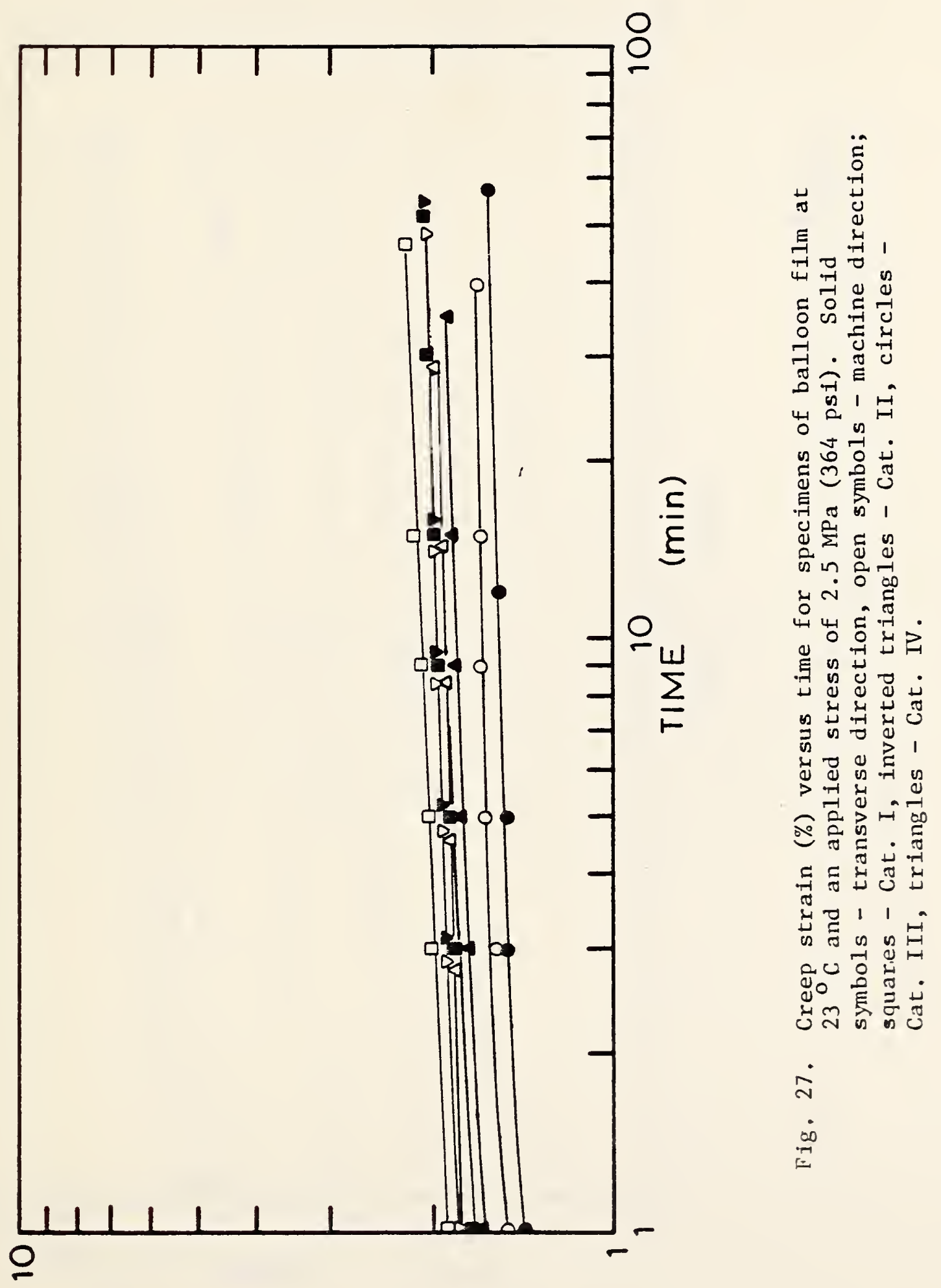

(\%) NIVy1S d $\exists \exists y J$ 



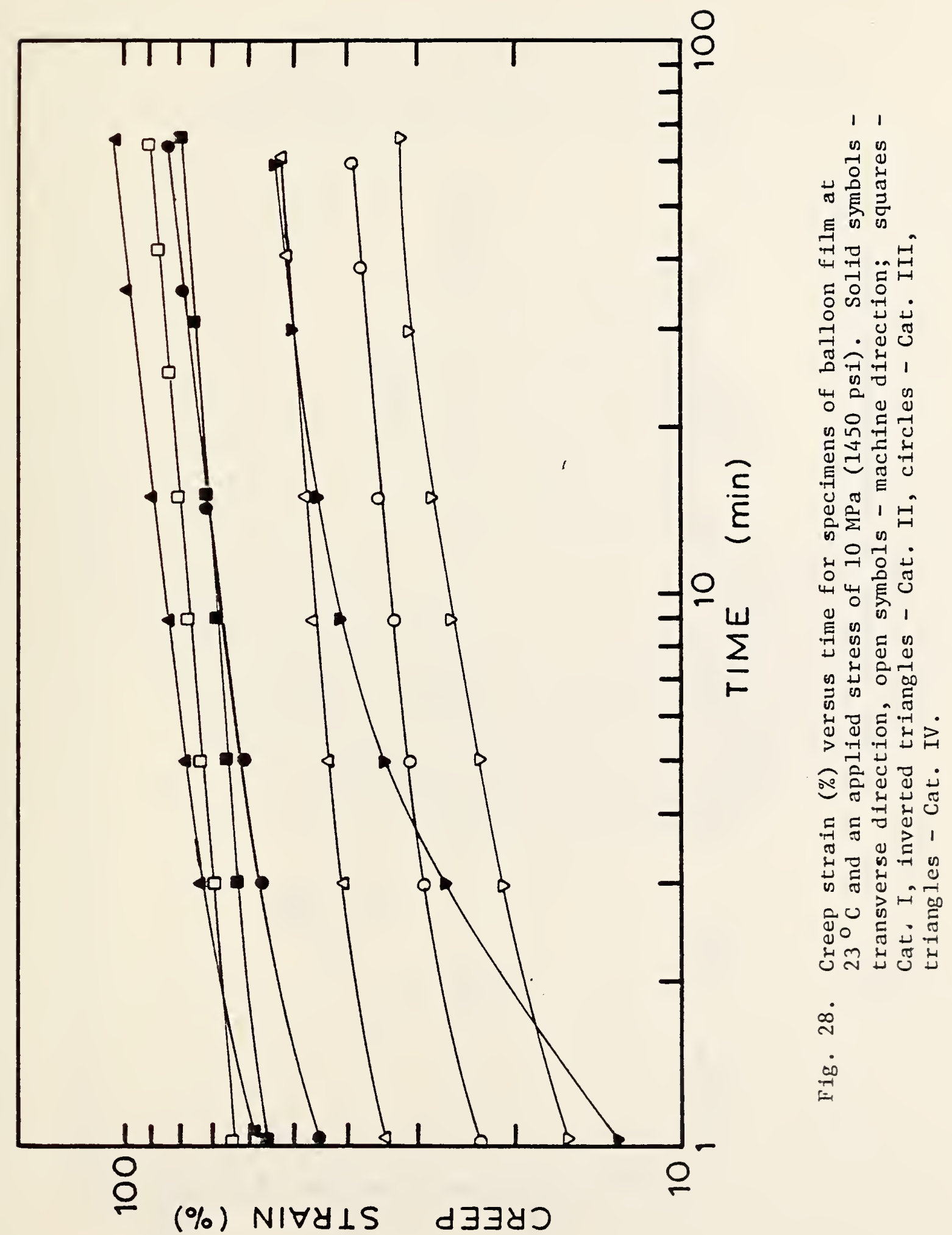





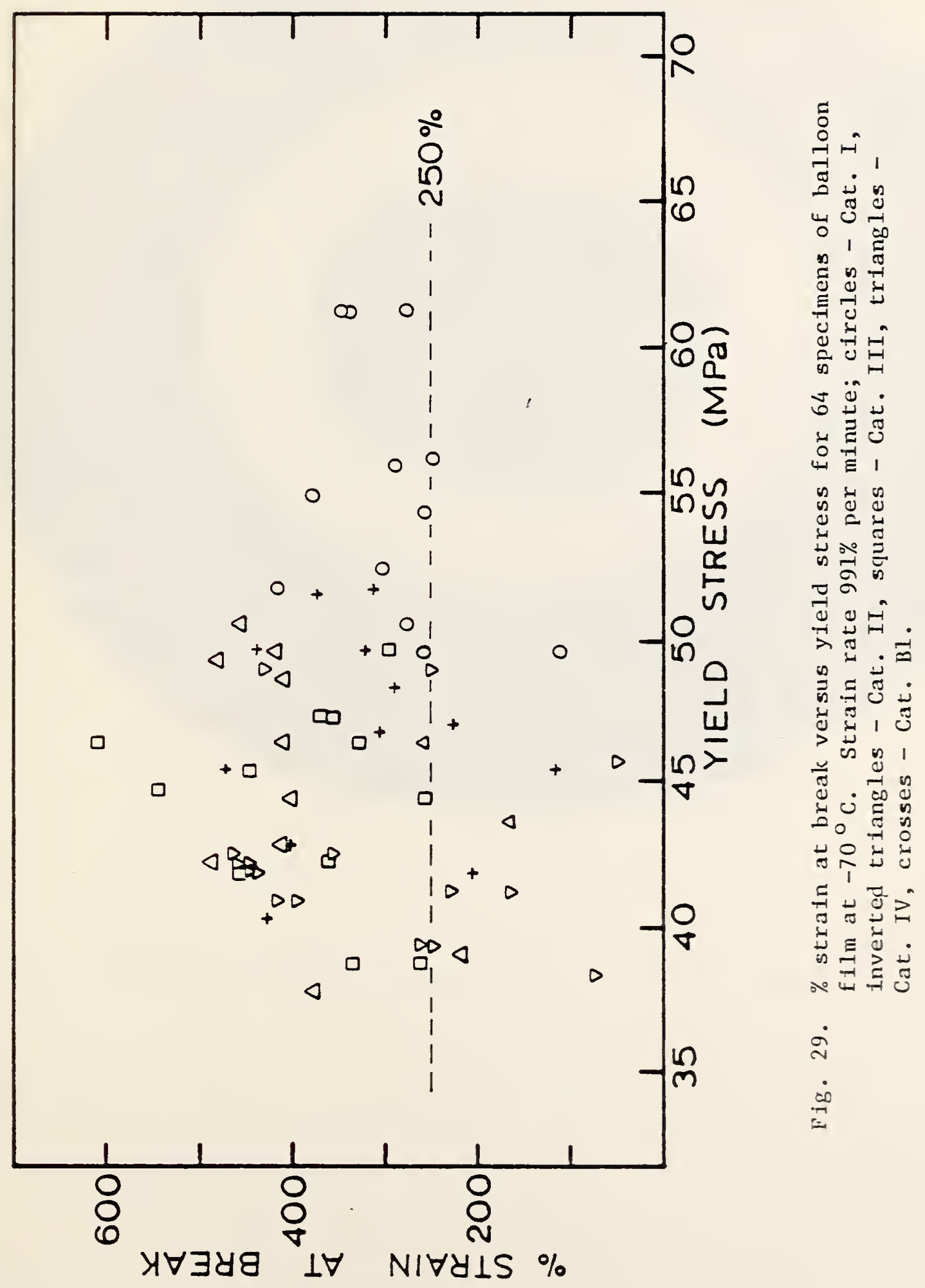





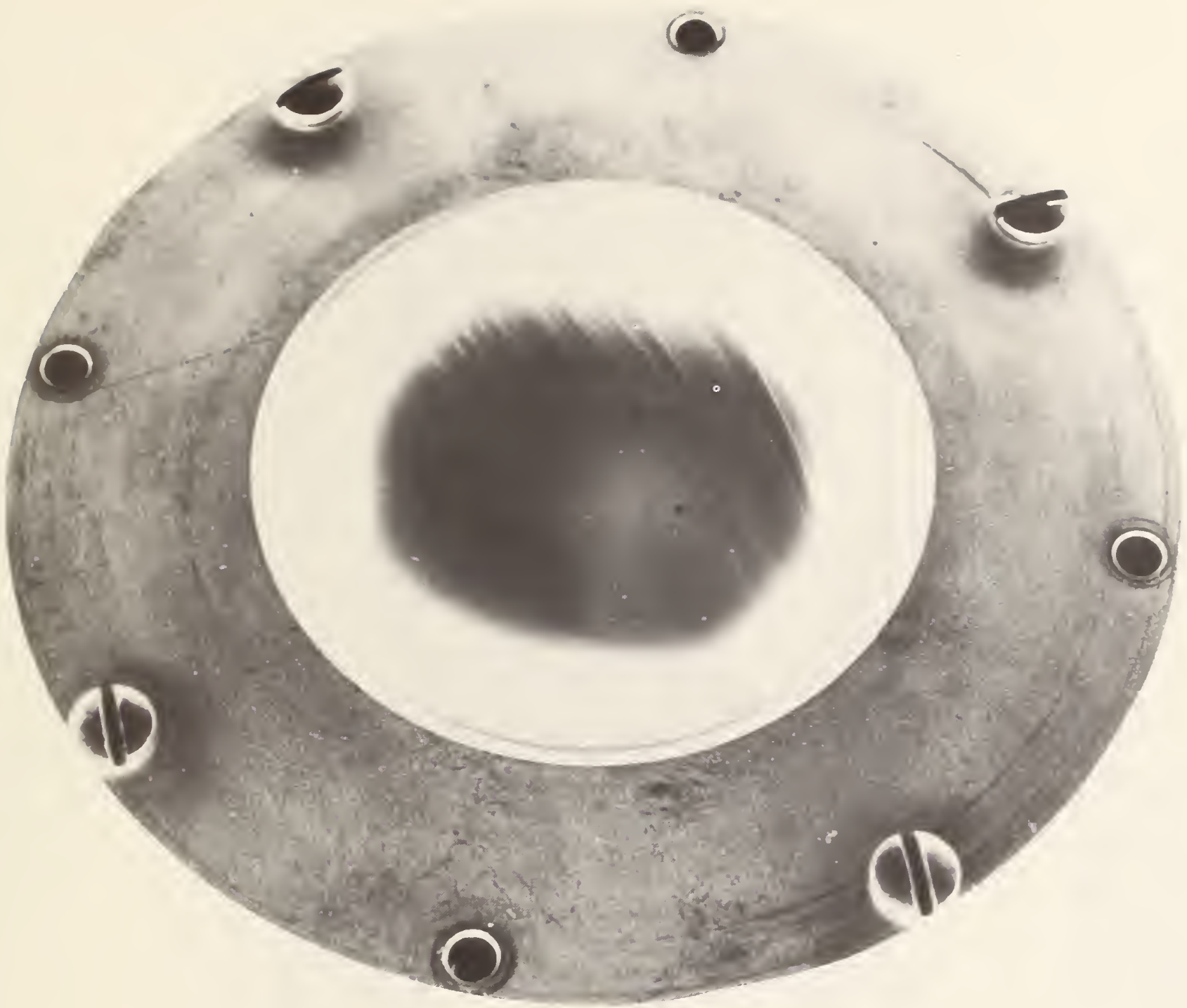

Fig. 30. An example of biaxially oriented film under inflation. 



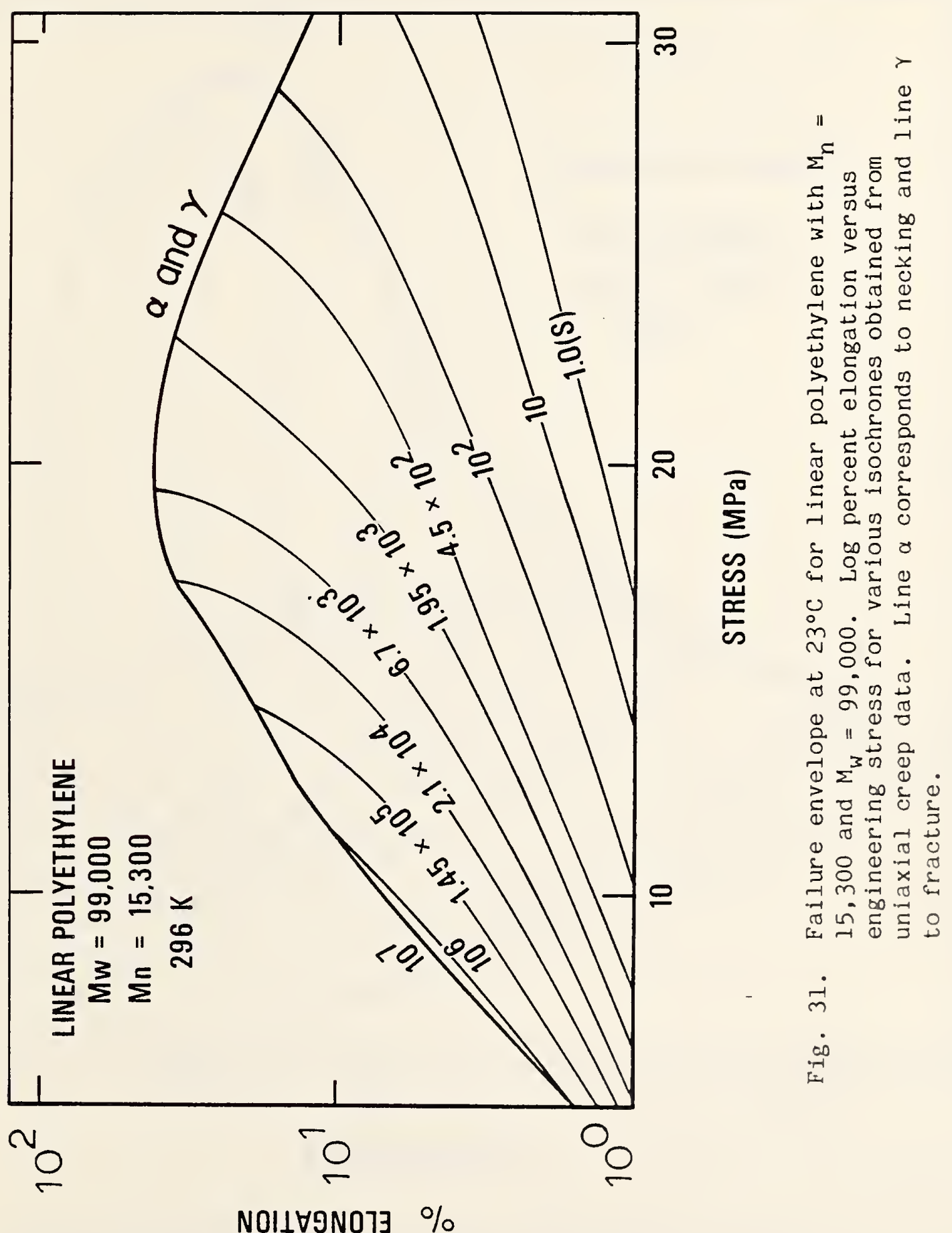






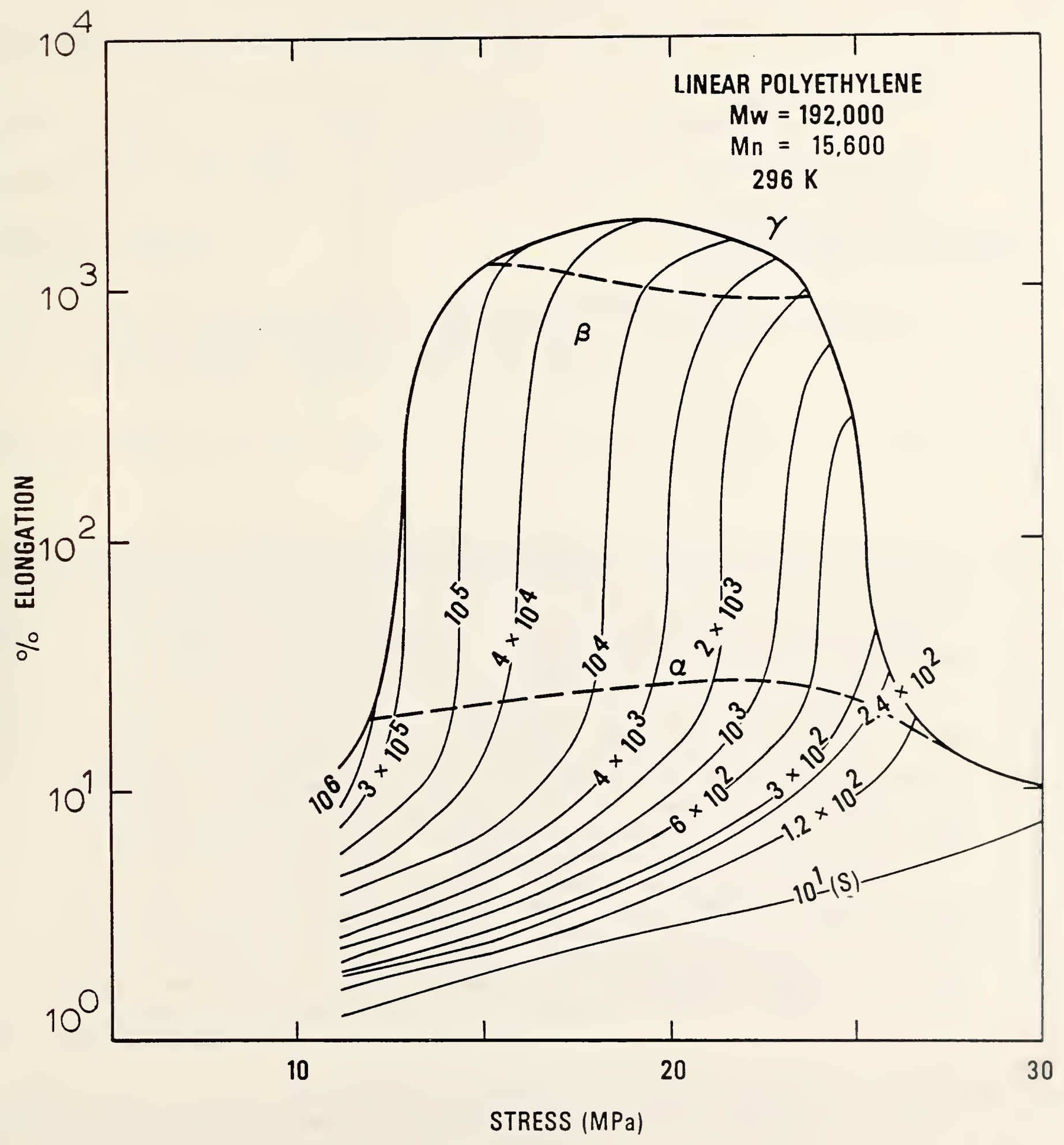

Fig. 33. Failure envelope at $23^{\circ} \mathrm{C}$ for linear polyethylene with $\mathrm{M}_{\mathrm{W}}=$ 15,600 and $M_{W}=192,000$. Symbols have the same meaning as in Fig. 24. 

4. TITLE ANO SUBTITLE

The Structure and Properties of Polyethylene Films Using in Heavy Lift Balloons

5. AUTHOR(S) F. Khoury, J. M. Crissman, B. M. Fanconi, H. L. Wagner, L. H. Bolz, and C. A. Harding

6. PERFORMING ORGANIZATION (If joint or other thon NBS. see instructions)

NATIONAL BUREAU OF STANDARDS

DEPARTMENT OF COMMERCE

WASHINGTOH, D.C. 20234

7. ContracuGrant No.

NASA Order 5018340

9. SPONSORING ORGANIZATION NAME AND COMPLETE ADDRESS (Street, City, State, ZIP)

NASA Goddard Space Flight Center, Wallops Flight Center, Wallops Flight Facility,

Balloon Projects Branch, Wallops Island, VA 23337

10. SUPPLEMENTARY NOTES

Document describes a computer program; SF-185, FIPS Software Summary, is attached.

11. ABSTRACT (A 200-word or less foctual summory of most significant information. If document includes a significant bibliography or literoture survey, mention it here)

The following features of five polyethylene films used by NASA in the construction of heavy lift balloons have been examined: molecular weight, molecular weight distribtuion, branching, melting behavior, density, surface texture, birefringence, orientation of crystalline regions, uniaxial deformation in the machine and transverse directions, and the effect of sample geometry and strain rate on deformation behavior. The goal of this exploratory study was to determine whether there are significant differences in any of the above mentioned features, or combination of features between the films. The acquisition of such information is a first step towards determining whether there are any specific correlations between film characteristics and the incidence of catastrophic failure of balloons during ascent through the troposphere. This exploratory study has resulted in the identification of similarities and differences between various features of the films. Close similarities have been found in methyl group content, crystallinity, and peak melting temperature. The preferred orientations in the crystalline regions appear to be qualitatively similar or related. Differences among the films have been revealed in two features, namely between their molecular weights, and in the balance of the strain to break behavior in the machine direction relative to that in the transverse direction.

12. KEY WORDS (Six to twelve entries; alphabetical order; capitalize only proper nomes; and seporate key words tr semicolons) Balloon film; branching; mechanical properties; molecular weight distribution; morphology; orientation; polyethylene

13. AVAILABILITY

Xnlimited

For Official Distribution. Do Not Release to NTIS

[] Order From Superintendent of Documents, U.S. Government Printing Office, Washıngton. D.C. 20402.

[X] Order From National Technical Information Service (NTIS), Springfield, VA. 2216I

14. NO. OF PRINTED PAGES

10.8

15. Price 

$$
\text { - }
$$ 
